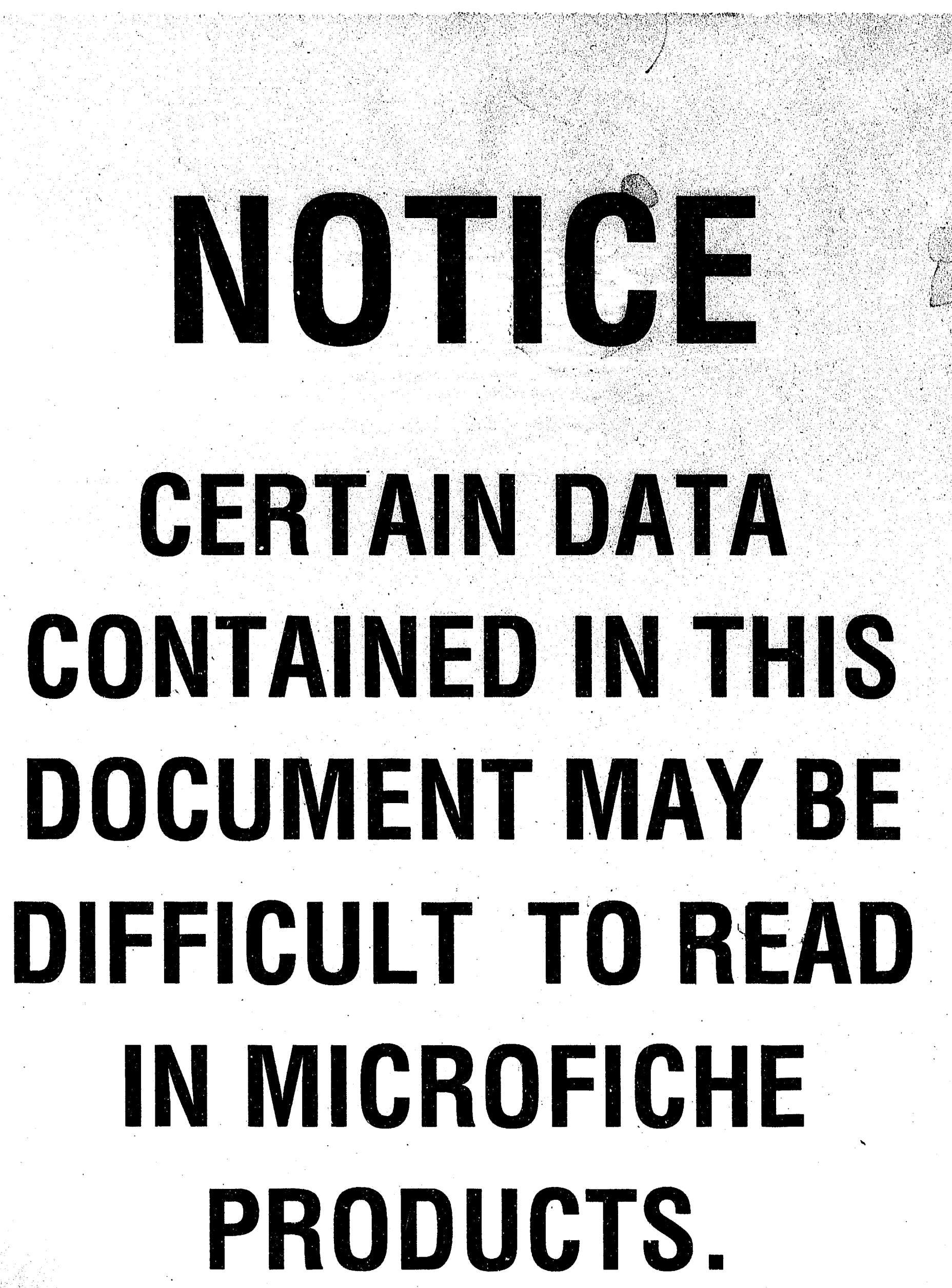


$\mathrm{DOE} / \mathrm{ER} / 12813--1$

DE93 011734

\title{
MULTIPARTICLE IMAGING TECHNIQUE FOR TWO-PHASE FLUID FLOWS USING PULSED IASER SPECKLE VELOCIMETRY
}

\author{
Final Report
}

September 1988 - November 1992

T. A. Hassan

Department of Nuclear Engineering

Texas AcM University

College station, TX 77843

December 1992

\begin{abstract}
PREPARED FOR THE U.S. DEPARTMENT OF ENERGY UNDER GRANT NUMBER DE-FG07-88ER12813
\end{abstract}

\section{DISCLAIMER}

This report was prepared as an account of work sponsored by an agency of the United States Government. Neither the United States Government nor any agency thereof, nor any of their employees, makes any warranty, express or implied, or assumes any legal liability or responsibility for the accuracy, completeness, or usefulness of any information, apparatus, product, or process disclosed, or represents that its use would not infringe privately owned rights. Reference herein to any specific commercial product, process, or service by trade name, trademark, manufacturer, or otherwise does not necessarily constitute or imply its endorsement, recommendation, or favoring by the United States Government or any agency thereof. The views and opinions of authors expressed herein do not necessarily state or reflect those of the 


\begin{abstract}
Development of Pulsed Liner lelicimetry Techniques for Messurement af Tw...Phase Interfacial Drạ in a Horizmal Stratitied Flow. (December ly!l,

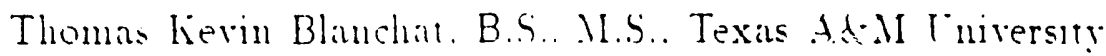

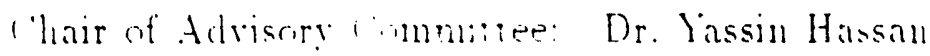

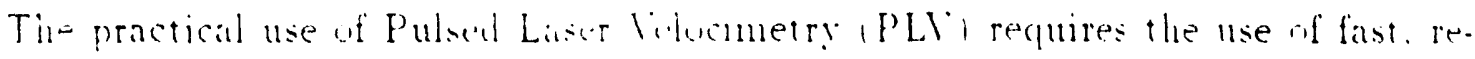

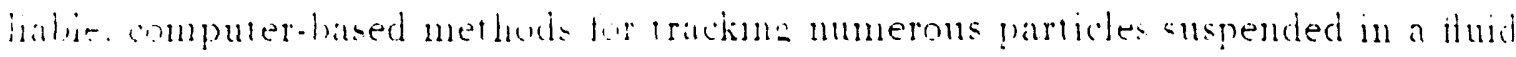

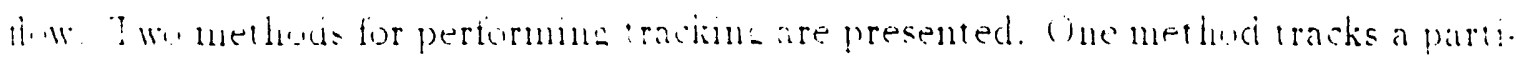

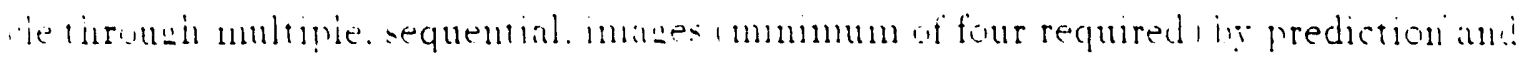
rentication of particle displatement and direction. The ot her method requiring nuly. wo sequential images, uses a dymamic binary. spatial. cross-correiation technique The aigorithms are tested on computer-generated synthetic datia and experimental data winch wats obtained with traditional PLI methods, ihis allowed error anaiysts and testing of the algorithms on real engineering flows.

A novel method is proposed which elimmates tedious. undesirable. manual. operittor assistance in removing erroneous vectors. This method uses an iterative proces: involving an interpolated field produced from the most reliable vectors.

Methods are developed to allow fast analysis and presentation of sets of PLI image data.

Experimental investigation of a two-phase, horizontal. stratified. flow regime was performed to determine the interface drag force. and correspondingly: the drag coefficient. A horizontal. stratified flow test facility using water and air was constructed to allow interface shear measurements with PLV techniques. 
The experimentally obtained local drag measurements were compared with thenretbai resula given by conventional intertacial drag theory. ('lose anreement was shown when boal conditions near the intertice were similar fo space-areraged conditions. However. heory hased on macrosonpic. space-averased flow behavior was shown h. wive incorrect results if the local sas velucity near the interface was unstable. transient. and dismilar trom the arerage gas velocity through the test facility. 


\section{TABLE OF CONTENTS}

('HAPTER

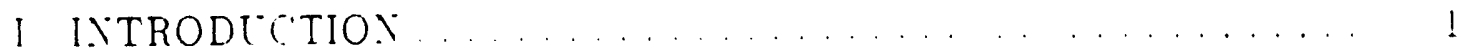

1.1 Background ............................. I

I.2 Literature revell . . . . . . . . . . . . . . . . . . . . . :

1.3 Methodology . . . . . . . . . . . . . . . . . . . . . . .

1.4 summary . . . . . . . . . . . . . . . . . . . .

II MLTIFRAME AND CROSS-C'ORRELATION TRACKINC C'ODE DESC'RIPTION

II.1 Introduction _.............................. 11

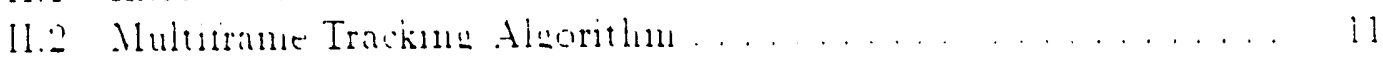

II..) ( rossorrelation Tracking Algorithm . . . . . . . . . . . . .

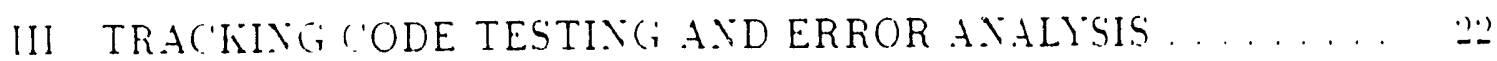

III.1 Introduction . . . . . . . . . . . . . . . . . . . 2

III.2 Srnthetic Data Production . . . . . . . . . . . . . . . .

III.3 Interpolatins Scattered Vectors into a Full Vector Field . . . . . . 25

III.4 Tracking Synthetic Data . . . . . . . . . . . . . . . . . 2S

III.5 Tracking Experimental Data ... . . . . . . . . . . . . . 42

III.G Interpolating. Cleaning. and Presentation of Experimental Data $4 ! 4$

II STRATIFIED FLOW THEORY AND EXPERIMENT . . . . . . . . . . .

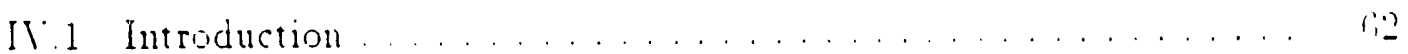

IV.2 Interface Shear titress Theory . . . . . . . . . . . . . .

IV.3 Design of the PLI Stratified Flow Test Facility . . . . . . . . . . . . lix

II.4 Light Scattering by small Particles ................. Ti

IT.5 Stratified Flow Data Acquisition . . . . . . . . . . . .

II.6 Image Analysis . . . . . . . . . . . . . . . . . . . 83

IV.T Vector Tracking . . . . . . . . . . . . . . . . 85

IV .8 Interface Shear Calculations and Results . . . . . . . . . . 91

$\checkmark$ CONCLUSION ........................ 104

NOMENCLATLRE ....................... 10 T

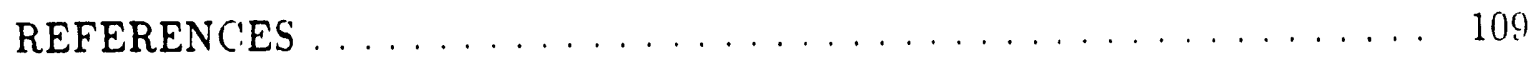


APPEIDIX Page

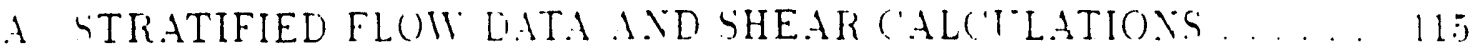

B MEGATISION 'LEANING METHODS AND IMACE DATA PRO-

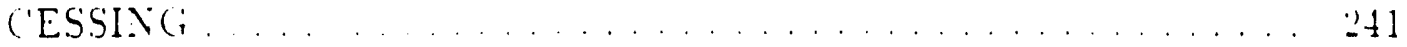

$\because$ CROSSCORRELATIONSET TRACKINC PROCIRAM LISTING . . Z ZtE

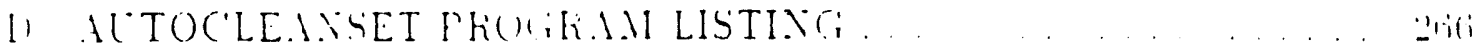

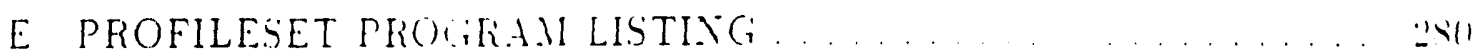

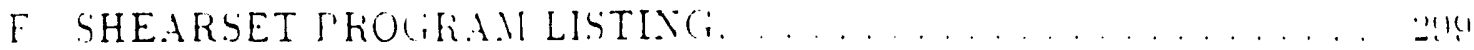

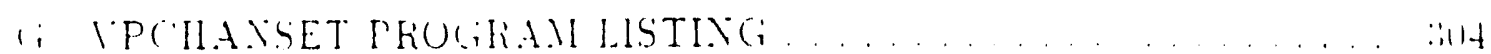

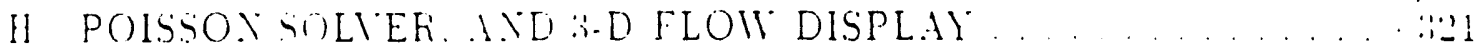

I PLOT3D D.ATA PREPARATION PROGRA.I LISTINC; . . . . . . . . IIZ

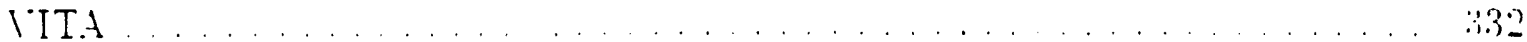




\section{LIST OF FIGURES}

Fi:ure

Pane

: Multiframe Tracking Deacription . . . . . . . . . . . . . . $1:$.

$\because \quad$ 'ross-correlation Trackine Description . . . . . . . . . . . . . . .

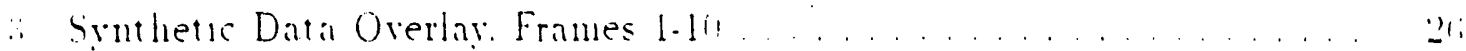

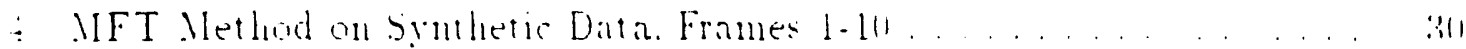

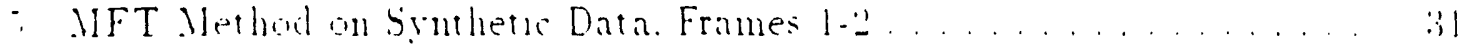

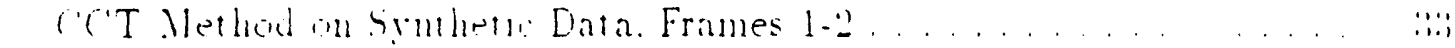

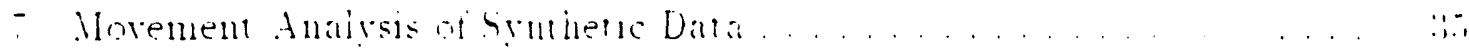

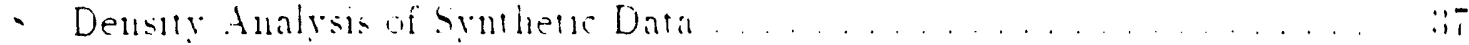

(PI Cost Analysis of Sruthetic Datia . . . . . . . . . . . . . . . . . .

!: Pulsed Laser Velocimetry step Flow Setup .................. 4 . .

11 Iultiframe and C'ross-correlation Track Distributions ............ . ti

:.- Comparison of ('C'T Method $R_{n}$, lahes for Symthetic and Experimental

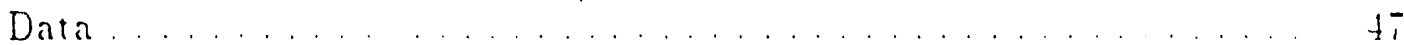

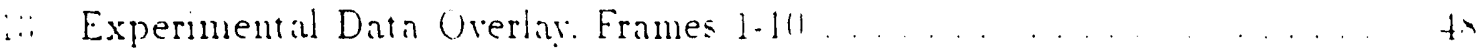

i: MFT Method on Expermental Data. Frames 1-111............ in

$\therefore \quad$ MFT Method on of Experimental Data. Frames $1.2 \ldots \ldots \ldots \ldots \ldots$. . . . . . .

10. MFT Method on Experimental Data. Frames 1-2 (with ('utoff) . . . . . ;2

1i Experimental Data Overlar: Frames 1.2 ................ 5.3

Is C'CT Method on Experimental Data. Frames $1-2 \ldots \ldots \ldots \ldots \ldots \ldots$ it

19 C'CT Method on Experimental Data Frames. 1-2 (with C'utoff) ..... . 5.)

20 Initial Interpolated Vector Field of Experimental Data . . . . . . . . . 
-1 Final Instantanenus Vectors whth Expermental Data . . . . . . . . . . in

$\because$ Final Interpulated Vector Field with Experimental Data . . . . . . . . . . .

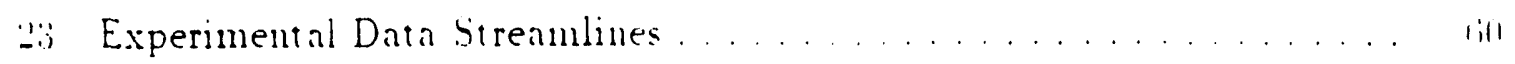

It Ciscurrent Equilibrium Stratified Flow in a Pipe . . . . . . . . . . . r. it

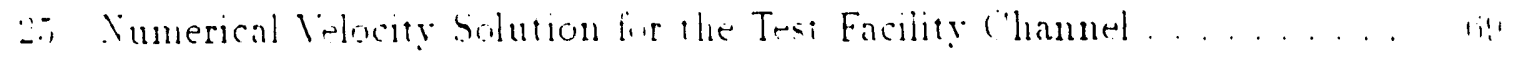

$\because \quad$ PLI Stratified Flow Test Facility . . . . . . . . . . . . . . . Ti

$\because$ Vozzle Desion for the PLV Stratified Flow Test Channel . . . . . . . . . . il

$\because$ Len Arrancement for Thin Shee Production . . . . . . . . . . . . i

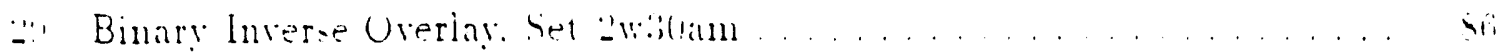

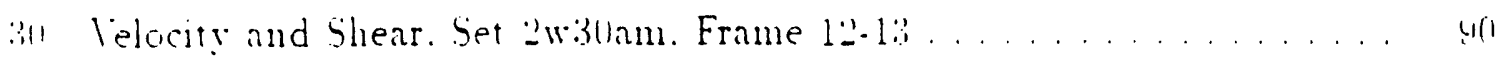

.31 Average Air Velocity. Set 2 w.3lam. Frame $12-13 \ldots \ldots \ldots$

32 Interface Velocity. Set $2 w 30$ am. Frame $12-13 \ldots \ldots \ldots \ldots \ldots$

an Interface tir Shear. Set $2 w 31$ am. Frame $12-13 \ldots \ldots \ldots \ldots$

it Shear Experiment rs. Theory Comparisons. Set 2w:30am .........

:.) Profile and Interfacial Shear ('alculations. Set $2 w 30$ am . . . . . . . . . wa

Shear Experiment rs. Theory Comparisons. All Sets. . . . . . . . . . 101

;i Velocity and Shear. Set

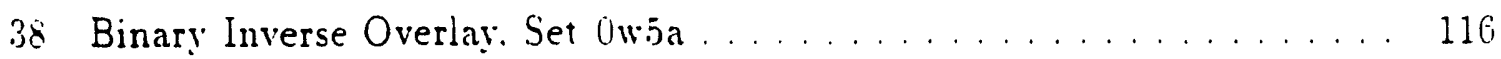

39 Velocity and Shear. Set 1 w5a. Frames $0-1 \ldots \ldots \ldots \ldots \ldots \ldots$

to Velocity and Shear. Set $0 w 5 a$. Frames $1-2 \ldots \ldots \ldots \ldots \ldots$

41 Velocity and Shear. Set $0 w 5 a$. Frames $2-3 \ldots \ldots \ldots \ldots$

42 Velocity and Shear. Set 0 w5a. Frames $3-4 \ldots \ldots \ldots \ldots \ldots$ 
Figure Page

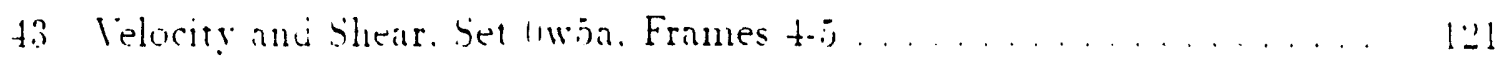

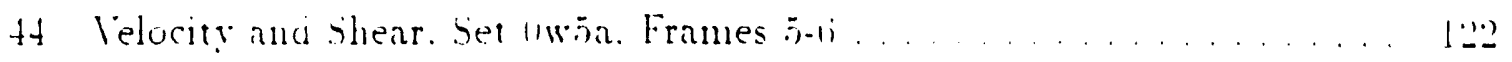

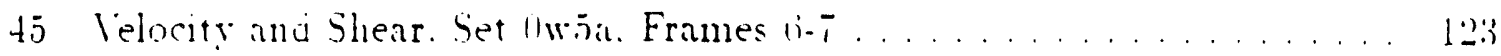

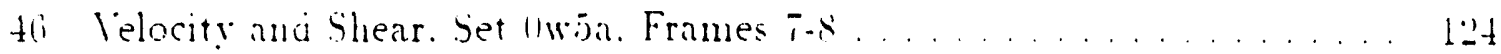

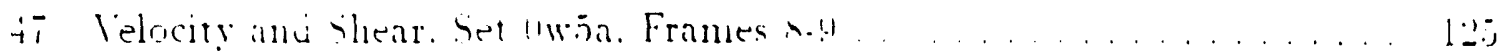

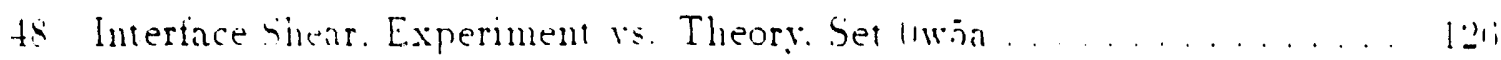

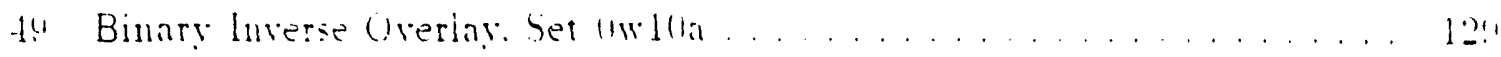

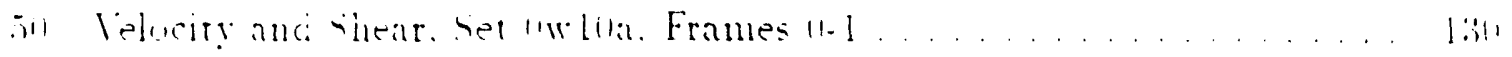

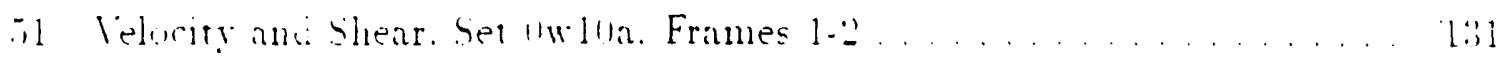

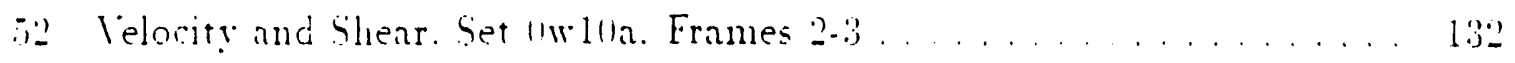

5.2 Velocity and shear. Set lly lla. Frames $3-4 \ldots \ldots \ldots \ldots \ldots$

jt Velocity and Shear. Set $1 w 1$ ar. Frames $t-5 \ldots \ldots \ldots \ldots \ldots \ldots$

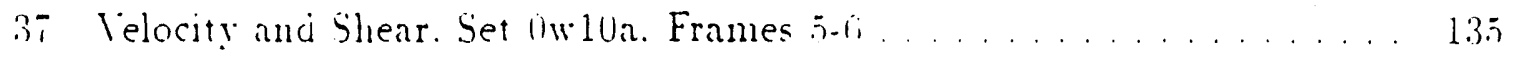

5.5 Velocity and Shear. Set 1 w11n. Frames $(i-i \ldots \ldots \ldots \ldots$. . . . . . . .

50 Velocity and Shear. Set lw lla. Frames $i-x \ldots \ldots \ldots \ldots \ldots \ldots$

ii Velocity and Shear. Set hw10a. Frames

58 Interface Shear. Experiment vs. Theory Set 1 w10a . . . . . . . . . 13:1

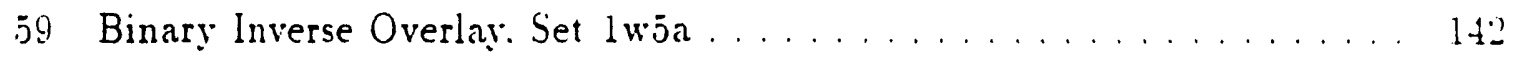

60 Velocity and Shear. Set 1 w5a. Frames $0-1 \ldots \ldots \ldots \ldots \ldots$

61 Velocity and Shear. Set 1 war. Frames $1.2 \ldots \ldots \ldots \ldots \ldots \ldots$

62 Velocity and Shear. Set 1 w.5a. Frames $2-3 \ldots \ldots \ldots \ldots \ldots \ldots$

63 Velocity and Shear. Set 1w5a, Frames $3-4 \ldots \ldots \ldots \ldots \ldots \ldots$ 


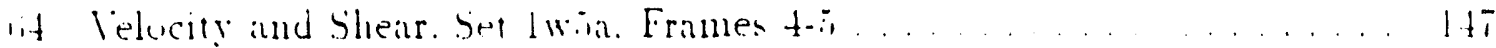

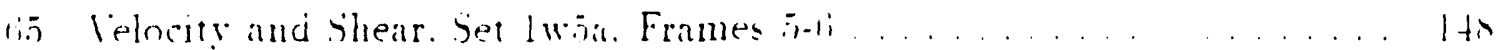

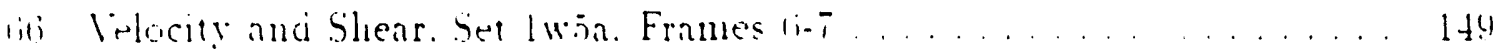

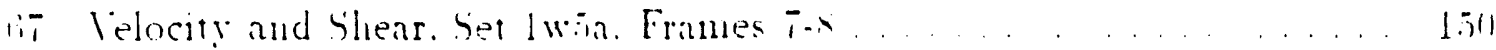

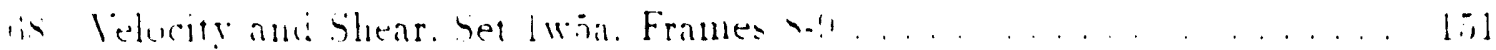

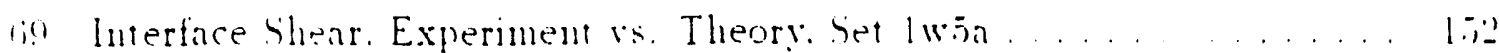

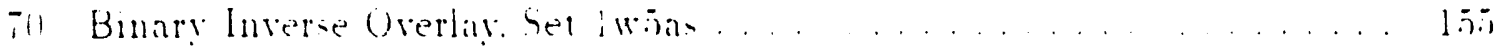

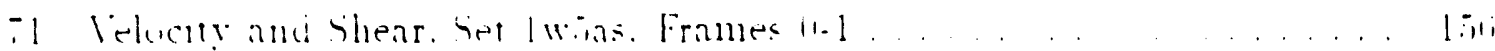

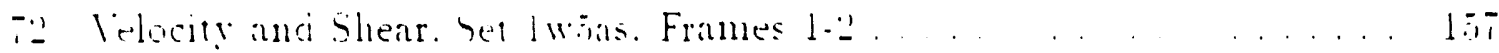

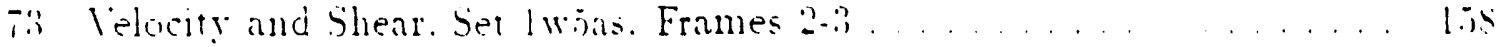

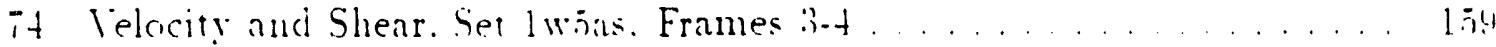

ij Velocity and Shear. Set 1 was. Frames $4-5 \ldots \ldots \ldots \ldots \ldots$. . . . . . . . . . . .

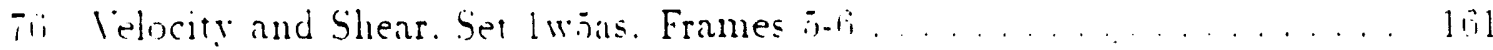

it Velocity and Shear. Set lwas. Frames bi-i . . . . . . . . . . . . . 10.

is Velocitr and Shear. Set lwins. Frames $i$. $\ldots \ldots \ldots \ldots$

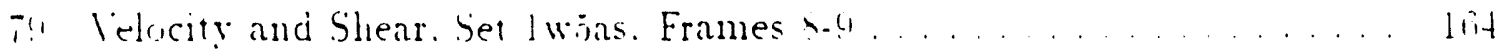

su Interface Shear. Experiment r.s. Theory. Set lwijas . . . . . . . . . . . 10

81 Binary Inverse Overlay Set 1 w $10 a \ldots \ldots \ldots \ldots \ldots \ldots$

82 Velocity and Shear. Set 1 w10a. Frames $(1-1 \ldots \ldots \ldots$. . . . . . . . 169

83 Velocity and Shear. Set 1w10a. Frames $1-2 \ldots \ldots \ldots \ldots \ldots \ldots$

84 Velocity and Shear. Set 1.40a. Frames $2-3 \ldots \ldots \ldots \ldots 1$

85 Velocity and Shear. Set 1 w10a, Frames $3-4 \ldots \ldots \ldots \ldots \ldots$ 


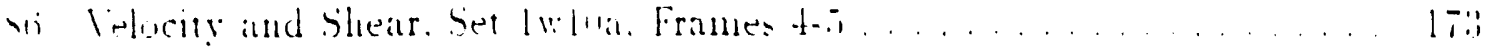

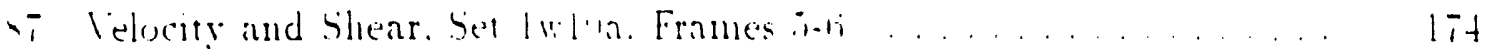

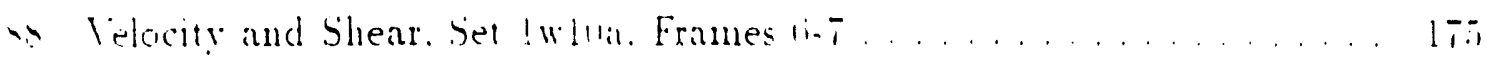

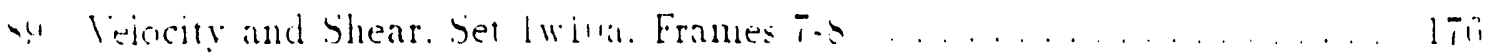

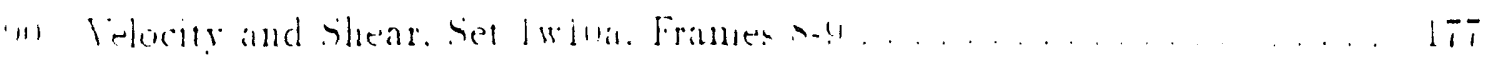

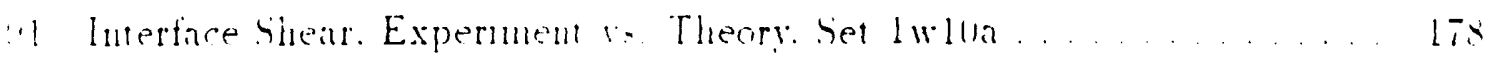

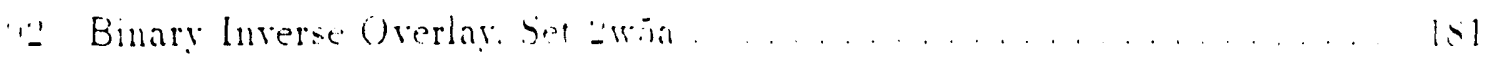

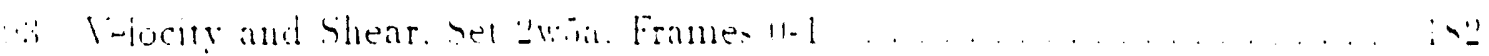

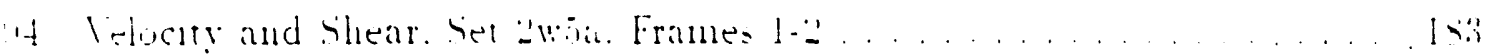

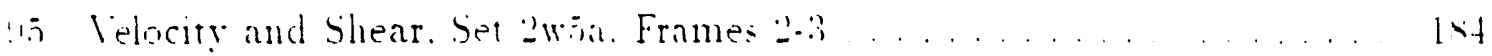

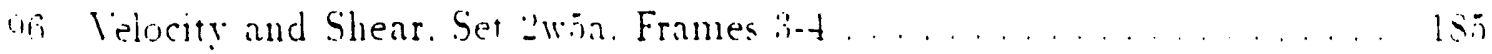

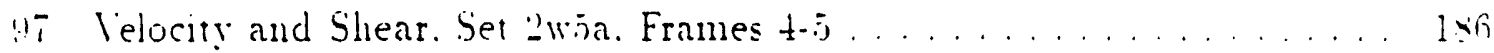

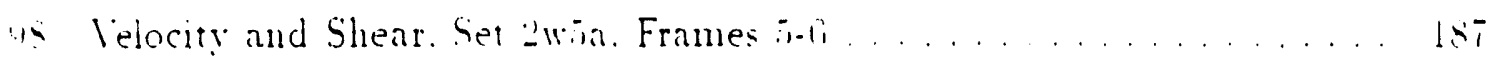

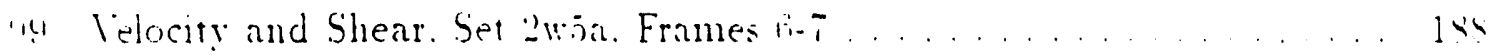

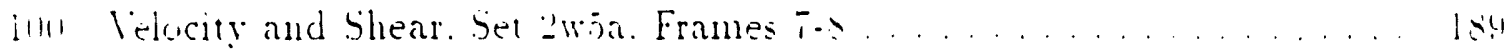

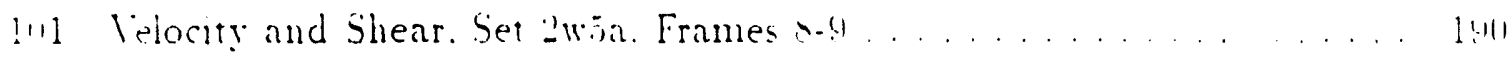

102. Interface Shear. Experment $\because s$. Theory Set $2 w 5 a \ldots \ldots \ldots \ldots \ldots \ldots$

103 Binary Inverse Overlay Set $2 w 10$. . . . . . . . . . . . . 14t

104 Velocity and Shear. Set 2 w10a. Frames $(1-1 \ldots \ldots \ldots \ldots$

10.5 Velocity and Shear. Set $2 w 10 a$. Frames $1.2 \ldots \ldots \ldots \ldots \ldots$

106 Velocity and Shear. Set 2 w10a. Frames $2-3 \ldots \ldots \ldots$. . . . . . . .

107 Velocity and Shear. Set $2 w 10 a$. Frames $3-4 \ldots \ldots \ldots \ldots \ldots$ 
Figure Pager

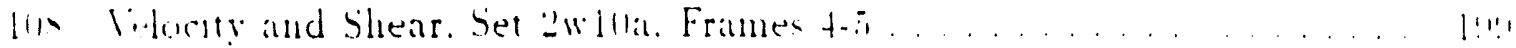

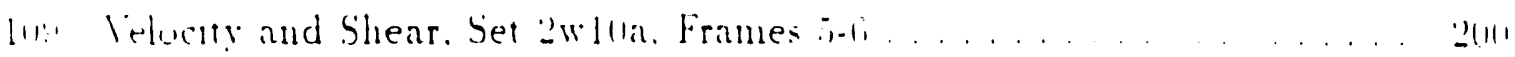

11! Velocity and Shear. Set :wlua. Frames

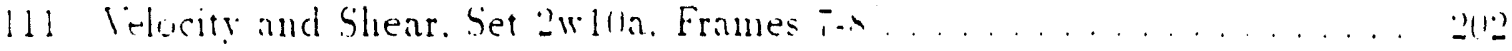

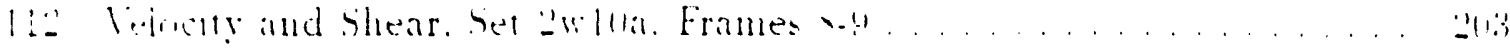

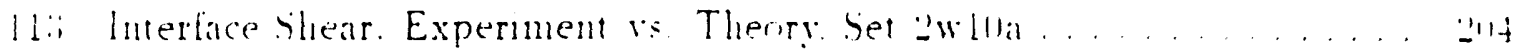

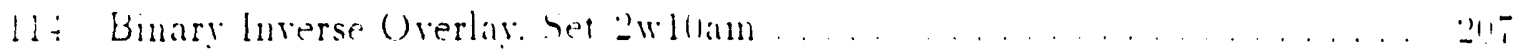

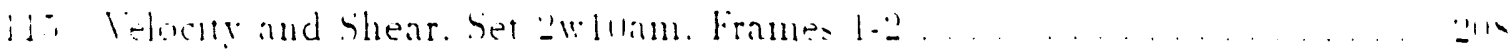

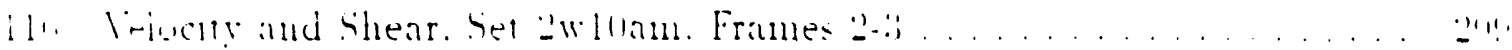

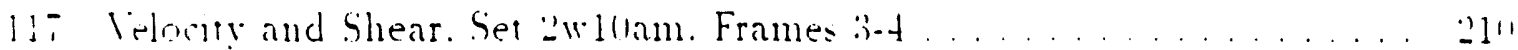

11: Velormy and Shear. Set $2 w$ llam. Frames $4-3 \ldots \ldots \ldots \ldots \ldots \ldots \ldots$

$11:$ Velocity and Shear Set $2 w 1$ Uam. Frames $5-6 \ldots \ldots \ldots \ldots \ldots \ldots \ldots$. 212

1211 Velocity and Shear. Set 2 wllam. Frames

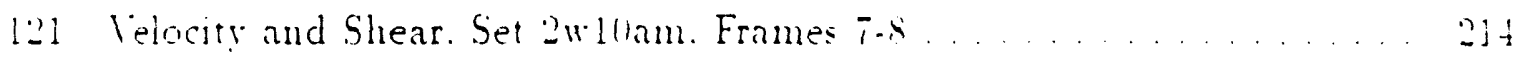

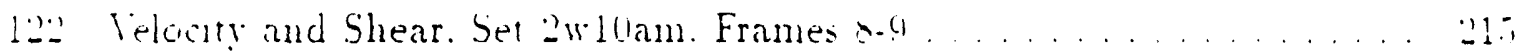

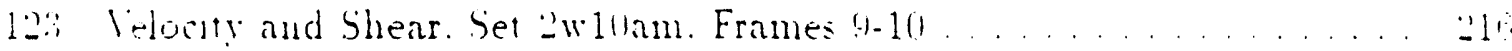

1.2- Velocity and Shear. Set $2 w 1$ (lam. Frames $10.11 \ldots \ldots \ldots \ldots$

125 Velocity and Shear. Set 2410 lam. Frames $11-12 \ldots \ldots \ldots \ldots \ldots$

126 Velocity and Shear. Set $2 w 10 a m$. Frames $12-13 \ldots \ldots \ldots \ldots$

127 Interface Shear. Experiment vs. Theory. Set $2 w 10$ an . . . . . . . . . . 20

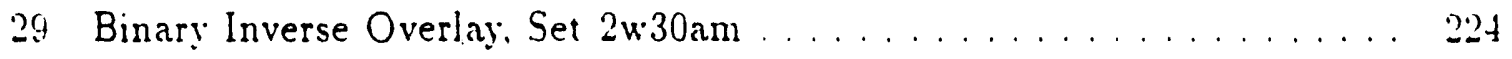

128 Velocity and Shear. Set $2 \times 30$ an. Frames $1.2 \ldots \ldots \ldots \ldots \ldots$ 
124 Velocity and shear set 2 wibam. Frames $2.3 \ldots \ldots \ldots \ldots$

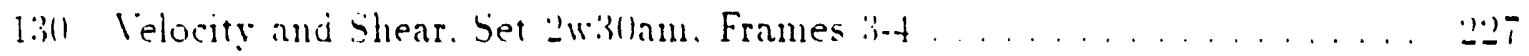

131 Velocity and shear. Set $2 w 30$ am. Frames $4 . j \ldots \ldots \ldots \ldots \ldots$

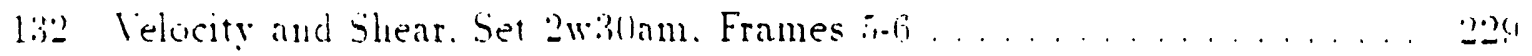

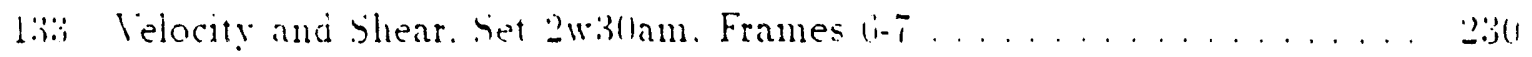

134 Velocity and shear. Ser 2 willam. Frames $i-s \ldots \ldots \ldots \ldots$

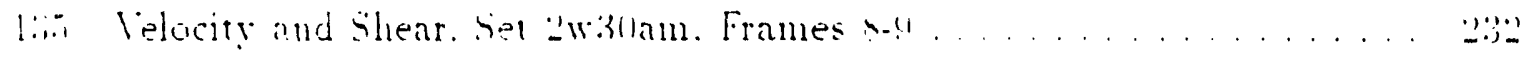

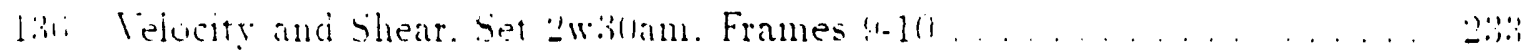

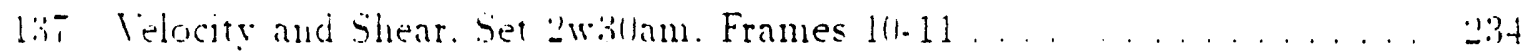

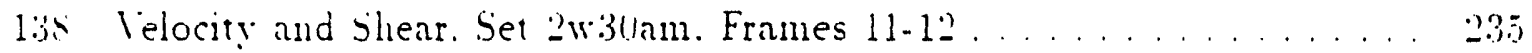

:30 Velocity and Shear. Set $2 w 30$ am. Frames $12-1.1 \ldots \ldots \ldots \ldots$

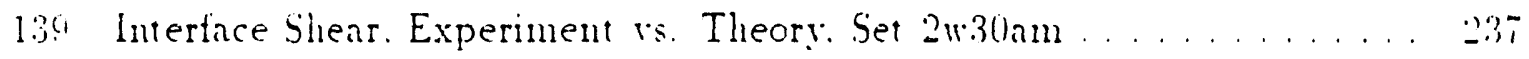




\section{CHAPTER I}

\section{INTRODUCTION}

\subsection{Backstound}

The fundamental difficulty in the measurement and analysis two-phase flow may he attributed tw the hare rariety of flow patterms and flow conditions that

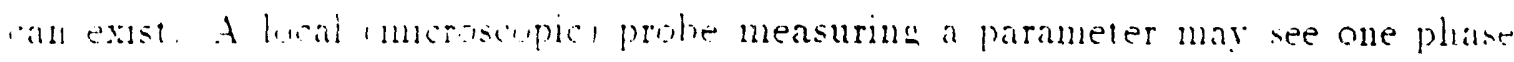
rontinuously such as that necurrus in a stratified flow or two phases intermittenty as in a hubbly or mist reamel. The space-averaged Imacroscopic behavior of the two phases. commonly the parameter of choice in practice. cammot identify the local condition at some particular point. Enfortunately. the interaction between the two phases or fluids, is dependent upon the miçroscopic behavior. The basic problem is how to predict the microscopic phenomena with practical and measurable macroscopic behavior. Interphase suriaces are encountered with two-phase fows that lead to jump conditions hetween the two phases. Only after the jump conditions are accounted for (which describe mass. moment um. and energy exchange between the phases). can it volume with two phases be treated as a single fluid.

Stratified two-phase flow in pipes may occur in various industrial processes. Examples include the flow of steam and water in horizontal pipe networks during certain postulated loss-of-coolant accidents (LOCA's) in a pressurized water reactor (PWR).

This thesis follows a style based on the ASME Transactions Journal of Heat Transfer. 
and the flow of oil and natural sas itwriphase. Iwrocomponent system in pipelines. Theories for the creation of a parthular interfice or the varions interactions vecurring at the interface are not get developed. Development if correlations to predict ranous flow patterns and identify intertacial actions. such as interfacial wariness and : ite resultant drag. is slowly progressne. and sometimes without satisfactorily results. The whjective at this study was l. estend Pubed Laser Velscimetry I PLI, flow ri-nilization techniques to allow andiyste of a two-phase. horizontal. stratified. fluid

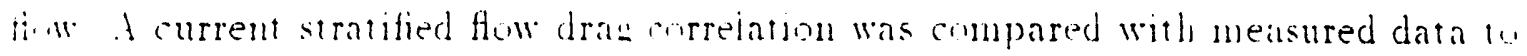
Fetermme if a new orrelation shruid lie developed.

Lurme a LOC'A m a PIVR. - tratified flow of steam and water may take place in a horizontal channel when the emerọency core cooling water is injected into the pipe. This rype of flow also uccurs in the auxiliary feedwater system of the stem senerator in a PIIR after stopping the main feedwater pumps. The flow stability. wh the rwo cases is very inportant th the safety analysis of the-water reactor. It is necessary to explicate the mechamsm of the transition from stratified flow to slug flow in horizontal. stratified. rats-liquid flow. Knowledge of interfacial shear stress and dirag is required for the athore anplications.

Analytical solutions do not exist for most complex geometry flow's. turbulent flows. and multiphase flows. Turbulent flow is described by the Navier-Stokes equations. since the size of the smallest eddy is generally much greater than the mean free path of the molecules of the system. The Navier-Stokes equations are nonlinear, partial differential equations that are difficult to solve in their rigorous form. and it is often necessary to make simplifications in order to reduce their complexity. Because of 
the three-dimensional nature of turbulent How. even today's supercomputers camnot rentre all the scales needed for a hivh Reynulds number simulation. Thus, the analysis is limited to the low number rance. Atrempts have heen made to successfully describe complex flow profiles hy the use of empirical formulie which are derived from expermental data and mumerical rorrelations ohtained by solving simplified forms of the conservation equations. Feliahle and accurate data from similar flow patterms musi he ohtained for these fechniques fin accurately predict a wiven flow s hehavior.

Pulsed Laser Velocimetry is a ponerful tow which performs both qualitative aud anamitative fluid How rismalization iy trackins seed particles suspended in the fluid. The resultant full-field fow visudization is capable of providing both time-varying and or instantaneous maps of fluid flow parameters. such as relocity rorticity. and turinlence. over extended areas. This quantitative flow information is necessary to verify analytical solutions. and to formulate new correlations. Tens of thousands of simultaneous. individual (localı. measurements with typical point flow probes would have to be pertormed to provide the same data grven by one PLI "smapshot". The full. field nature of thuid flow parameters provided hy. PLY measurements will provide the "bis picture". Fluid flow researchers and experimentalists have a powerful technique which should provide new insights to explain and predict fluid flow phenomena.

\subsection{Literature review}

Pulsed Laser Velocimetry ( $\mathrm{PLI}$ ) is a method to quantitatively extract information from complicated flows by tracking particles suspended in the flow. PLV is constantly. being improved with new algorithms and experimental techniques in the laboratory. 
Summaries of particle image velocimetry (PIV). one form ul PLV. can be found in a number of papers, Adrian and lao. 1!S3: Adrian. L!wa: Lourenco and Krothapalli. l!ss: Grant and imith. 1!ks: Adrian. 1!)!1।. The arcuracy of PLI research hat: adranced to where thousands of datta points can be accurately determined ( Adrian and lac. 1:st!. This acuracy is needed to insure the validity rif the quantitative results. Stucies of two phase flow are now possible with these new techniques (Delahunte and Hassan. 1!940: Hassan and Blanchat. 1091: Hassan and (anaan. 1941).

Flow risualizann with PLI involves seeding the fluid with "nentrad density" par. tides which are assumed ho follow the How pathlines, and then measuring thent movement wer a known period of time. PLV is performed hy illuminating the flud with a thin sheet of pulsed laser light. and then capturing images of the particles mor. ing in the flow either with photographic film or digital cameras. After data acquisition has occurred. tracer seed identification and tracking is performed.

The dimensionaity of the How. type of fluid. and speed of the flow should heconsciered prior 16 performing a PLI investigation. Turhulent flows are of interest 10 many invesigators. Turbulent flows are by their nature three dimensional. Care must be taken to produce two dimensional flow. unless the data can be taken in all three dimensions. If two dimensional data is being acquired. the effect of the third dimension can cause particle tracking algorithms to produce incorrect vectors (Simha. 1988). The index of refraction of the fluid medium should also be noted. The scattered light from the seeds will be refracted to some extent. possibly introducing another possible source of error (Sinha. 1988). Flow speed can cause difficulties in 
tracking particles. If the flow speed is ton fast. In reference to camera acquisition lime. the camers will not capture seeds in successive trames.

An algorithms abilitr 10 track complicated flows must he rerified. It is extremely difficult to produce a flow that can be accurately predicted to within several percent 1. Meynart. Lis:il. Therefore error analysis in a PLV tracer trackina program should

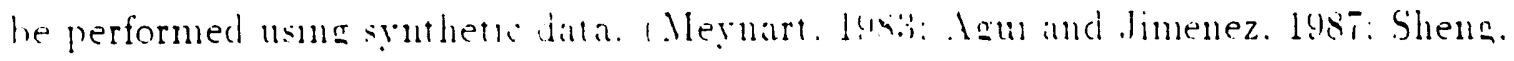
L!Mu: Cinezenne: and Kiritsis. 1!n!111.

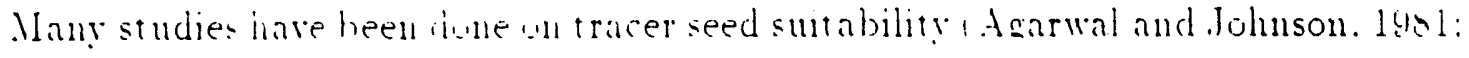

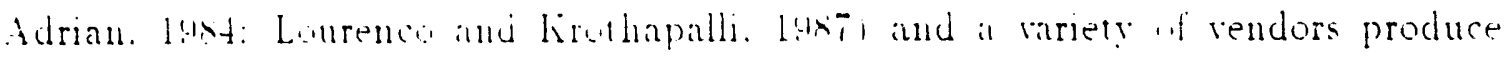
seeds whth dessrable features. The main features. In determmun the suitability of the seed. are the seed density. size. color for fluorescencel. and concentration. as well as the fluid medium that will he seeded. The density and size effect the seed"s ability to accurately follow the flow. The seed must have a neutral huovancy in the flud medium. The ability of the seeds io follow the flow is dependent upon

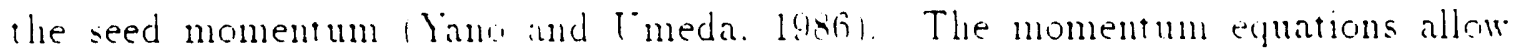
estimating the time required for a seed to achieve the flow speed, Bram et al. 19g(n). These equations show that the tme required for the seed to match the flow speed is dependent upon fluid riscosity. as well as seed density and size. This is particularly. important if studying turbulent flow. because of the small time and length scales involved. Further. the size of the seed affects the ability to scatter ligit. (Lourenco and Krothapalli. 1988). Very small seeds will scatter light according to Mie scattering theory: whereas large seeds undergoes Ravleigh scattering and reflection (Adrian and Yao. 1985). The color of the seed. for some experiments, is also of importance. Many. 
studies have heen done on the effect of color (Lakshmanan. Lysti: Economikos. Lysix:

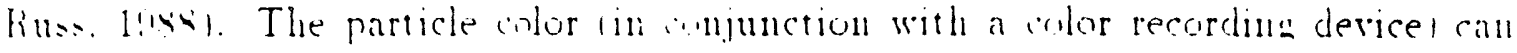
ine ased to discrimimate hetween tracer seeds and hubhles in the Huid. Some seeds are thorescent. and :hus make discrimination easy with the nse of bandpass light filters. The concentration. .r source density. of the tracer seeds is alson of concern. The -inure densiyg must he small encingh su that the recording instrumentation can racend individual seeds. This is dependent an the resolution af the eyumment and

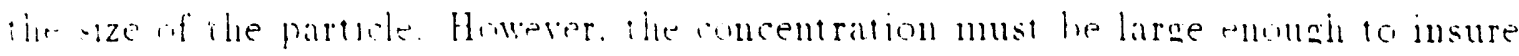

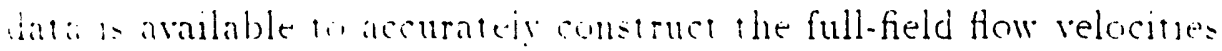

Tit production of a thu shen ef puised litser light is a key element m PLI research. This fiash of light provides the ability to determine the instantaneous positions of the seeds in the How. In a two dimensional study, the laser light should be shaped inco "thin light sheet. Vote that errors can still be introduced even with very thin light sheets. hecause of out of plane motion /Lourenco. 1986: Sinha. 19sisi.

A pulsed laser can be used to produce the light sheet. The four major aspects of lisers, in regards to PLI research, are the peak power, the laser wavelength. the pulse frequency: and the pulse width. The peak power and laser wavelength are important parameters to be considered in the scattering of light by tracer seeds. Scattered light will increase with higher laser powers. allowing smaller seeds to be used. However. too much light can overexpose camera tubes or C $C D$ arrays, producing permanent damage. The light wavelength affects the Mie scattering characteristics. Also. depending upon the fluid media. certain wavelengths are inappropriate. For example. 
infrared wavelengths would not probe water very well due 10 a large absorption coefiicient. The pulse frequency determines the maximum possible How speed which can he meas".red. It is often necessary la use the highest pulse trequency 10 study the letails wf turbulent flows. In addition. the smallest pulse width is desired to obtain in mstantanous "smapshor" if the How.

The wo major menus of image recording are photographic film and digital cameras. There are many film and exposure parameters ihat affert the recording ( Lourenco and

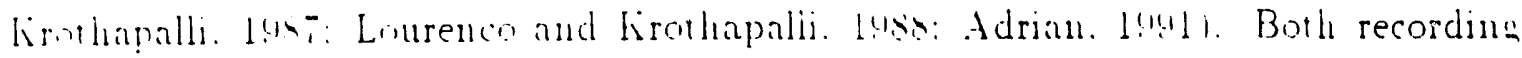
ierles have a maxmmm frame alyustion -peed. Which determmes lhe maximum pube trequency. Douhle pulsinn experiments typically have very fast pulse frequenSies. cansing image acquisition difficulties. and many methods have been suggested 10 wercome them A Archbold and Ennos. 14i-: Adrian. 198io: Collicott and Hesselint. 14sin: Adrian. 1988b: Dudderar et al. 1988: Landreth et al. 1988: Adrian et al.. 19901. Une such method is called laser speckle velocimetry. In this met hod. a double-exposed spectlerram is illuminated by a laser beam and analyzed using loung s fringe patterns

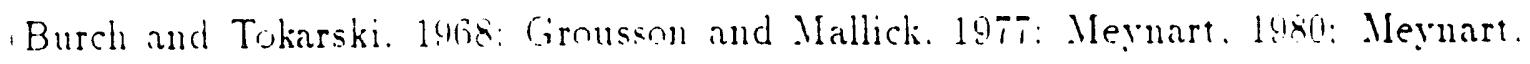
142): Robinson. 1483: Meymart. 195j: Arnold et al. 1980: Huntley. 1:86: Coupland and Pickering. 1988: Huntley. 1989: (hen and (hiang. 1990: Adrian. 1991).

After the imaging system has recorded the scattered light, it is necessary to derive individual seed or spot data. Digital cameras record the scattered light in the form of gray levels. Spot data can be found through thresholding and edge detection techniques (Hueckel. 1971: Otsu, 1979: Haralick. 1980; Chu. 1987: Hanzevack and Ju. 1988: Hild. 1989). The threshold choice can introduce a major source of error. If 
the threshold value is too high. then many faint spots may not be identified. and the spots that are cientified may have misplaced centroids. If the thresholding value is set foo low. then batizround may he bientitied as heins part of spots. This can lead to errors when using iraching algornthms. Whach require accurate pixel locations when determining spon arrehtion. The use of a single threshold value is inappropriate for many images. liegional threshohl rahes shombl he used if the laser sheet is mot periectly maform. "when hlere are mequal sattering properties in the media. snch

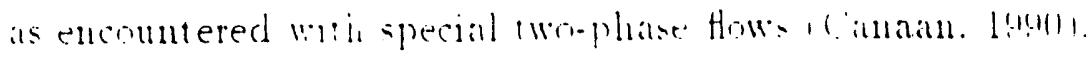

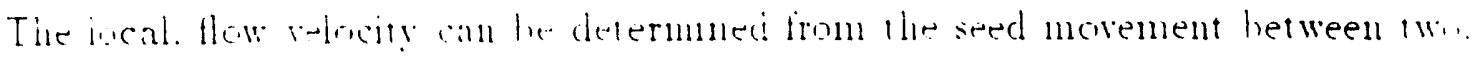

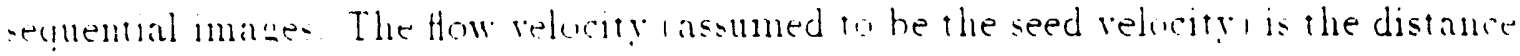
the seed traveled drided by the pulse time. Some algorithms that determine relocit! require many difierent imanes taken $n$ sequential time steps. Other programs require only two time steps. Some double pulsing experiments produce one double-exposed image. This results in a directional ambiguity problem for the tracking program:

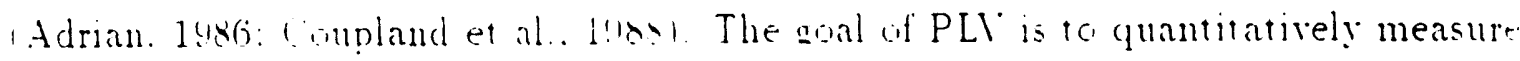
large numbers of vectors over the full-field. which will require fast. relatively error-fret parucle trackins aløorithms

At the present time. no methods currently exist for direct measurement of interfacial shear. and consequently. interfacial drag. Previously proposed criterin for predictins interfacial stress did not represent high gas density experimental data (Kowalski. 198T). Theory does not exist which predicts interfacial effects. and development of correlations to model interface interactions are progressing slowly. and sometimes with unsatisfactory results (Oh and Mahalingan. 198i). Knowledge of interfacial 
effects is of utmost importance in many applications. such as PIIR accident safety anilyses and investhaturs are finding that interficial hear stress contributions are

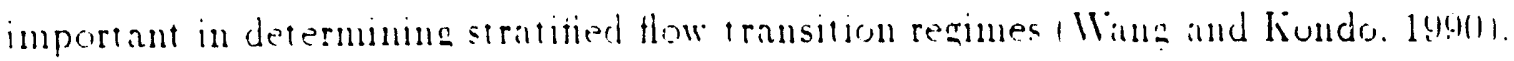
PLI techniques have heen used to measure horizontal flow velocities, hut only with

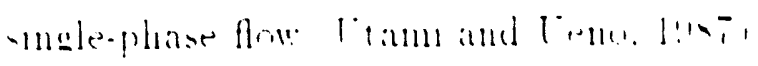

1.: Methuldu:

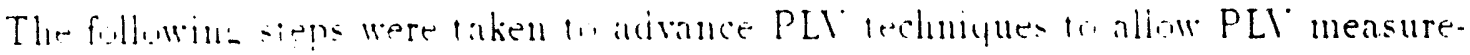

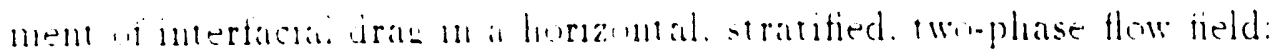

$1 /$ Literature searcites of PLI and associated measurement techniques were performed.

2) Literature searches of twrinphise interaction phenomenn were performed. especially. relating to interfacial dras experiments and correlations.

:it A computer proram wis developed to analyze ingh-speed. full-field. spatial. flow Jati wiramed with PLI methods. This program milizes crosscorrelation tech. mques on binary data wh horrelatme regons chosen dyamically to mprove speed and reduce computer cont. Methods were utilized to double-check the rectors computed by the program.

4) The new two-frame. spatial tracking method was verified with sunthetic production of twpical fluid flows. The production incorporated random generation of seeds in a typical camera riew. and flow-field equations to "move" the seeds to simulate data obtained with PLl' methods. 
$\therefore$. Methods were developed to allow interpolation of sparse vector data into full-field maps. and extran flow parameters, -llch as streamline and resticity. The inter-

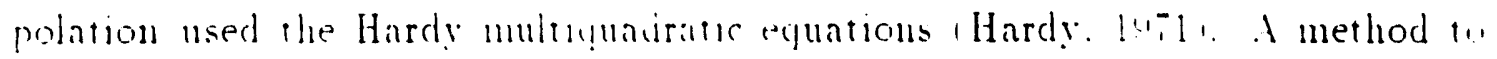
amtomatically remove erronems rechers was implemented.

1 A facility to allow investigation of a mo-phase. horizontal. stratified flud flow with PLI reciniques was designed. himli. and terted.

- Interplatse draz chata whained whis ille stratified How facility was ampared with

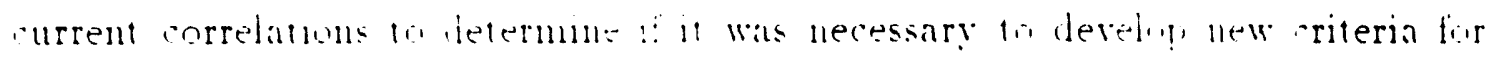
predicting interiacial dras.

\section{$1+$ Summary}

A new PLY tracking aløorihm wa developed which performs particle trackins on two. sequential. images obtained with either a slow. single-pulsed mode of laser operations. or a high-speed. donble-pulsed. mode of laser operation. The algorithm was tested with s!nthetic data to provide error estimates. and to demonst rate method reliability: A method trinterpcinte and remove erroneous vectors from the flow tield was developed. and methods bextract flow parameters such as streamline and vorticity determined. Two-phase. horizontal. stratified. interfacial drag̣ measurements were performed. A new PLI flow channel was constructed to facilitate this goal. Tracking of experimental data with the tracking algorithm highlighted the practical aspect of applying the new method to real engineering flows. ('urrent interphase drag correlations used in industry and research were reviewed to see if new criteria for predicting interphase drag would be needed. 


\section{CHAPTER. II}

\section{MULTIFRAME AND CROSS-CORRELATION TRACKING CODE DESCRIPTION}

\section{1.: Introduction}

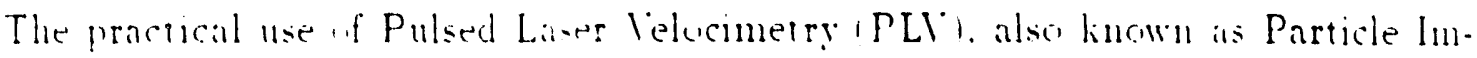

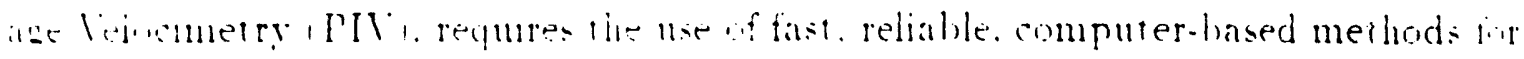
tracints mumerous particles suspended in a flud flow. Two methods for performins irakin! are presented. One method tracis a particle through multiple. sequential. mages I minimum of four required 1 by prediction and rerification of particle displacement and direction. The other method. requiring only two sequential images. uses a drinamic binary spatial. cross-correlation ic innque.

\section{II:- Multiframe Trackin: Algoritim}

The purpose of the multiframe particle tracking code was to track images through multiple (tent time steps Hassan et al. log)(1). A minimum of four sequential images are required for this method. The input into the code. Which performs a direct point. by-point matching of particles from one frame to the next. is usually the output from an image analysis program operating on data obtained with a PLI system. The output from the particle tracking code is a listing of a track (composed of sequentia) frame numbers and particle centroid) for each particle tracked. These tracks are plotted as velocity vectors. 
The 10 files that are created as the output of the image analysis i particle determinathon, program ir ṣnthetic data production program contain all the data necessary bor any tracking scheme. The trackins sibeme tracked particles through four sequen. thal frames at a time. A track was based on the minimum variance of length and

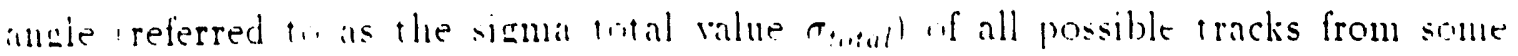
starting particle entroid. The traching was arcomplished hy the prediction of the displarement and the direction of the particle through four consecutive time step:

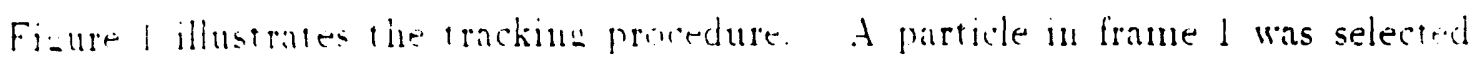

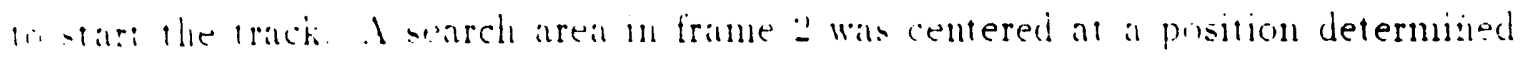
hy the frame 1 particle centroid. The search area in the second frame for a particle starting in the first frame was determined by a rough estimate of the maximum flow relocity. The search areas in the third and fourth frames were based on a fraction of the seond frames search area. The center of the search area in frame 3 was found iy strashthline projectuon of a possible track for a particle found in frame?. For ench particle then found $1 \mathrm{n}$ frame 3 . the center of a search area in frame 4 was determmed usma the length of the track from frames 210.3 and the deviation of the track s angle between frame: : and 3. A statistical method was used to determine and dispose incorrect tracks if more than one track shared the same particle. The following relations are used to calculate $\sigma_{\text {total }}$ :

$$
\sigma_{l}=\sqrt{\frac{\left(l_{1-2}-i\right)^{2}+\left(l_{2-3}-i\right)^{2}-\left(l_{3-4}-\bar{i}\right)^{2}}{3}}
$$




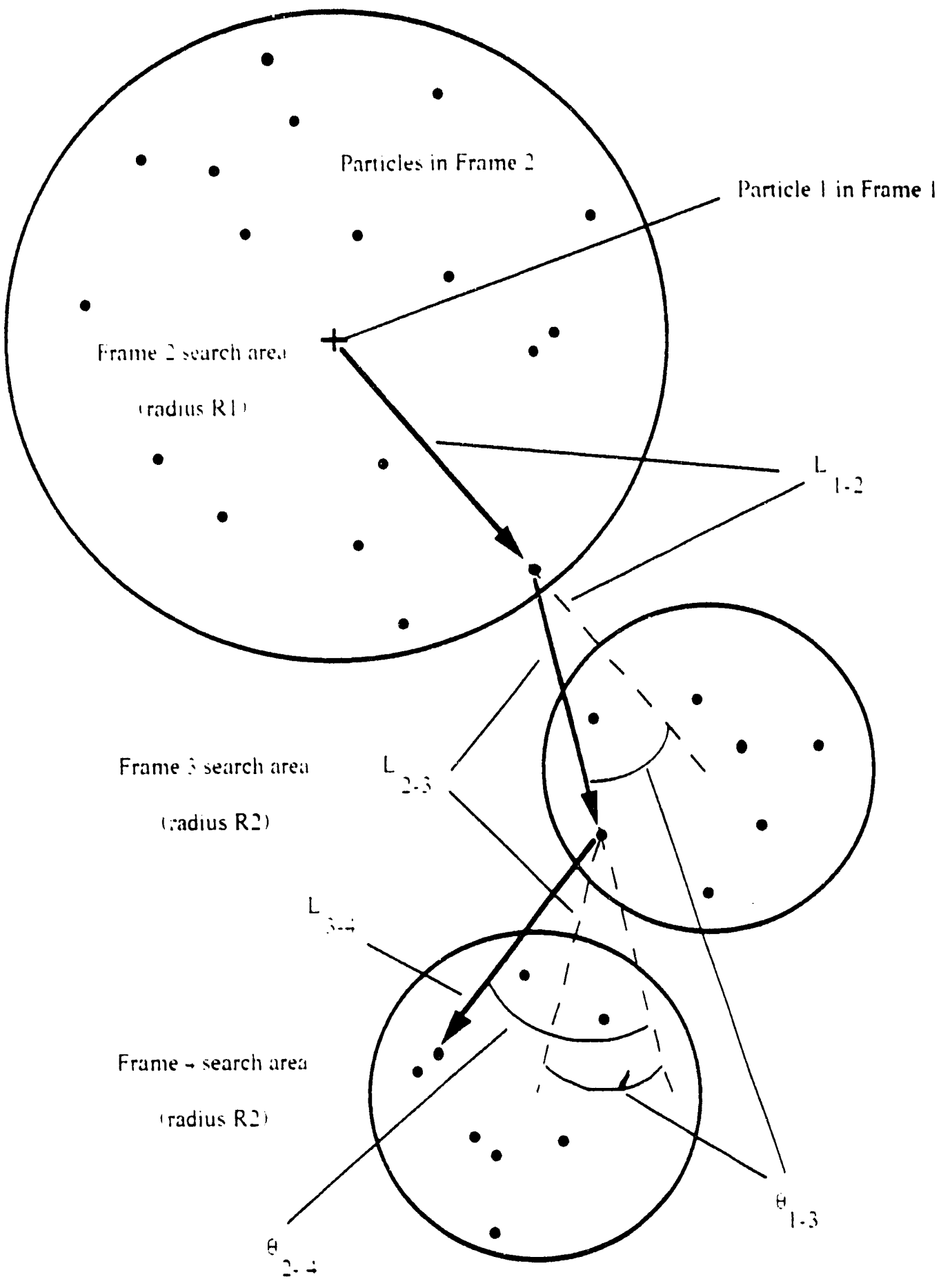

Figure 1. Multiframe Tracking Description 


$$
\begin{aligned}
& \sigma_{H}=\sqrt{\frac{\left(H_{i-A-H}\right)^{2}-\left(H_{I}-i-F !^{2}\right.}{\varrho}} \\
& \tau_{\cdot n t: i}=\sqrt{\frac{\sigma_{i}^{2}}{\bar{l}^{2}}-r_{\ddot{\mu}}^{2}}
\end{aligned}
$$

where

$$
\begin{aligned}
& \text { l:-z= length hetween particles in the lst and 2nd frames. }
\end{aligned}
$$

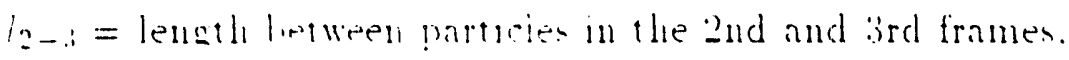

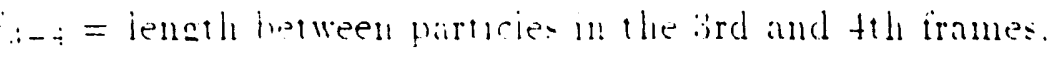

$$
\begin{aligned}
& M_{-3}=\text { ansle between } i_{--:} \text {and }:-\ldots \\
& m:-i=\text { ande hetween in-a and in-i. } \\
& i=\text { arerage iength hewreen particles }=\frac{1-2-12-3-i 3-4}{3} \\
& \bar{H}=\text { avernge angle between rectors }=\frac{\theta_{1-3 \cdots-A_{2}-4}}{?} \\
& \pi_{1}=\text { standard deviation for the lengths of the rectors. } \\
& \sigma_{H}=\text { standard deviation for the angles hetween the vectors. }
\end{aligned}
$$

Vote that the perfect rack would have a $\sigma_{\text {total }}$ malue of 0.0 . The dirision hy $i^{\prime}$ in equation $(3)$ is used 10 nondimensionalize the $\sigma_{\text {total }}$ value. Tracks originate in frames 1 through $T$. and conclude in frames $T$ through 10 . After these seven sets of four-frame tracks are calculated. any tracks which start in different frames. but use the same particle in their common frames, are added together to form long tracks up to 10 frames in length. For example. consider two four-frame tracks, originating in frames 1. 2. 3. 4 and frames 2. 3. 4. 5. respectively. If both tracks share common 
nartucles in frames 2. 3. 4. and each track has a $\sigma_{\text {total value less than some selected }}$ mmmum ralue. the two sets if four-frame tracks are combined int one five-frame

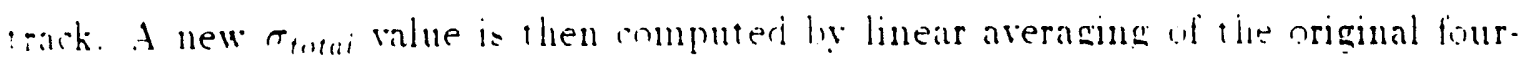
irack $\sigma_{\text {inai }}$ alues. For example. assume the previously mentioned wo four-iracks

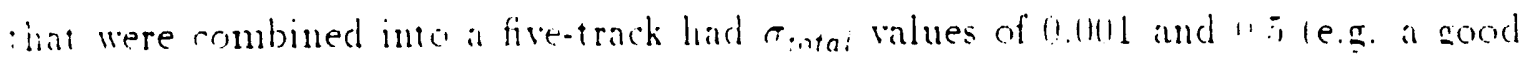
anck and a poor tracks. The new if allowed). combined track otota. walue would be 27.5. and provides an opportumty for later remoral of "bad" tracks.

After track anmhining in pertormed. the tracks are then cross reterenced agnanst

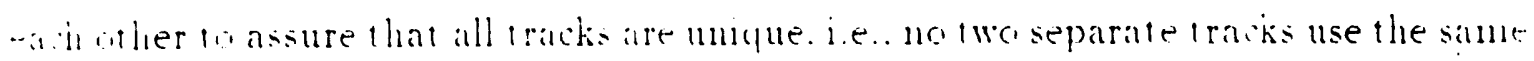
particie. This occurrence is called track crossing and orcurs infrequently. but often enough that it must he treated. If a track crossing has been determined. the track With the largest $\sigma_{\text {toral }}$ value is assumed to be the incorrect track. and is discarded.

\section{II.: Cross-correlation Tracking Algorithm}

Adrnamic particle trackins method can he quickly performed between two sequeninal. high resolution $11024 x 1124 x$ : bit images. if the particle tracer information is first converted to binary data. The binary data conversion is a method where all the --bit 10-25.5 gray level) pixels defining a particle have been converted io 2 -bit (value 11 or 1$)$ pixels through image processing techniques, e.g. thresholding and connectivity. algorithms. The particle velocity is found by determining the correspondence between particles in two sequential video frames. This correspondence is obtained through the calculation of a correlation coefficient between a referenced pattern in the first binary image and a possible candidate pattern in the second binary image. where the latter 
is shifted so that the centroids of the possible particle pair coincide I Vamamoto et al. luser). Every particle helongs to a characteristic group which has a specific locol distribution pattern. One particle in the first imane will correspond to the particle in the second imase which keeps the most similar pattern. providing the local pattern of the distributeci narticles changes little hetween sequential video frames.

This method is especially useful when only two sequential manes are arabable. and when the muitrame particle tracking method a requiring at least four sequenta! videg images cammin lie pertormed. The riden rechnology currently available t.. us can capture multiple. Ligh resolution. imases at intervals of approximately 1,1, frames sec. However. imanes of fister phenomena can be acquired through the use of two or more cameras. or hy double exposure of a single image with a pulsed light source. The method described below (modified for single frame data) has been successful in analyzing particle velocities on a chuble exposed image obtained with a pulsed laser light source $(1.5)$ microseconds between pulses $)$. yielding an effective frame acquisition rate of hibig trames sec I Delahume and Hassan. 1:14)(1).

The algorithm is illustrated in Fig. 2. Acquisition of two video frames has ar. curred. and image processing of grạ level information (noise removal. thresholdin:". tracer particle labeling. and binary conversion) completed (Hassan et al.. 1990). Two separate frame arrays are "filled" with 0 's and 1 's. The fill pattern is an outward spiral centered at each particle centroid. with the spiral stopping when the total number of pixels in the particular particle being "filled" is reached. The arrows denote the expected flow field direction and magnitude. 


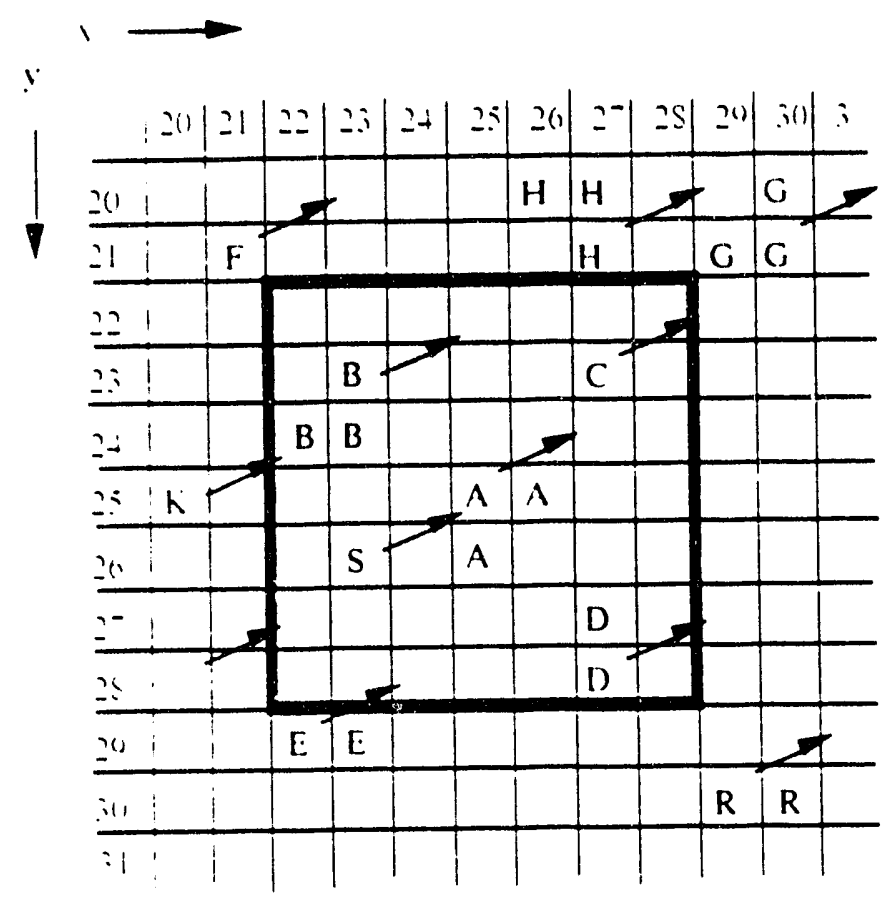

[) namic region in frame I centered at particle $t$

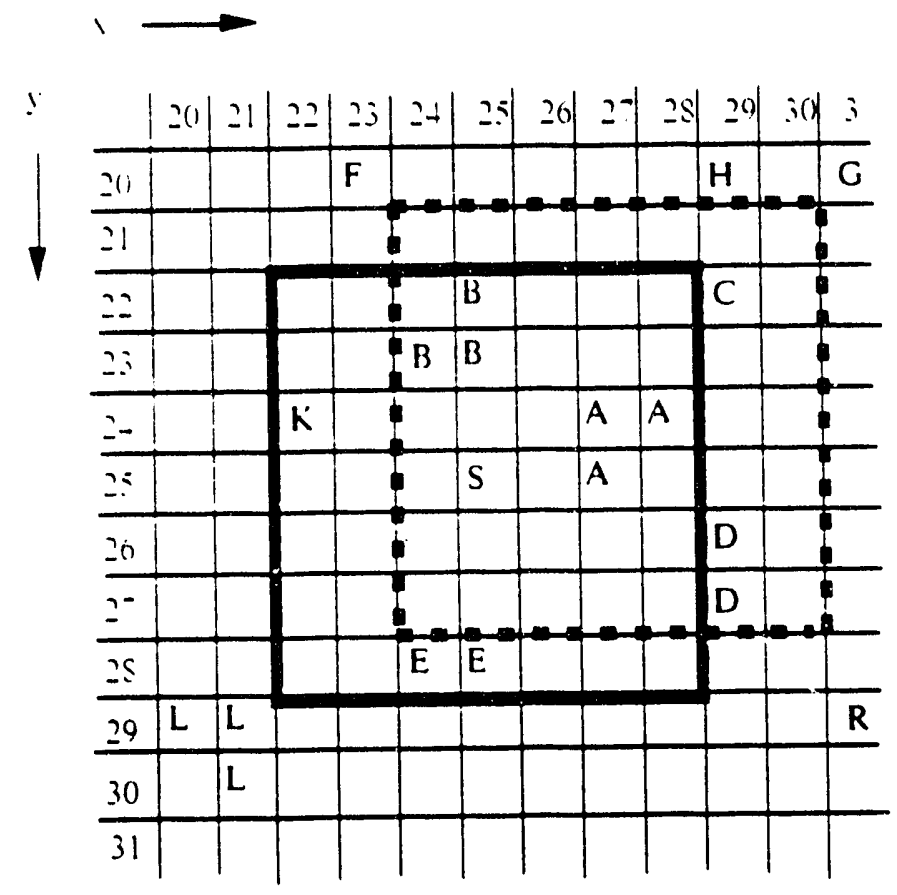

Dunamic regions in frame 2 centered at particles $S$ and $A$

Figure 2. Cross-correlation Tracking Description 
A rectangular andadate rengon shown by the solid line ts rentered in frame:2 at

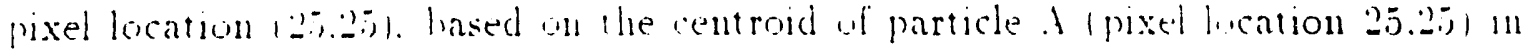
frame 1. The size and shape if this search remon is hased on the maximum possible particle velocity experted. All particles that lie within this andulut region in frame? are then determmed. Five possilite andidates have heen find comsisting of varying mumber af prets. They are dented hy the letters K. BBB. S. EE. and A.A. All ihese particles mow hecome candidates for paring with particle Am frame 1.

Vext a iumame region is pliced m frame - so that it is centered at each of the

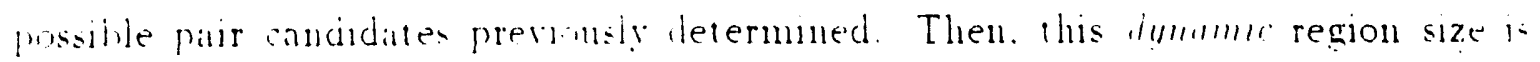
adjusted to chtam a minimum if tive particles. Correlations are performed between the dynamic resion centered on particle $A$ in frame 1 and the dynamic region centered an each of the candidates in frame 2. The cruss-correhtion coefficient on binary images. $\left({ }^{\prime}\right.$, . between dynumic regions in frames 1 and 2 is calculated from

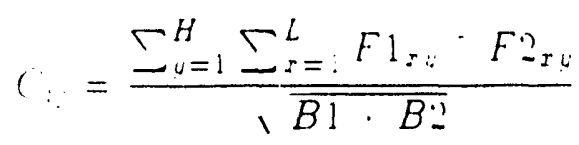

where

$F l_{x y}=$ binary pixel value at position $x . y$ in frame 1.

$F:_{x y}=$ binary pixel value at position $x . y$ in frame 2.

$B 1=$ total number of pixels with value 1 in frame 1.

$B 2=$ total number of pixels with value 1 in frame 2.

$L=$ length of dynamic region in pixels.

$H=$ height of dynamic region in pixels. 
The numerator gives the sum of the logical products of the hinary data between the iumumu regions in the two images. The logionl product in a test wibch is only true it the corresponding pixels in the iunumu regons are both of walue 1 . Tote that $B 1$ and $B$ : determine the total number of pixels for all the particles in their respective imumic regions. Rememher that a preel whth a value of 1 denntes that it is part of "pirticle and a pixel with ralue 1 mplies $n$ o particle at that location.

hetermn to Fin. 2. the sum of the lonical products between the imamo region in

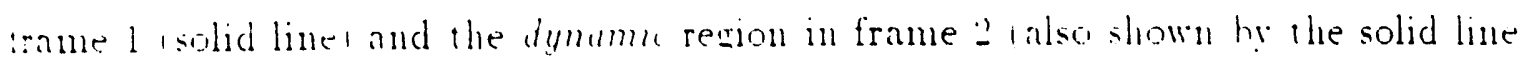

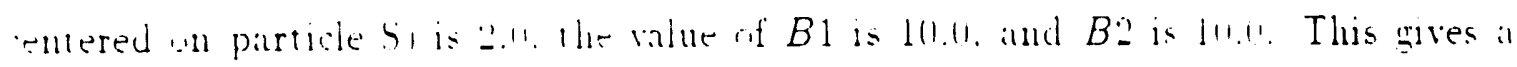

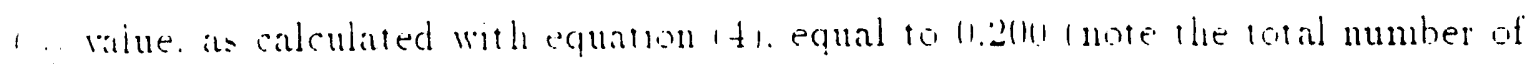
pixels in the dunamu region is $f(1)$. However. the $C_{i j}$ ralue for the tunamuc region in

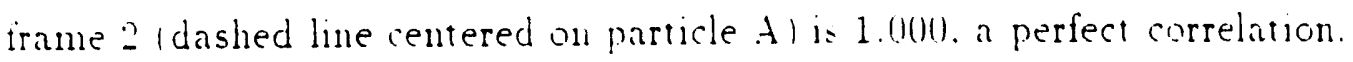

The relocity for a particle is determined by the particle movement divided hy the mage acquisition time. The candidate pair with the largest $\epsilon^{\prime}:$ ' value is identified as the correct particle pair match. Civen an irrotational flow. Large values of $\left(^{\prime} \because\right.$ , close to 1.011 are cbtained for the correct particle correspondence In regions of high vorticity. the $i^{\prime}$, values can he much smaller. and the identificd mattes are not alwars correct. Another means of checking is required to remove erroneous vectors. Two checks are performed. The first check calculates the sum of the distances between all overlaying particle centroids. For example. in Fig. 2. during the correlation between the frame 1 dynamic region (solid line) and the frame 2 dynamic region (solid line). two particles in frame 2 are overlaid with particles from frame 1 . B-K (particle B in frame 1 and particle $K$ in frame 2) and A-S. The sum of the distances between the 
avertad centroids is approxmately " puxels. For the correlation between the frame 1

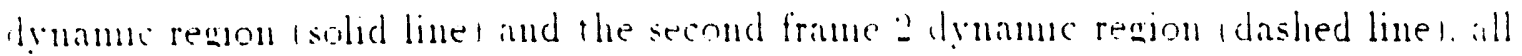
five particles in frame '- are perfecty overlad with particles from frame 1. vielding zero for the sum of the distances between the avertad centroids.

The senud check determunes a reliability ndex. $R$, for a possible andidate pant

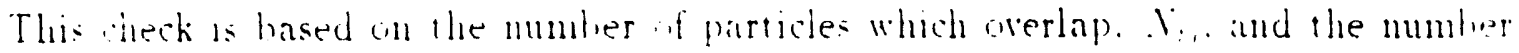

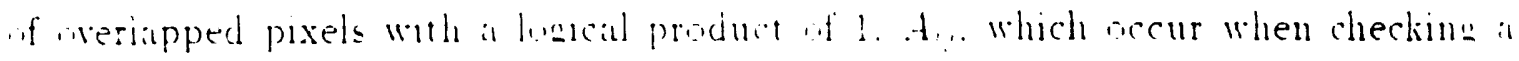

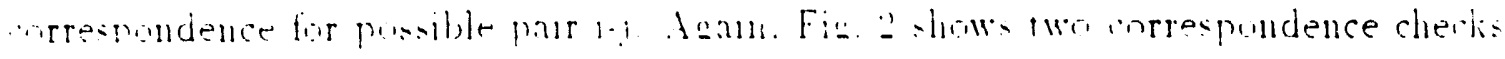

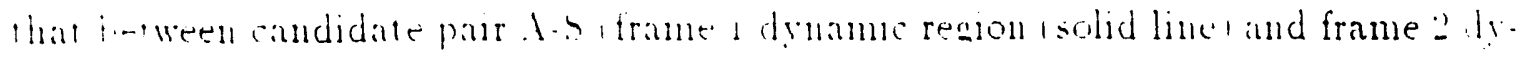

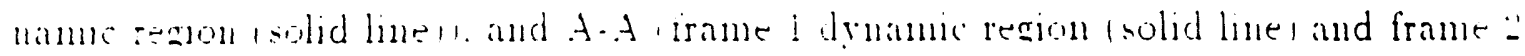
dyname region idashed linell. For the A.S candidate pair. two particles have over-

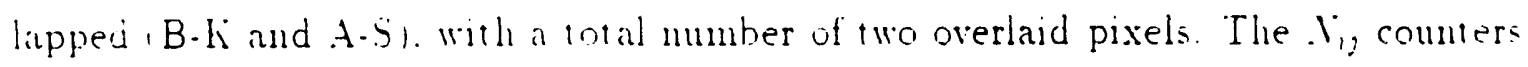
for hotin pars B-K and A.S are merememed hy I since the par benn checked vil

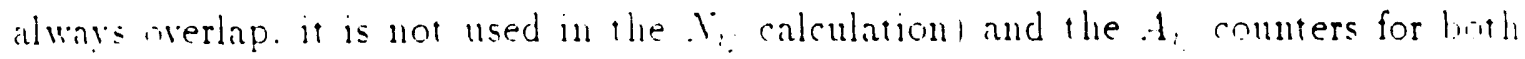

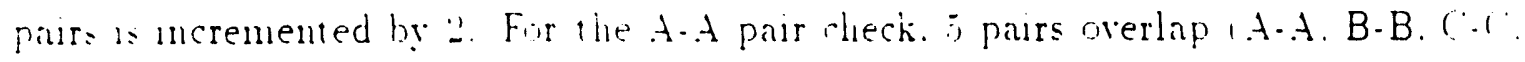

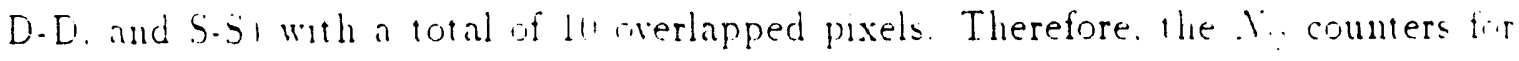
each on the 5 pairs are incremented by $t$. and each $A_{1,}$ pair counters by 10.

As other particles in frame 1 are corresponded to possible pair matches in frame :? the counters for the A.S and A.A pairs may also increase. since each particle usually belongs to some local group. When all correspondences are completed the reliabiitity index $R_{i j}$ is calculated using

$$
R_{i j}=X_{i j} \times A_{i j}
$$


where

$$
\begin{aligned}
& \therefore_{:}=\text {mumber if overlapped particles. } \\
& d_{1}=\text { number toverlapped pixels. }
\end{aligned}
$$

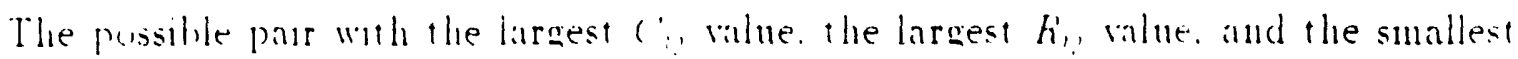
-lum of the distance hetween centronds. is generally found he he the correct match. Vite that this algorithm will find a correspondence anot necessarily correct for a

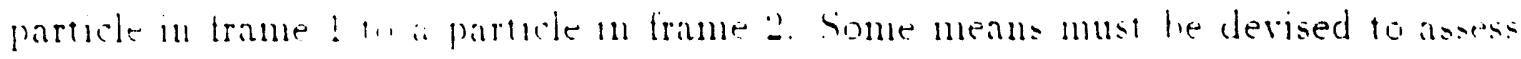

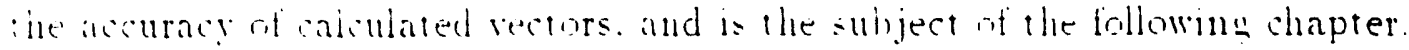




\section{CHAPTER III}

\section{TRACKING CODE TESTING AND ERROR ANALYSIS}

\section{I1.1 Intrieduction}

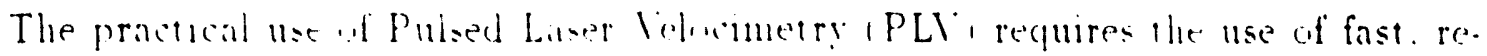

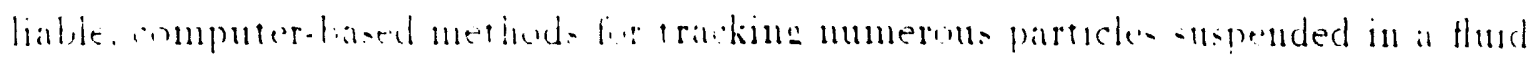

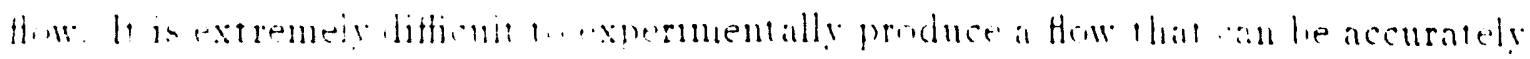

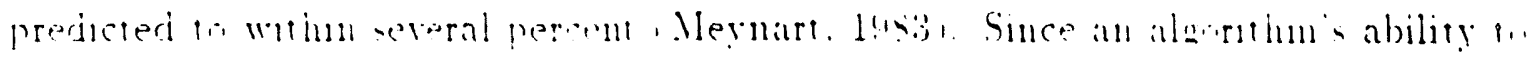
mack complicated fiow: must he verified error analysis on a PLI macer tracking pro. gram should he performed usins sythetic data (Meymart. 1!4:3: A sui and Jimenez. 1ust: Sheng. Luss: Cinezennec and Kirntsis. Lyoli. The multiframe tracking (MFT) algorithm and the cross-correlation tracking / C'C' $T$, algorithm were tested with sinthetic data and experimental data. The synthetic data was computer generated and the expermental data was cimaned whth traditional PLI melhods. This allowed error analysis and testun of the aloorithms un real encineerma Hows

\section{III.2 Sỵthetic Data Production}

The production of synthetic data is necessary for the validation of tracking methods. There must be a standard set of particles with known positions moved through several frames. This produces a known particle track. The tracking method can then be performed using these frames of data to produce particle tracks. C'omparisons are then made between the tracks produced in the method and the know'n particle tracks. 
The sprnthetic data set. used for testing. simulates invscid flow about it cylinder

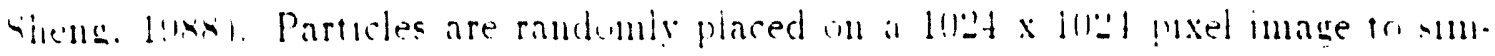

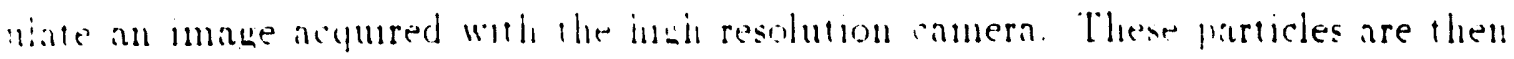
mined in subsequent frames ly usm: the following equations. First. a transforma. won from a rectangular fo pular …rdinate system is necessary 1 . Whe the equation of

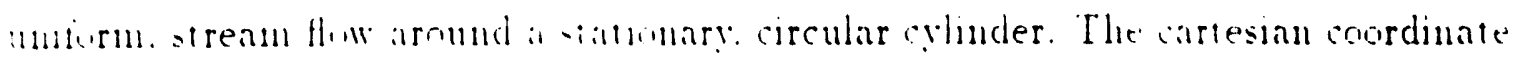

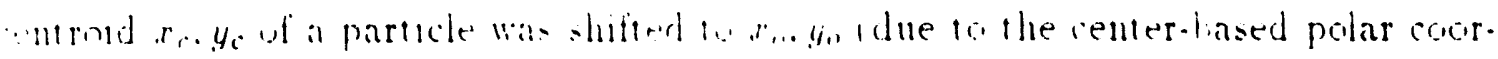

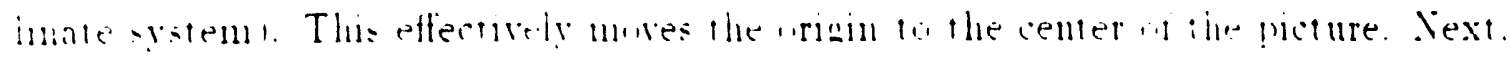

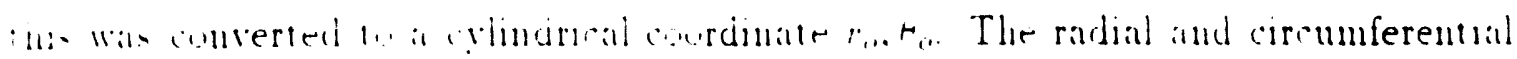

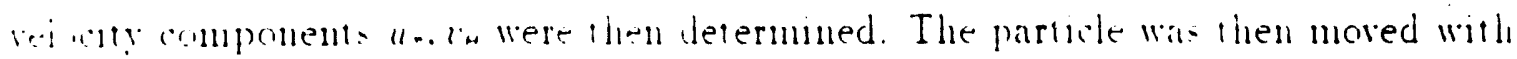

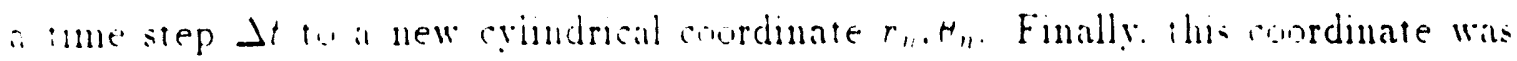
iransformed wa $x^{2}, 4$ : lo correspond with the original cartesian system.

$$
\begin{gathered}
x_{1}=x_{c}-. j 12 \\
y_{1}=y_{i}-. j ! 2 \\
r_{n}=1 \overline{\left(x_{0}^{\prime \prime}-y_{0}^{2}\right)} \\
H_{1}=\arctan \left(\frac{y_{0}}{x_{0}}\right) \\
u_{r}=I^{\cdot}\left(\frac{R^{2}}{r_{0}^{2}}-1\right) \cos \theta_{0}
\end{gathered}
$$




$$
\because:=r_{1}-11 \cdot \Delta t
$$

$$
r=r_{.}-\left(\frac{l_{10}}{r_{1}}\right) \Delta t
$$

$$
\because=\because \cos \mathrm{H}-712
$$

$$
\varphi_{n}=r_{r_{i}} \sin H_{1:}-i 12
$$

where

$$
\begin{aligned}
& \therefore=\text { old cartesian coordimate in } \mathrm{x} \text {. } \\
& 4=\text { old cartesian coordmate m! } \\
& x_{1}=\text { shifted ald cartesim romodmate } 11 \mathrm{x} \text {. } \\
& y_{1}=\text { shifted old cartesian condinate in } ! \\
& \because "=\text { old cylindrical coordmate } \mathrm{m} \mathrm{r} \text {. } \\
& t_{0}=\text { old cylindrical coordinate in } A \text {. } \\
& u_{r}=\text { radial velocity component } . \\
& l_{A}=\text { circumferential velocity component. } \\
& { }^{*}=\text { freestream velocity. } \\
& R=\text { cylinder radius. }
\end{aligned}
$$




$$
\begin{aligned}
& \Delta t=\text { ume ster parameter. }
\end{aligned}
$$

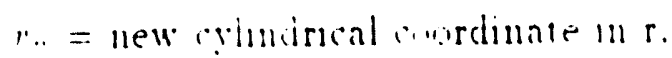

$$
\begin{aligned}
& H .=\text { new cylmidrical coordinate } m H \text {. } \\
& \therefore \text { = new cartestan courdinate } 11 \mathrm{x} \text {. } \\
& y_{n}=n+w \text { cart-sian courduate in! }
\end{aligned}
$$

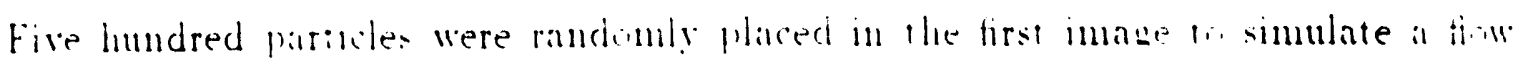

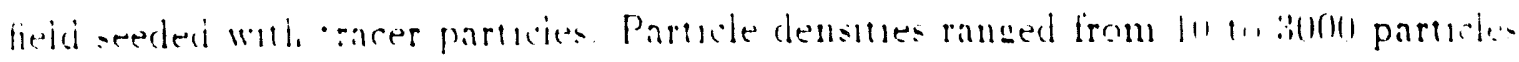

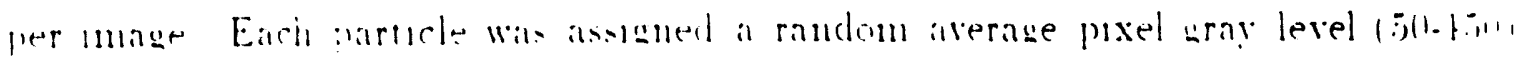
and areat bi:-i pasels. Particie morement in the followns "sequential time" imates: was accomplished hy setting the time step parameter $\Delta t$ and the freestream veloculy. $r^{\circ}$. The analysis with synthetic data set $R$ equal to 1.50 pixels. C' equal to 1 and It ranged from $: 4,12 \%$. This provided a particle morement hetween image: if

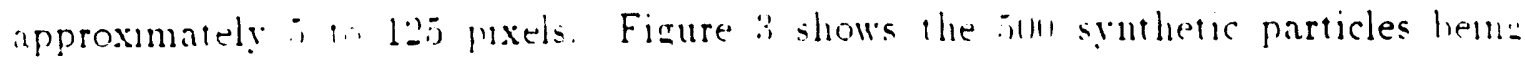
moved in mme ${ }^{\prime} t=10$ i hroush ten frames. This figure overhys the ten synthen data files. to allow flow msuahzatmon. Iote that the flow moves brom right to left.

\section{III.3 Interpolating Scattered Vectors into a Full Vector Field}

A method for interpolating sparse. scattered. velocity data was needed to produre a vector at any given point in the flow field. The interpolation method that was developed is based on the Hardy multiquadratic equations (Hardy. 1971) as discussed by Narcowich and Ward (1991). The basic equations are 


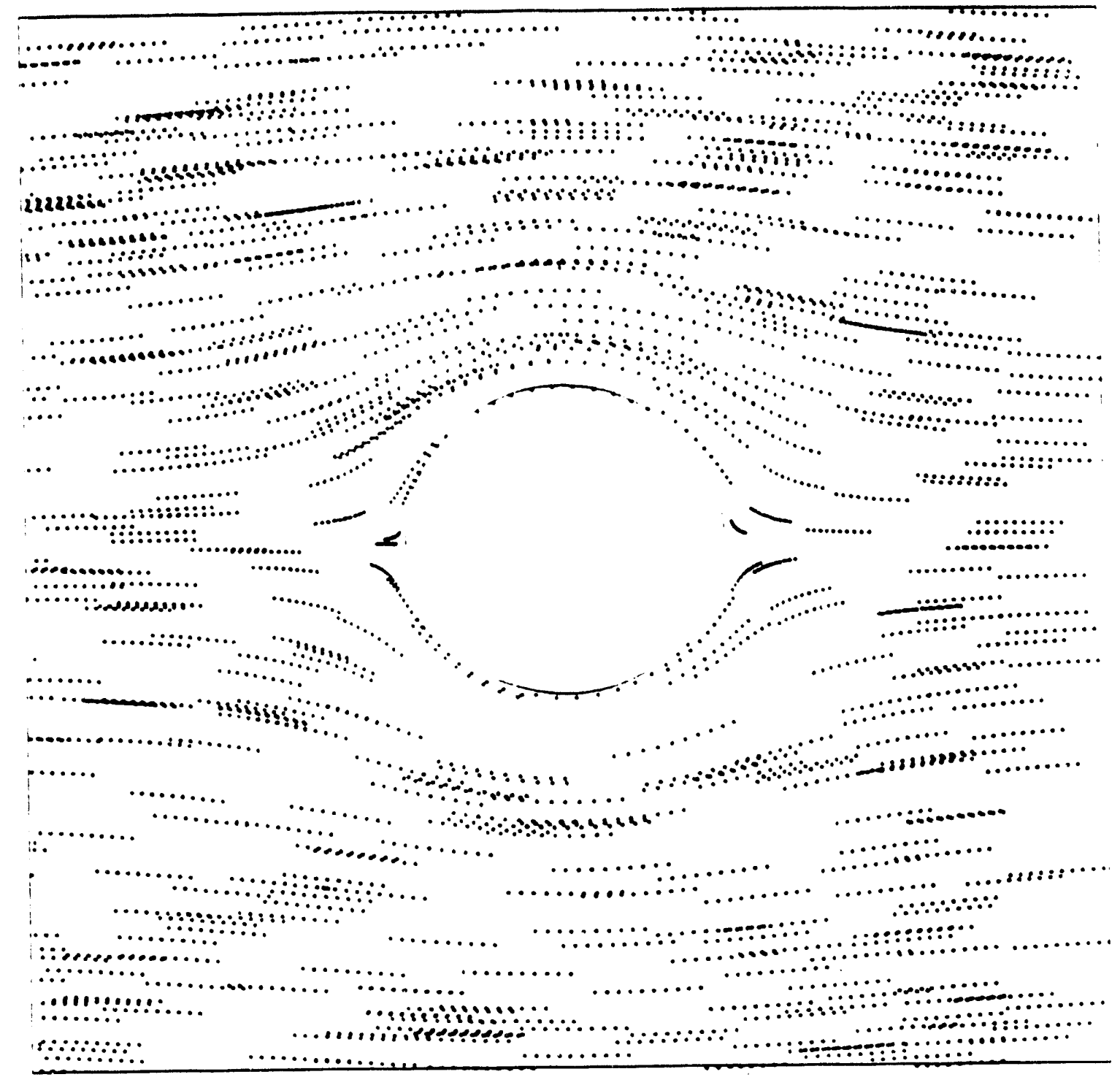

simmlated flow from right to left

C'amera view: $1024 \times 1024$ pixels

Figure 3. Synthetic Data Overlay. Frames 1.10 


$$
\begin{aligned}
& \left.v_{i}=i 11, \ldots\right) \\
& \text { Iliil }
\end{aligned}
$$

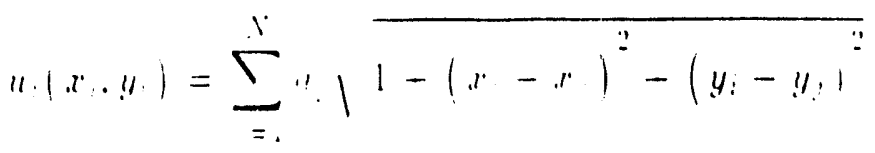

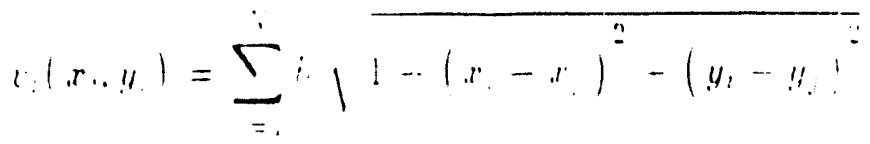

uinere

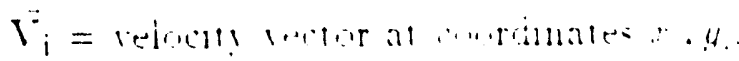

$$
\begin{aligned}
& \therefore=x \text { compontm } 1 \mathrm{~V}_{\mathrm{i}} \\
& i=? \text { component if } \vec{V}_{i} \\
& r=\text { number of rectors nsed in merpolation. } \\
& r:=x \text { coordinate of } \vec{V}_{\mathrm{j}} \\
& \because=y \text { roordimate of } \vec{V}_{\mathrm{j}} \\
& t=x \text { omponent instants } \\
& i_{1}=\text { ?omponent instant: }
\end{aligned}
$$

For each vector component. the Hardy equations involve a set if I simultaneons. equations, with .1 unknowns (the constants $a$, and $b$, ). Solutions to these equations can be found by a variety of mat nx operation techniques. such as Ciaussian elimination or Gauss-Siedel methods. A Gaussian-elimination matrix solver was written utilizine. full scaling and implicit partial piroting to find the constants $a$, and $b$, Uising these constants, and their associated $x$, and $y$, position coordinates. the velocity can be 
determmed at any point in the How field hy replacing $x ;$ and $y$, in equations $(17)$ and 1: whin the and 4 condinate of interest. Virticity and How streamlines can then ie dermed nsing the equations for the interpiatied vector feeld.

An example using equations 1 lit through 1 lif follows. Assume two. horizontal ver.

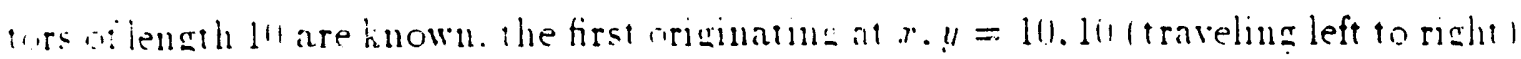

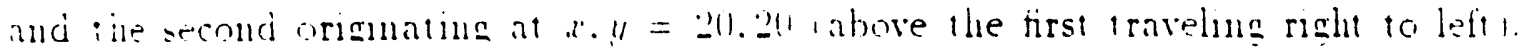
This amulates iwo plates sliding in uppostte directions across ench other. Therefore.

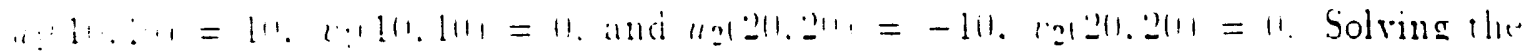

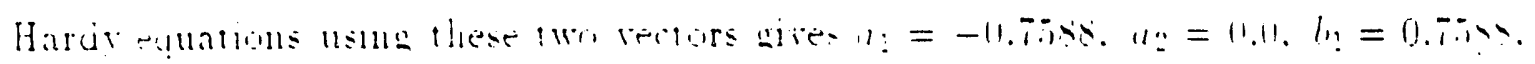
and $:=11.11$. Itith these constants. a reforty of zero las expected is determined at $x . y=15.15$. agam usin@ the Hardy equatuons

\section{4 Tracking Synthetic Data}

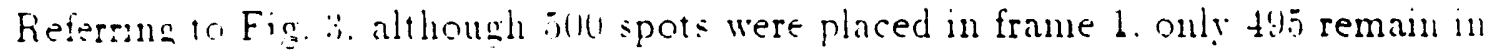
frame :. $4: 2$ spots reman throuch frame 4 . and 4.5 .5 spots remain in the view area throusin all 10 frames. This is due to motion of spots out of the imaginary riewing areat hy the fow tield. Further scrutiny will show that there are high density regions (upper right side) and low density regions (directly helow the cylinder / of particles. alon! with a mix of straight and curving flow regions. The multiframe tracking technique uses all ten frames of data (only the first four frames are used for anaiysis purposes/. while the cross-correlation algorithm is performed on the first two frames of data.

Figure 4 and Fig. 5 are produced with the multiframe tracking program. Figure 4 shows the particle trajectory tracks through all 10 frames. essentially 'connecting the 
dots from some starting particle. Figure i plots instantaneous vectors by pulling allt the plece of s track which started in trame 1 and stopped in frame 2. The vector magnitudes have been multiplied hy :. The tail of a vertor "arrow" marks the point uf the velongy coordinate. A velucity scate is provided. and can be used in the

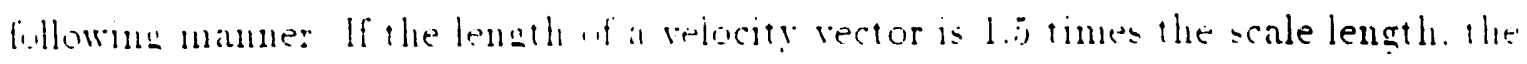

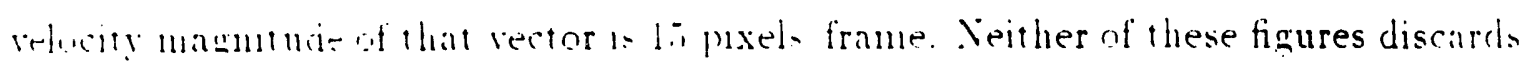

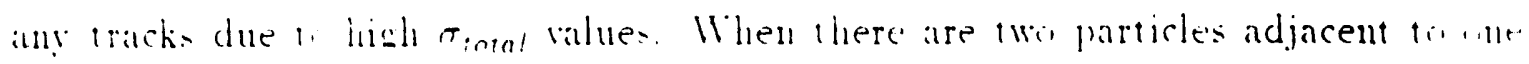

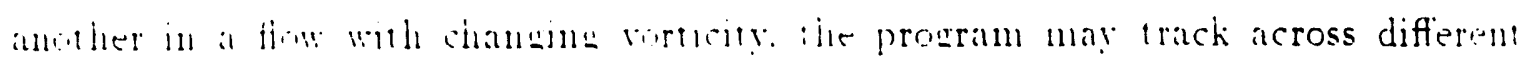
ipots through the :urn. This creates difficuly in combinins sets nf four-tracks and als. in deterint tracks which incorrectly share a common spot. This is erident will the small incorrect track startinu with the little circle near the lower left hand portion of the cylinder shown in Fig. 4. The small circle indicates that this track started in frame j. obvionsiy incorrect since all tracks started in frame 1, and therefore 11, shown in Fia. i.

Finure i was produced by ploming the output of the cross-correlation program. The cross-correlation program shows more vectors leaving the view area at the left side of Fis. (i. as compared to Fig. 5 . This is due to the less stringent requirement of only two sequential frames. vice four frames for the multiframe tracking program. Also. Fig. is shows that the cross-correlation program correctly determined the wo vectors missed (previously mentioned) by the nultiframe tracking method. However. there are two vectors (near the bottom and top right portion of the cylinder) missing. Cross-correlation uses the overlaying of neighboring particles between frames. The 


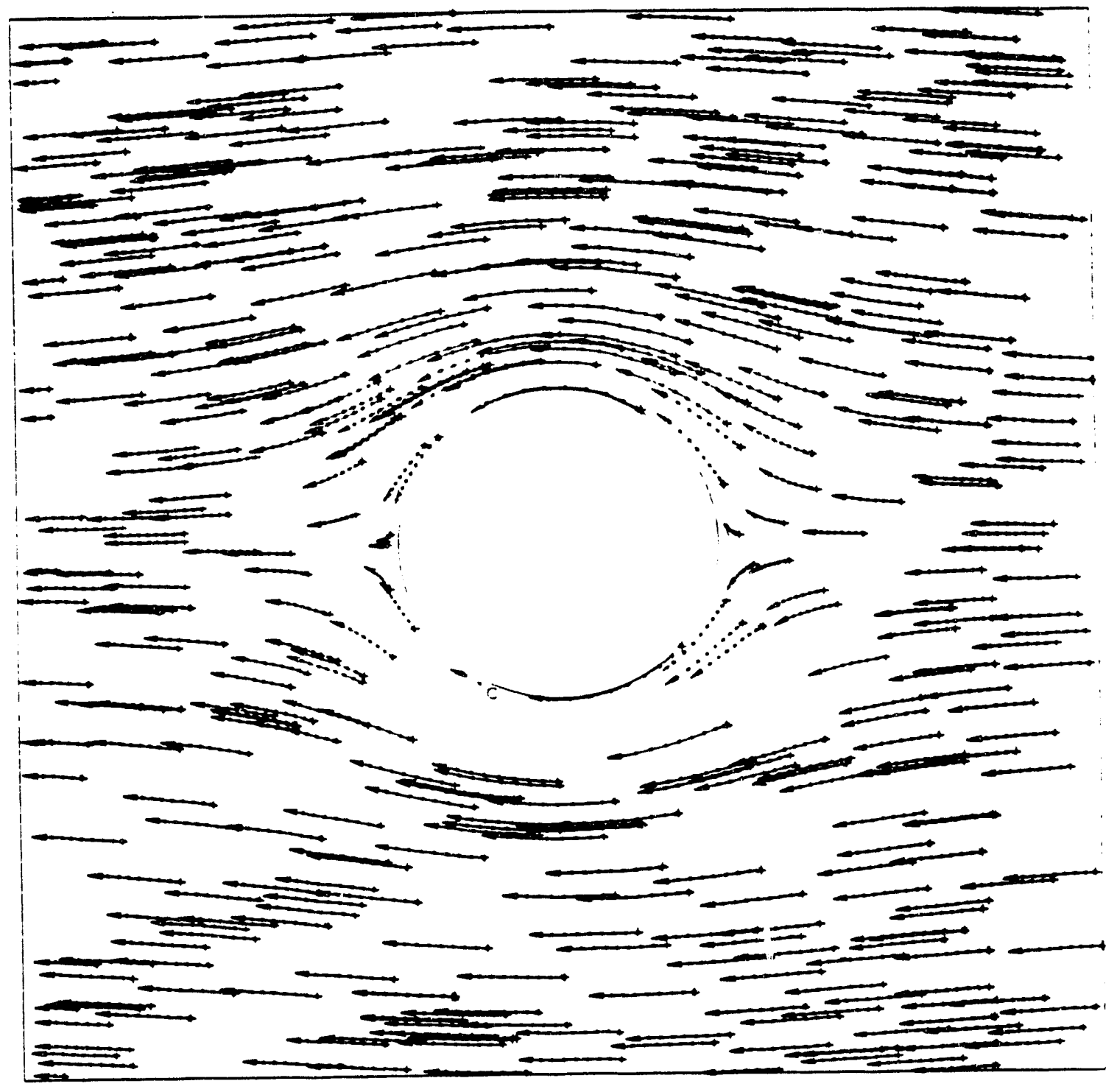

Camera riew: $1024 \times 1024$ pixels

Figure 4. MFT Method on Synthetic Data. Frames 1-10 


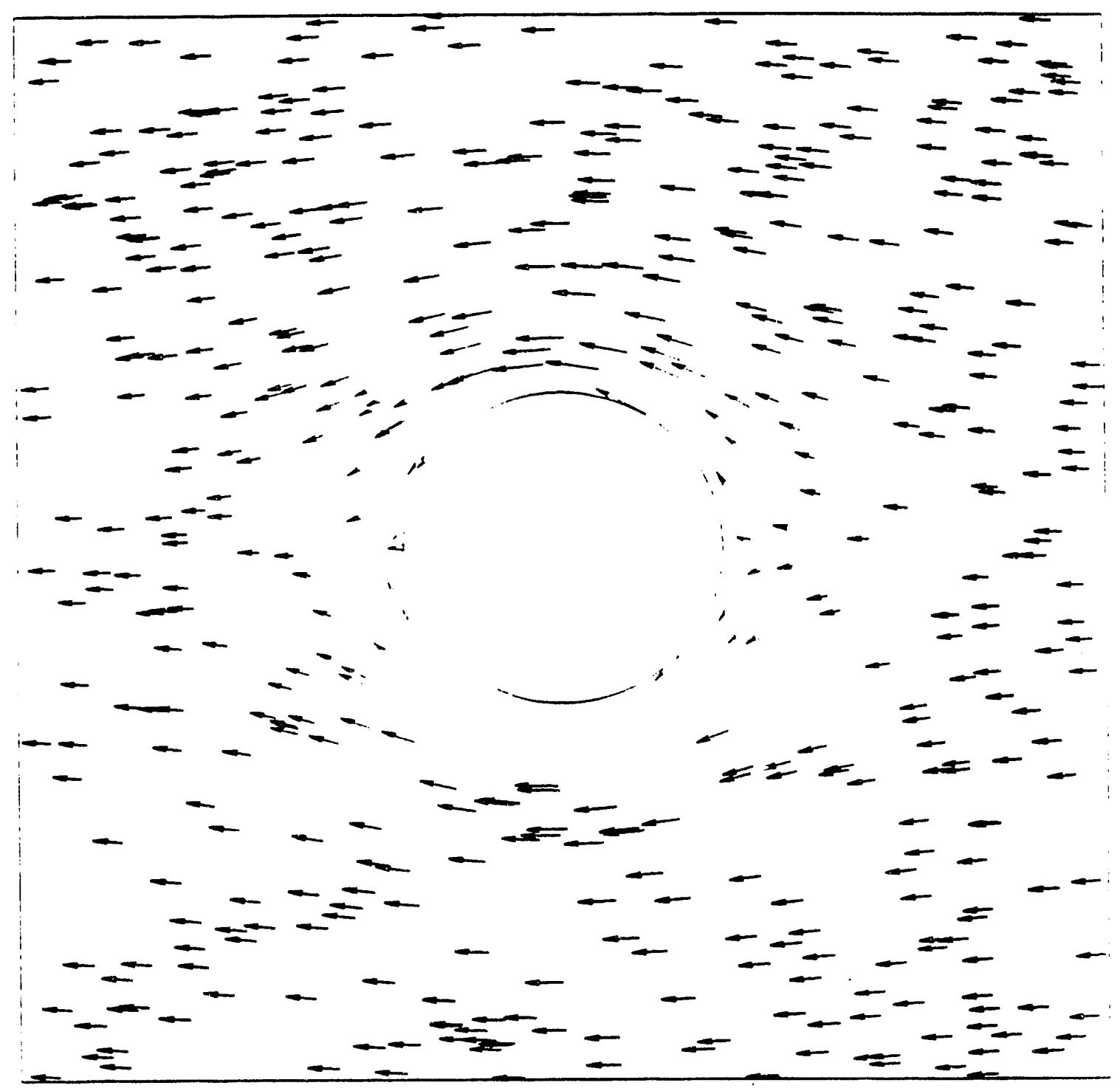

Camera view: $1024 \times 1024$ pixels

Velocity scale: -10 pixels / frame

Vector multiplier: 3

Figure 5. MFT Method on Synthetic Data, Frames 1-2 
dynamic correlation region will expand to ensure at least j particles are included in the correlation for a specific particle match. The program did find these vectors. Imt the reiability index for these parmele pairs were 11.0 . due 10 nu chose neighbors. and consequenty not plotted.

There are many parameters thit can affect the functioning and computer speed if

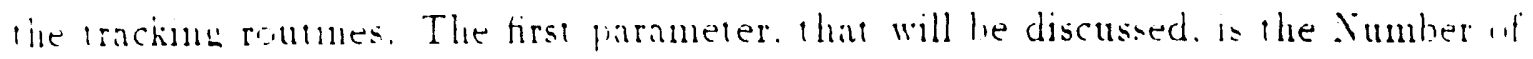

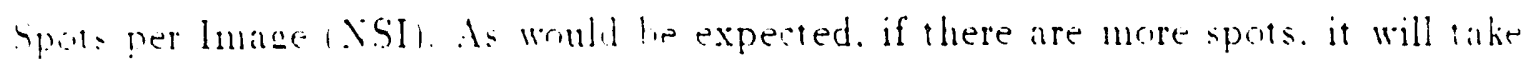
the rachine programs loneer we track all of them.

Tir wond parameter is munler density Cumber density is the number of sput:

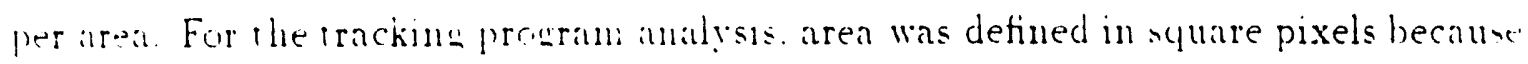
the dirmal imager used to obrain expermental data had a resolution of $1024 \times 102.4$ pixels It is irrelevant. To the tracking programs. Whether the camera was viewinn a $50 \mathrm{~cm}^{2}$ area or a $25 \mathrm{~cm}^{2}$ area. The number of square pixels remained the same. Vumber density is a concentration measurement. Whereas. NSS is a measurement of the total seeds captured. Tumber density was defined in terms uf number of spots per $1024 \times 1024$ image. Thus. if 506 spors were evenly distributed on a $1024 \times 1024$ image. the number density and XSI are equal to 500. If the jol spots were present only on the right half of the image. the number density (for the right half of the image) would be 1000. and the NSI would remain 500. The number density is an important parameter to the tracking programs. The cross-correlation algorithm requires adjacent spots for its tracking, and the local number density could significantly affect the results.

A third parameter is the spot movement between sequential camera frames (or images). This is the distance, in pixels. that a single particle travels between two 
ii:

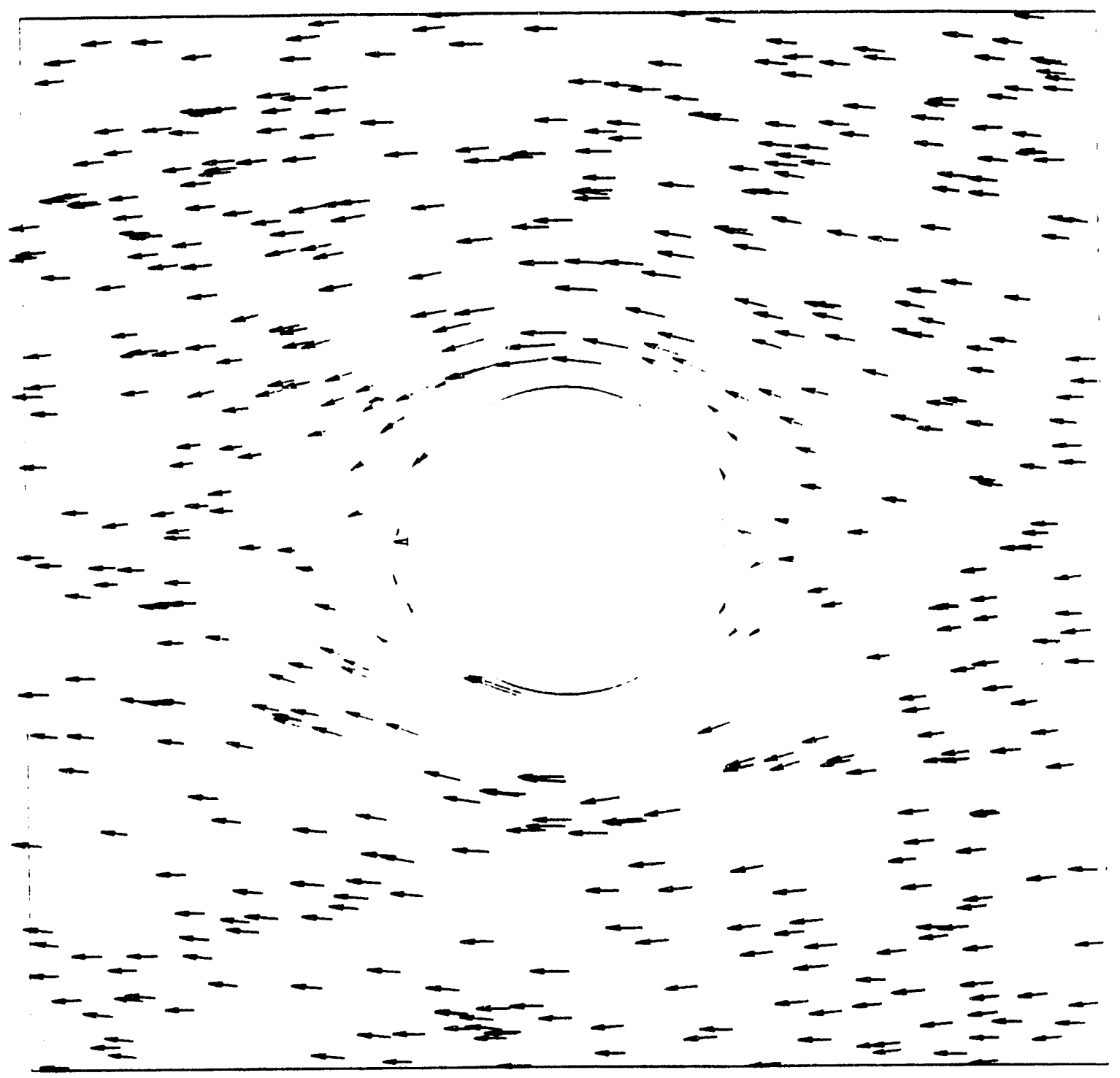

Camera view: $1024 \times 1024$ pixels

Velocity scale: -10 pixels / frame

Vector multiplier: 3

Figure 6. CCT Method on Synthetic Data. Frames 1-2 
consecutive imanes This is particularly important if the flow has significant hunt

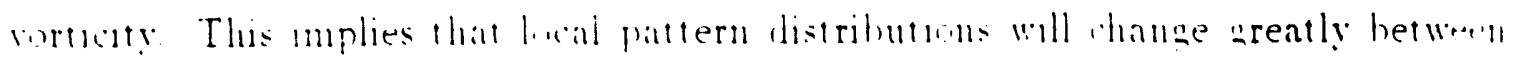

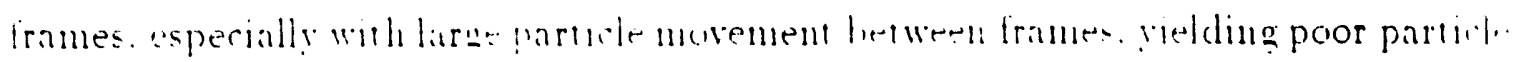
armip correlations

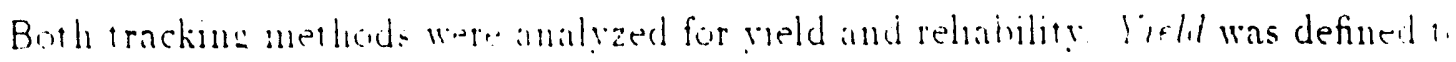

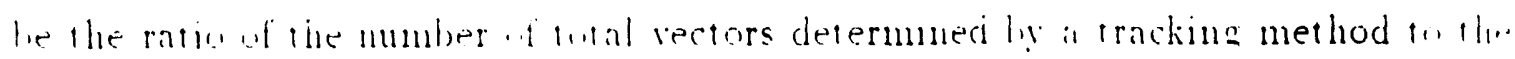

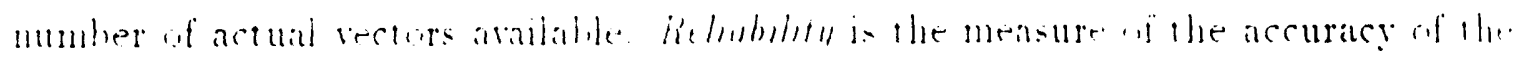

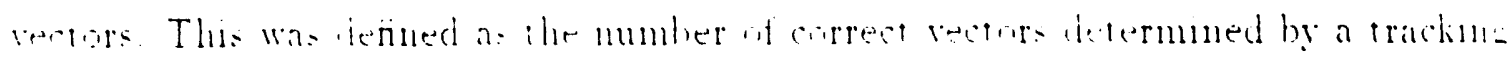

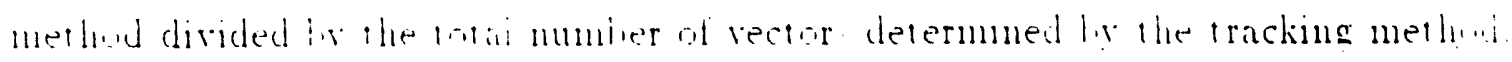

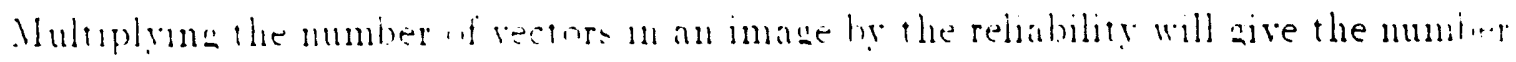
of accurate vectors produced hy the tracking program.

Figure $i$ compares the effects of spot movemem for the two tracking methoi:.

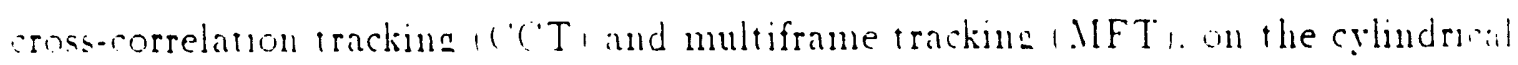
flow field. Spot movement defines rarious freestream relocities. i.e. a spot movement of 11 simulates a particle ireestrean velocity of 11 phels frame 1 m the $x$ directum, In order to accurately compare the tracking methods. particles were randomly plawi Isimulating a tracer seed release, near the rylinder bounded hy j11 $\cdot x \cdot 111:$. and $256 \therefore y=75 \%$. This allowed the seeds to remain in the picture through at least four sequential frames. even with large pixel movement. which is a requirement of the multiframe tracking method. Analysis was made with movements of 5 . I11. 15. 20. 25. 50. 75.100 , and 125 pixels between frames. NSI was a constant 1:5 particles. and number density was held constant at 500. Reliability and yjeld for 


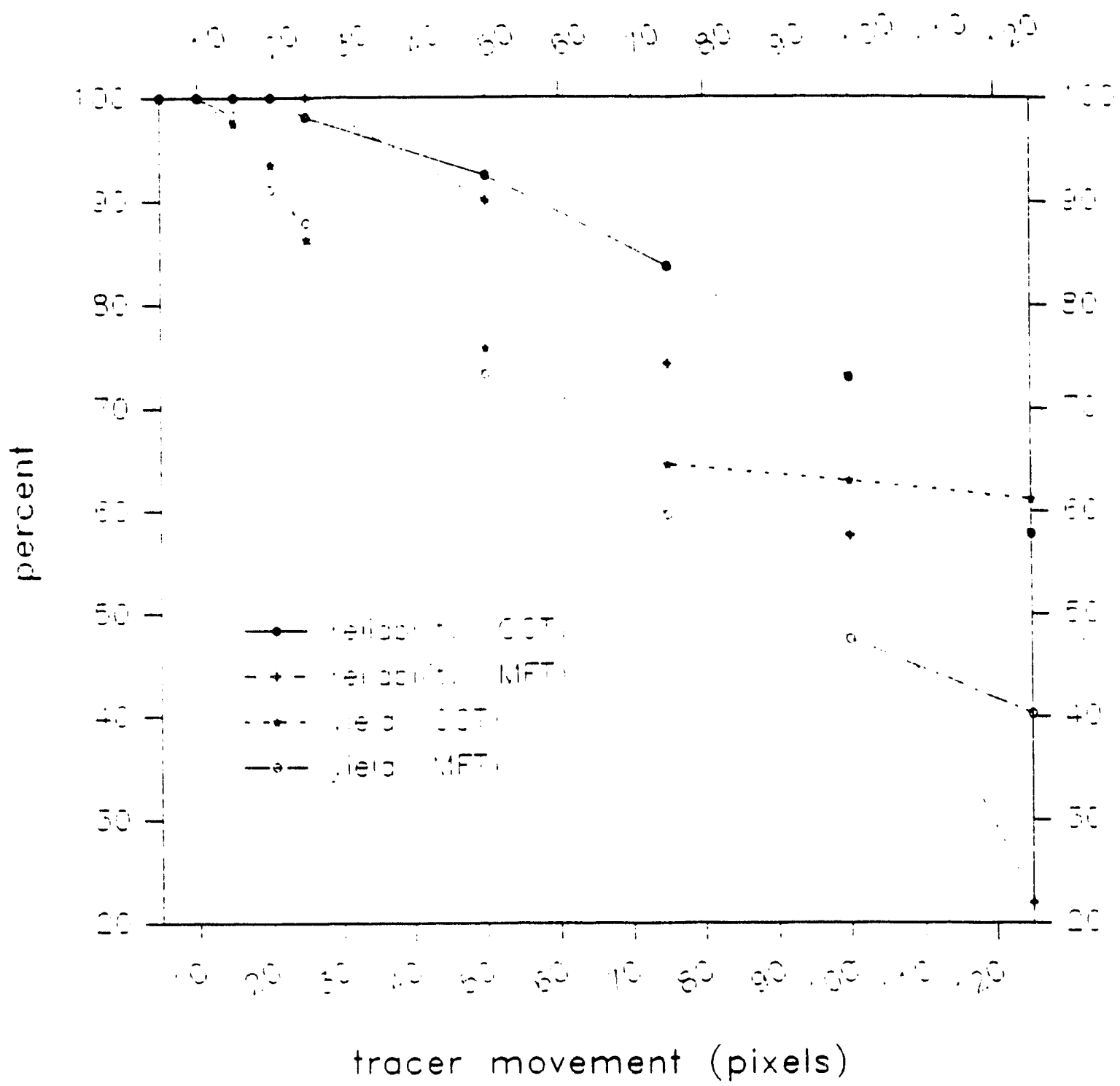

Number density constant at 500 tracer particles

Figure 7 . Movement Analysis of Synthetic Data 
hoth tracking techniques were arenter than $701-$ for movements as large as 511 puxels

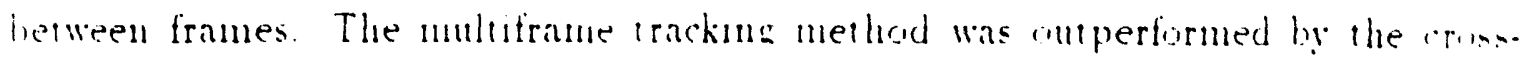
romelation technique for partucle movements areater than :i: puxels. This was due $\therefore$ the tracer seeds moring in somewhat "s-shaped" patterns around the cylinder.

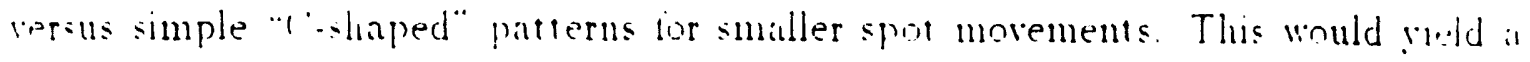
larse value for the devatum from the mean of the vector angles tequation 12 il. and

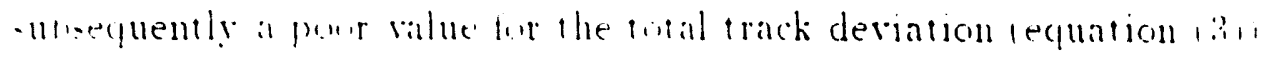

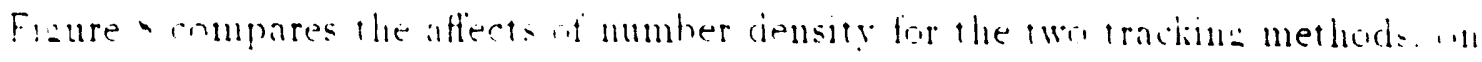
like yindrical flow. The glut moventent was hept constant at lu puxels per frame. $A=$ the tigure shows. number densuly does not affect lhe accuracy of the irackin: methods to any significant degree. except that the cross-correlation method camnot track properly if there are very few spots on an image. This was because there are no adjacent spots to correlate. which then gives a reliability index $R_{1}$, value equal $1 .$. 11.'1. and subsequently not tracked.

Figure "shows the ('PC cost analysis for the tracking methods usme a VA. viilu computer. Even hough the binary cross-correlation tracking method is generilly. more reliable than the multiframe tracking method. it can cost considerably more C'PI time. It should be noted. however. that the binary correlation uses far less ('PI' time as compared to an 8 -bit gray level correlation. where the number of floating point operations can be significantly higher (Yamamoto et al. 1988). This figure demonstrates the expected effect that increasing movement and number density increases the time for analysis. 


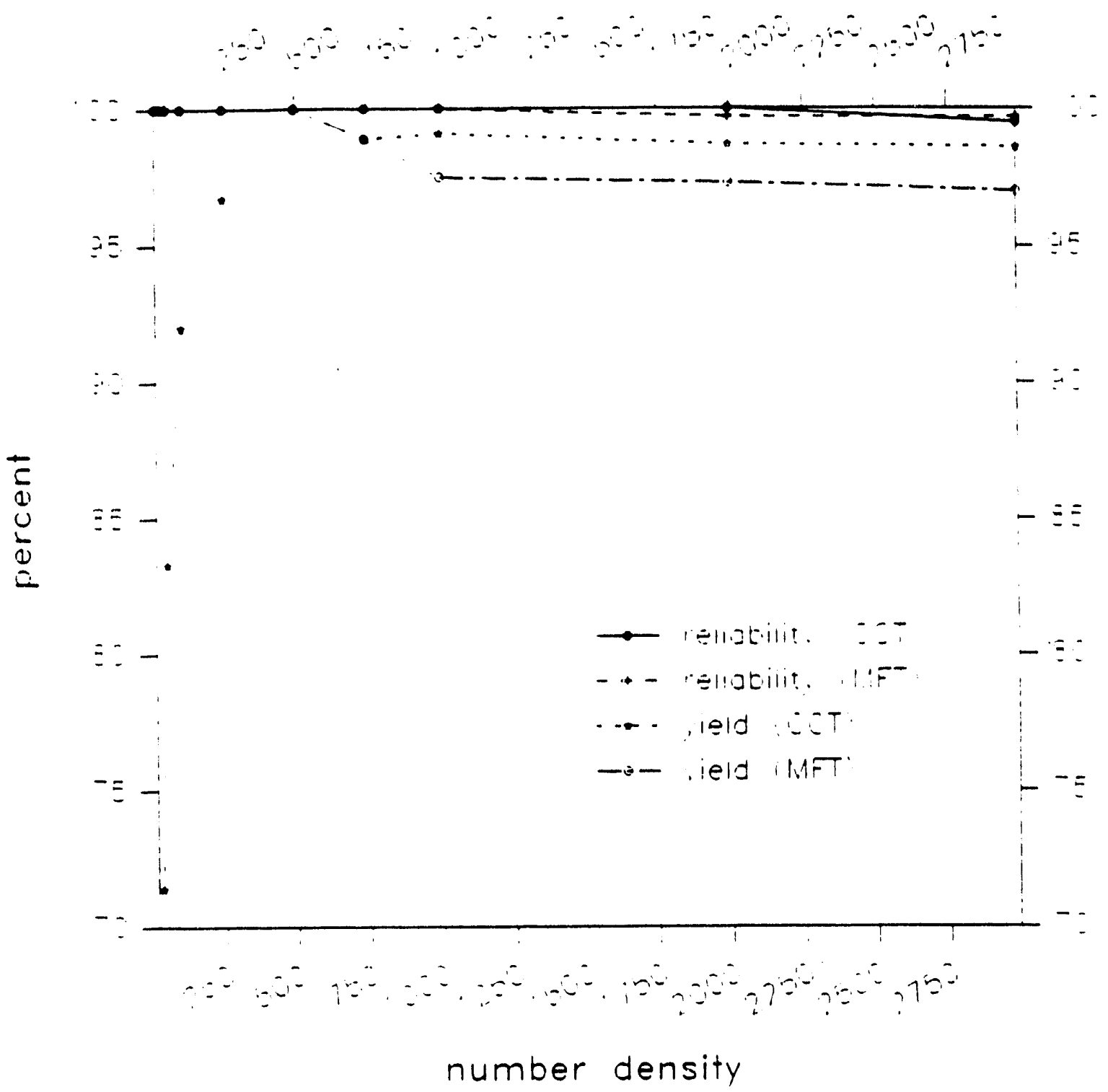

Spot movement constant at 10 pixels/frame

Figure 8. Density Analysis of Synthetic Data 

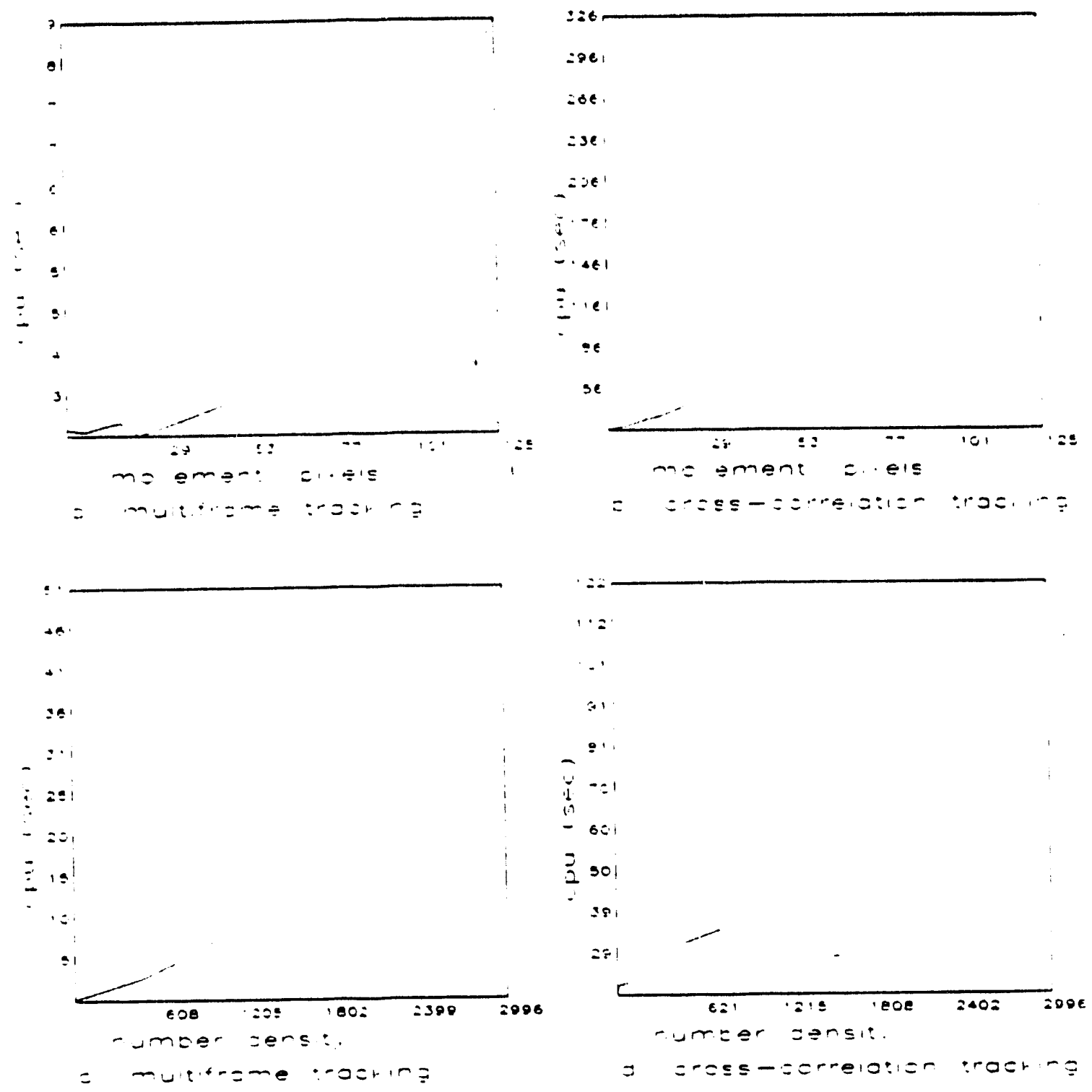

a) Number density constant at $5(0)($ spots

b) Number density constant at 500 spots

c) Spot movement constant at 10 pixels iframe

d) Spot movement constant at 10 pixels iframe

Figure 9. ('PI' Cost Analysis of Synthetic Data 
Table I summarizes the analys for the two tracking methods. The simulations

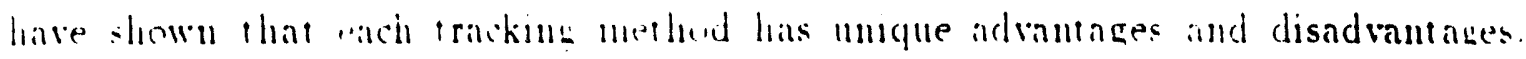

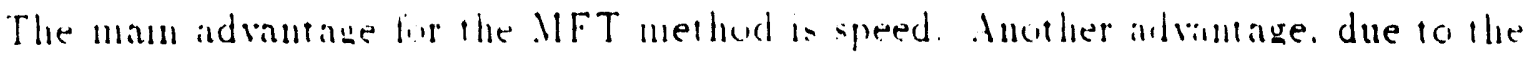
requirement of $t$ sequential frames. is that the additional data heips contirm a track. The requirement of $t$ squenthil tammes is also the higgest disadrintage especially

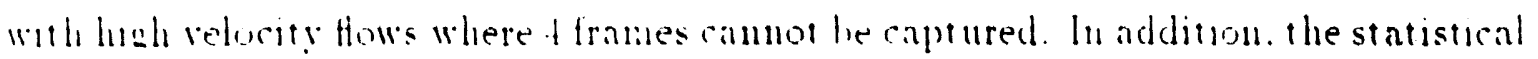
alarithm which computes hhe hest track breaks down with complicated. turbuient. Hows Alor. a litte thught all the yuestion Mhat if the allowed search radius a fior the MFT method are bu harwe" will give the answer that perted and completely wrone! tracks an he bund. Tha is due to the statistical prohability that particle positions can be found. guven hrọe search areas. Which sives a boud $\sigma_{\text {total ralue }}$ lespecially for hish seed concentranomi.

The main advintanes for the CCT method are that only :- sequential frames are requred. and that the method is more toleram to large particle movement between frames than the MFT method. The major disadrantage is slower run times. Another possible disadrantage is that it rector will almost always he found for each partucle In the first frame inlerent an the method). This rector may not he correct. shown later by the tracking of experimental data. Lastly a good vector can be found by the ('CT method and wrongly discarded. if the reliability index for that vector is poor due to a low local seed concentration.

Since both tracking methods have demonstrated an ability to track 'clean' synthetic data (a noise-free, extremely smooth flow field) accurately and efficiently, it becomes necessary to test them on experimental data. 
Table 1. Analysis Summary for Trackine Methods

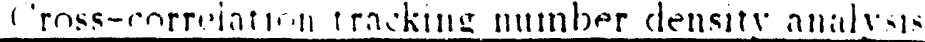

\begin{tabular}{|c|c|c|c|c|c|c|}
\hline$=$ densily & $\mathrm{ISI}$ & fintal vactor & nood rectors & rield & relinhility & cpu \\
\hline 12 & 3 & - & 一 & 一 & - & - \\
\hline 25 & $i$ & $\therefore$ & 5 & 11.714 & 1.111111 & $19.0^{\circ}$ \\
\hline tis & $1: 1$ & 111 & 111 & $11.5 .3: 3$ & 1.111111 & 21.32 \\
\hline 1111 & $\because 5$ & $\because: 3$ & 3 & 11.9120 & 1.111111 & 21.89 \\
\hline $2+5$ & $(i 2$ & iil & lill & 0.4107 & 1.111111 & 26.45 \\
\hline$f ? 11 i$ & $1: 1$ & $\because \because 4$ & $1: 4$ & 1.111111 & 1.111111 & 32.18 \\
\hline 7111 & $19 j$ & $\vdots \because$ & 193 & $11.4 \times 4$ & 1.111111 & 3.3 .35 \\
\hline$\because 41$ & 24 & $\because 47$ & $\because 17$ & $11.9011]$ & 1.111111 & $\$ 1.06$ \\
\hline $14+11 i$ & $f(y)$ & $1 \div: 3$ & $4 \div: 3$ & 11..9א7 & $1 .(11111)$ & 70.47 \\
\hline 249610 & $i t 4$ & $7.3 ! \cdot$ & 7.36 & 0.986 & 1).816:1 & $1: 2.62$ \\
\hline
\end{tabular}

Multiframe tracking number density analysis

\begin{tabular}{|c|c|c|c|c|c|c|}
\hline$=$ density &. $\mathrm{SSI}$ & lotal vectors & gond vectors & rield & reliability & сpu \\
\hline 12 & 3 & 3 & 3 & 1.01010 & i.cown & 0.71 \\
\hline 28 & $i$ & $i$ & $i$ & 1.000 & 1.011111 & 0.97 \\
\hline 48 & 12 & $1:$ & 12 & 1.000 & 1.111111 & 1.06 \\
\hline 100 & 25 & יו. & 25 & 1. 1000 & 1.110111 & 1.30 \\
\hline 248 & 02 & 132 & 62 & 1.000 & 1.01011 & 2.09 \\
\hline 496 & 124 & 124 & 124 & 1.000 & 1.000 & 3.51 \\
\hline 740 & 185 & 182 & 182 & 0.989 & 1.000 & 5.61 \\
\hline 996 & 249 & 243 & 243 & 0.975 & 1.000 & 8.18 \\
\hline 1996 & 499 & 486 & 485 & 0.973 & 0.997 & 22.96 \\
\hline 2996 & $i+9$ & $i 2 i$ & $i 25$ & 0.970 & $0.99 \pi$ & 51.24 \\
\hline
\end{tabular}


Tahle 1. romtmued

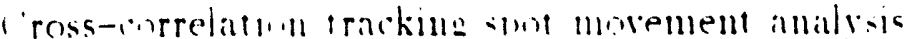

\begin{tabular}{|c|c|c|c|c|c|c|}
\hline pixel movement & $\therefore s 1$ & luinal rectors & ronid rectors & rield & reliability & spu \\
\hline$\therefore$ & $1: 1$ & 121 & 124 & 1.111111 & 1.111111 & 20.112 \\
\hline 111 & 124 & 124 & $1: 4$ & 1.111111 & 1.111111 & $2 ! 19.14$ \\
\hline $1 ;$ & $1: 1$ & $\because 21$ & $\because \because 1$ & $11.97 \div 1$ & $! \cdot 11111$ & $: 34.12$ \\
\hline$\because 1$ & $1 \because 1$ & $111 ;$ & $! 11 i^{\prime}$ & $(1.495$ & 1.111111 & $37.2 !$ \\
\hline$\because \because$ & $1: 4$ & 1117 & $111:$ & 11. wii: & $\because \because M !$ & 42.311 \\
\hline in & $1: 1$ & .14 & $\therefore$ & 0.735 & 1142.5 & 83.45 \\
\hline$\therefore$ & 124 & $\because 11$ & $\therefore i$ & $11.14 t i$ & $11 .: 15$ & $1+9,3: 3$ \\
\hline 11111 & 124 & i & $\therefore$ & $11,1 i 24$ & $11-7311$ & 23491 \\
\hline $1: 3$ & $1: 4$ & $\because i$ & 4 & 11.0112 & 只只 & 326.41 \\
\hline
\end{tabular}

Multiframe tracking spot morement analysts

\begin{tabular}{|c|c|c|c|c|c|c|}
\hline pixel morement & $\mathrm{XSI}$ & total vectors & good rectors & rield & reliability & cpu \\
\hline$\therefore$ & 124 & 124 & 124 & 1.01111 & $1 . \operatorname{lin} 110$ & $3.3=$ \\
\hline 111 & 124 & 124 & 124 & $1.0(110$ & 1.01101 & 3.35 \\
\hline 17 & 124 & 12.1 & 122 & 0.45 .8 & 1.111111 & $3.4:$ \\
\hline 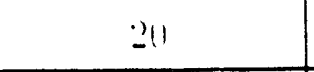 & $1:-4$ & 113 & 11.3 & 0.411 & 1.11001 & $3.4=$ \\
\hline 25 & 124 & 1114 & 1119 & $0.87,4$ & 1.111111 & $3.2 ! !$ \\
\hline 80 & 124 & 11 & $\therefore 2$ & 0.733 & $11.9 n 1$ & 3.75 \\
\hline $7 j$ & 124 & it & 5 & 0.596 & $0.7+3$ & 5.04 \\
\hline 100 & 124 & 59 & 34 & 0.475 & 0.576 & 6.64 \\
\hline 125 & 124 & .50 & 11 & 0.403 & 0.220 & 9.10 \\
\hline
\end{tabular}




\section{III.: Tracking Expermental Data}

The enthetic data produced for this report was very lean ti.e. nne particle moved -minthly from nne frame to the next. particles did not appear ror disappear in the middle of the picture. and none of the given data was actualiy moise that could he alled a partucle ly : ite imawns ṣstems. Experimental data. no matter how carefully the experiment is performed. will usually have these siurces of error. Infortumately. the actual vectors are mot known and quantified error anaiysis cammot be performed.

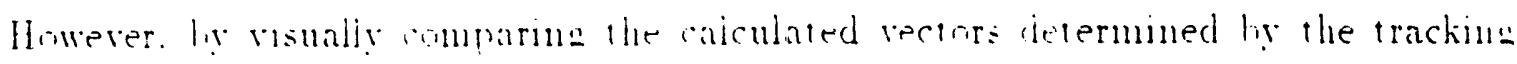

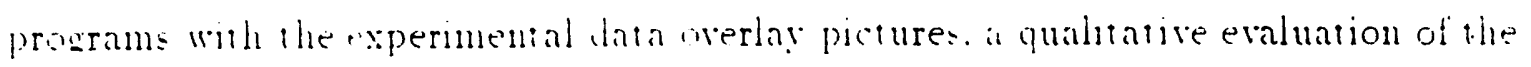
nenerai patlern of flow an he extracted.

The experimental data was obtained with a Pulsed Laser Velocimetry setup (Hassin and Blanchat. 1U41 : shown in Figure 10. A pulsed laser light sheet was obtained usms a Spectra. Phỵsics Id: Y.t high energy laser and a series of four cylindrical lens: and directed to the flow resion of study hy five mirrors. The laser can produce a 1 J pulse with a $\mathrm{ns}$ pulse wath. This experiment imaged How produced by a jet located icm above the bottom of a large tank: thereby creating a step flow. The camera viewpoint was 1 i $\mathrm{cm}$ above the flow step and $15 \mathrm{~cm}$ from the tank inlet. The tank was $44 \mathrm{~cm}$ wide. $92 \mathrm{~cm}$ long. and $32 \mathrm{~cm}$ high. Water. pumped at $5 \mathrm{gpm}$. entered the jet inlet region. where a series of screens produced a distributed flow at the step. The principal flow path was out of the step. up and to the right. where the water would flow over a wall to a pump suction plenu... However, three recirculation regions were found to exist. The first. directly below the step. was small and had a clockwise rotation. 


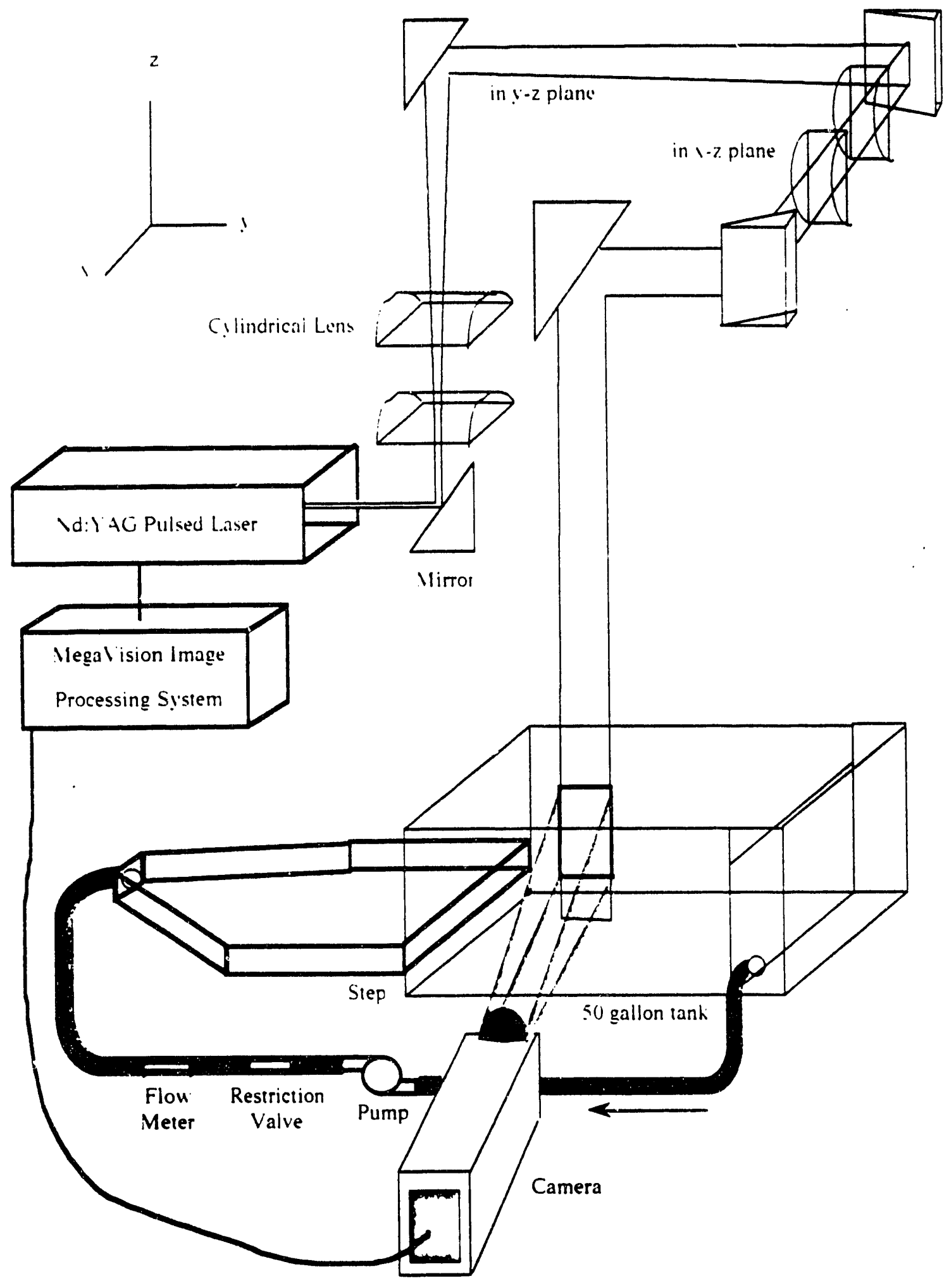

Figure 10. Pulsed Laser Velocimetry Step Flow Setup 
The second. directly above the step. was much larger. and had a counter-clockwise rimation. The buck of this second recirculation region. where the water flowed left and down. was where the linht sheet was directed. coplanar to the wo-dimensional pathlines. The water fiow was seeded with if $\mu$ m diameter. neutral density. polystyrente particle tracers 11.0 ? specific arnvity. The images were recorded with a .Mega Vision

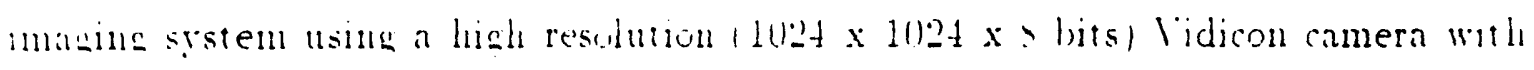
11: principal axis nomal to the haser sheet. The camera viewing area of the linht

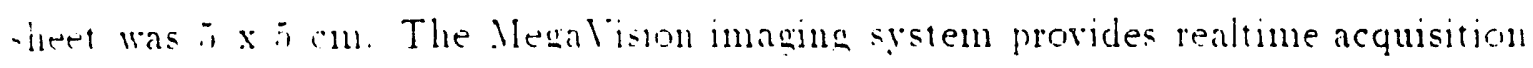

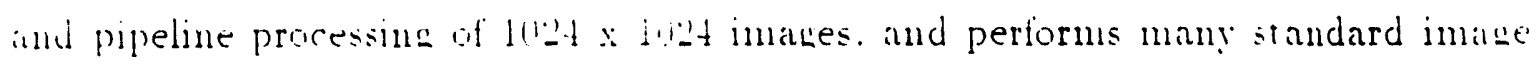
processing funchons. Multiple time frame digitization was achieved using a $1511 \mathrm{~ms}$ ume separation between laser pulses. and obtained by allowing a vertical drive camera signal to externally fire the laser.

Distributions of the track values are presented in Fig. 11. which compares the multiframe $\sigma_{\text {total }}$ values of tracks between the strnthetic data simulating flow around a cylinder and experimental dat abraned from the step flow facility. This figure als." compares the cross-correlation method $C^{\prime}{ }^{\prime}$, values of tracks using spmthetic data and experimental data. Given symthets data (i.e. no noise). the majority of the $\sigma_{\text {torat }}$ track values should be approximately zero. and the majority of the $C^{\prime}{ }_{i}$ correlation values should be near one, as shown in Fig. 11. It is readily apparent from Fig. 11 that the sources of error in the experimental data will shift the distributions: $\sigma_{\text {total }}$ values move away from zero and $C_{i}$ ig values move toward zero. The consequence of these shifts makes it harder to differentiate between 'good' and 'bad' vectors. Remember that perfect vectors have $0.0 \sigma_{\text {total }}$ values and $1.0 C_{i j}^{\prime}$ values. 

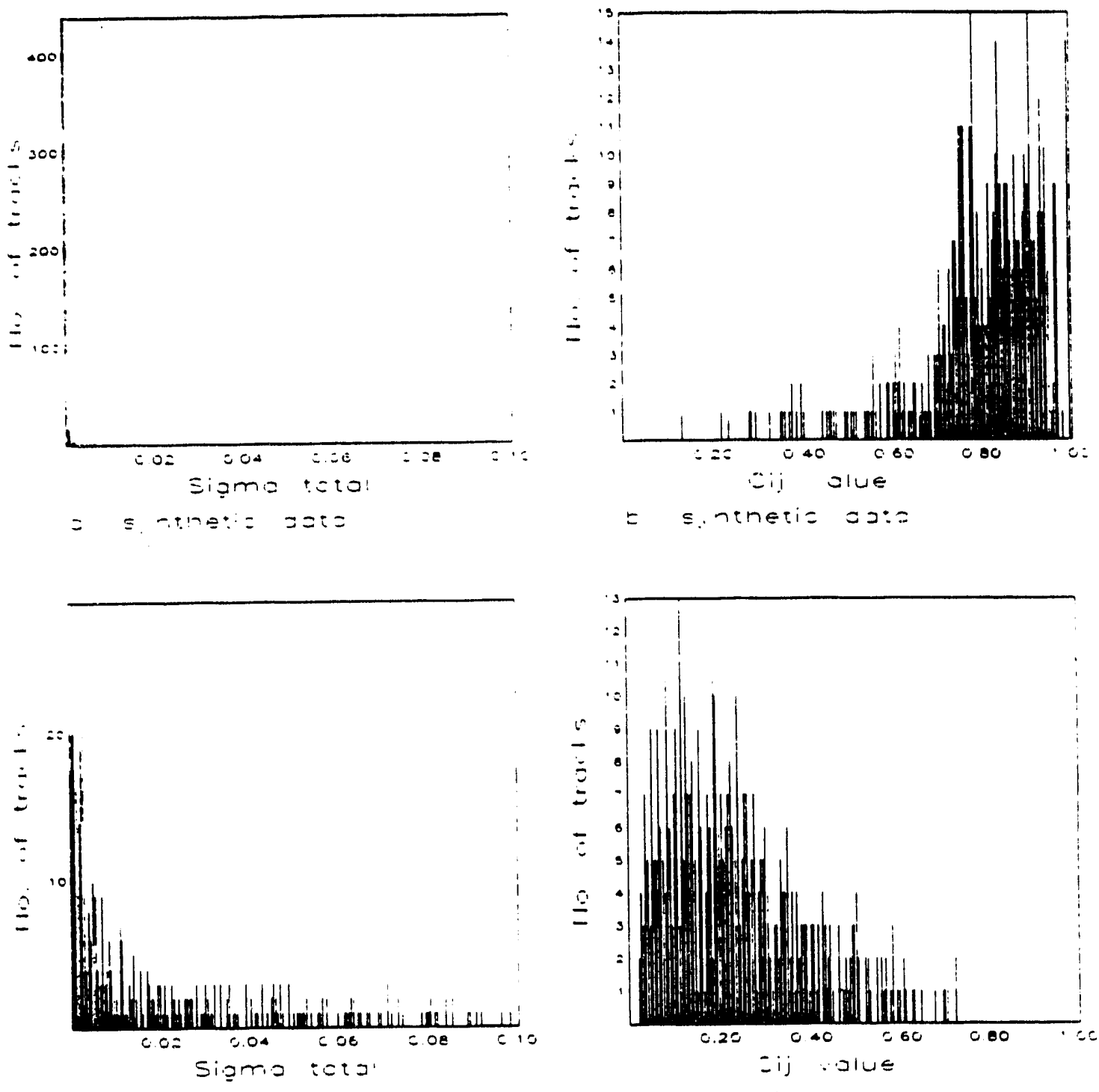

$=$ experimienial jato

a: e.perimentol $=000$

Figure 11. Multiframe and ('ross-correlation Track Distributions 
Distributions of irack pair reliability index values are presented in Fig. 12. This: figure enmpares the sythetic rs experimental data $h$, walues for each track obtabued with the cross-rorselation trackins method. Aramatically showing the effect now has on the C'C'T method. Each data sel hald approximately in)(racks. and they were sorted and phomed in urder of reliability index. The $k_{1}$ : for the noise-frem symhetic data tymally are rery harge providing a measure uf anfidence for these track pairs. The smalier $h$, for the xperimental data introduce an uncertainty ant. the confidence of their tracks.

In Fig. 1.. len onsecutive expermental frames are overlaid to produce a "multipi. exposure" picture. Cinte the noise at the image top. hottom. and right boundaries This was due to the camera tube begiming to fail due to a small crack. releasins the racuum. As mentioned previously. flow issuing from the jet was from left to right. Which produces a recirculation pattern flowing down and to the left. in the ramera view area located above the jet. Strenmlines of the flow. predicted by the :- [1 computational fluid hydraulics code FLCE.XT. along with the position of the imate plane of the camerit. are also shown in Fig. 13. It was relatively easy to visually track most of the seed with little ambiguity. except at the edges where noise was locateci and the flow was nearly stagnant. Figure 14 show's the particles that were tracked through all 10 frames. Figure 15 and Fig. 16 show instantaneous vectors (magnified by 3 for clarity $\mid$ for particles found between frames 1 and 2. Figure 15 has 132 vectors on it. although it appears through visual comparison with the flow pattern shown in Fig. 13 that maybe $15-20 \%$ of these are probably incorrect. Figure 16 shows the effect 


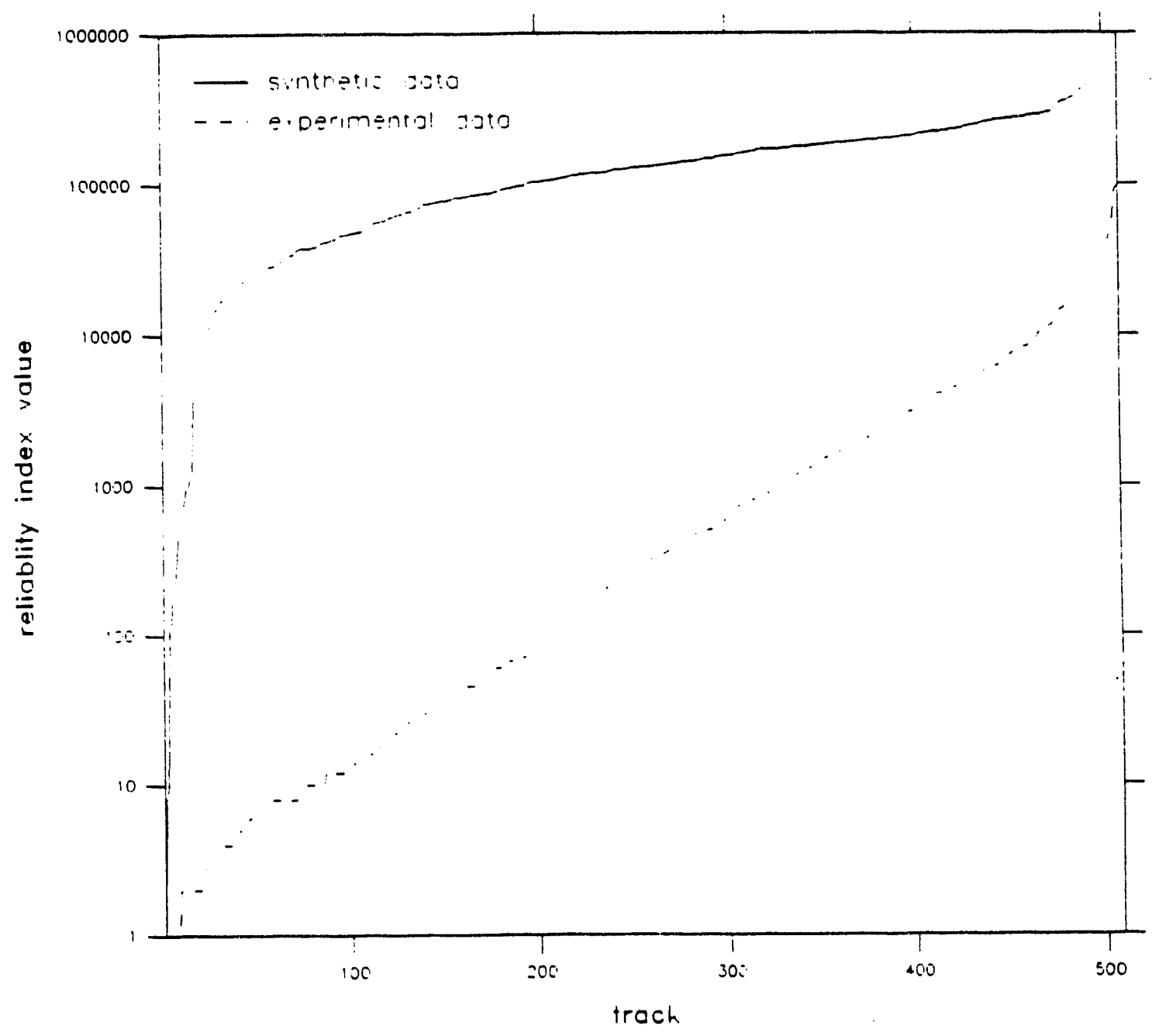

Figure 12. Comparison of CCT Method $R_{i j}$ Values for Synthetic and Experimental Data 


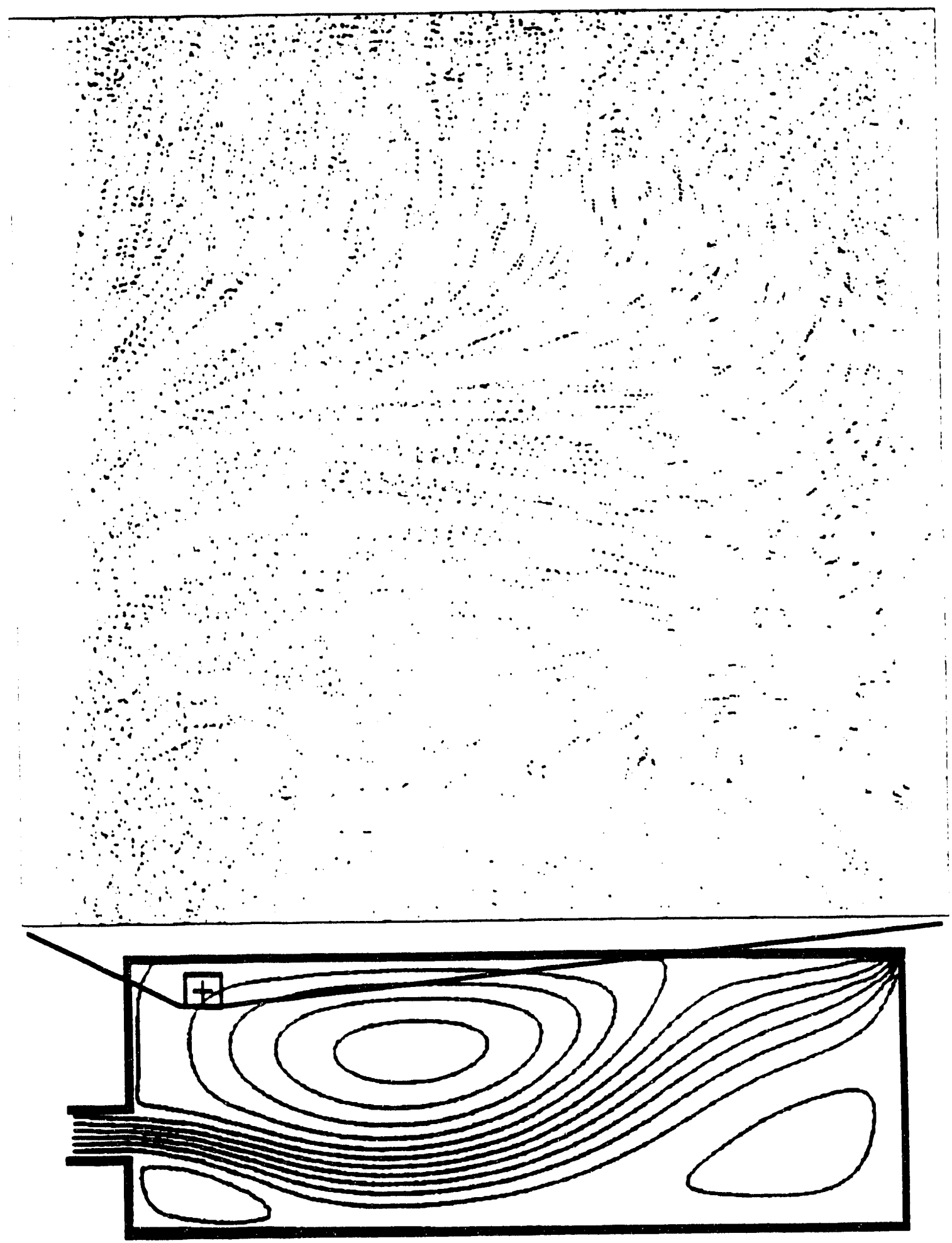

Flow direction in camera view $(50 \times 50 \mathrm{~mm})$ is right to left and top to bottom

Figure 13. Experimental Data Overlay. Frames 1-10 
if usins a $\sigma_{\text {tota! }}$ curoff of 11.1114 an Fig. 15. leaving 30 rectors. Figures $14-16$ show

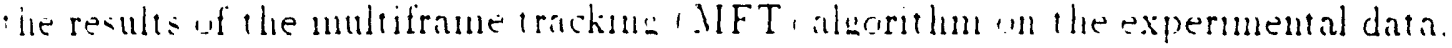

Figure 17 is an werby of frames 1 and 2 of the experimental data. Figure le

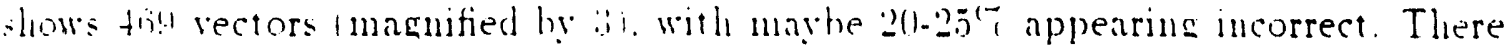

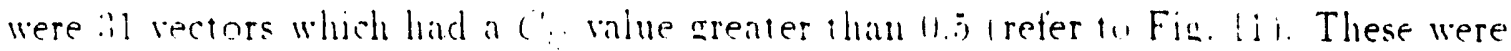

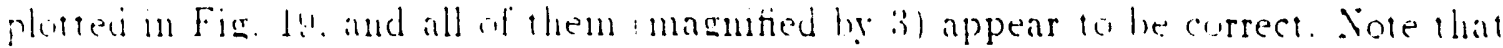
Fins. :- l!l present data llsed hy. and results from. the cross-correiation tracking (1T method.

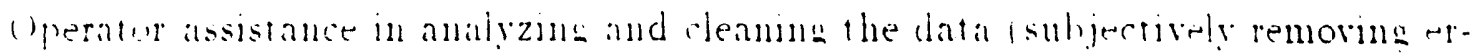
ronems rectors, is tedions and undesirable. The above numbers sngaest that the cutoft malues $\left(\pi_{\text {tnai. }}\left(C_{i},\right)\right.$ can he used to intially clean the data. Horever they also eliminate many accurate rectors. Looking at Fig. 15 and Fig. 1s. many rectors ap. pear a he wrong. Thus, a computational means for cleaning the data was developed usina suggestions from Landreth and Adrian 1498 ).

III.6 Interpolating. Cleaning. and Presentation of Experimental Data

To determine the accuracy of the Hardy equations lequations $16-1$ s 11 . they were first applied to the vectors from frames 1 102 of the synthetic data. A rector map of the interpolated vector field was produced. Verification of this field was performed by applying the flow equations (equations $(6-15))$ to the same locations as the vectors in the rector map. A comparison between what the flow field should have been. and what the interpolated field produced. was then performed. The mean of the errors in the $x$ and $y$ directions were 0.0112 and 0.0104 , respectively, and the standard deviation 


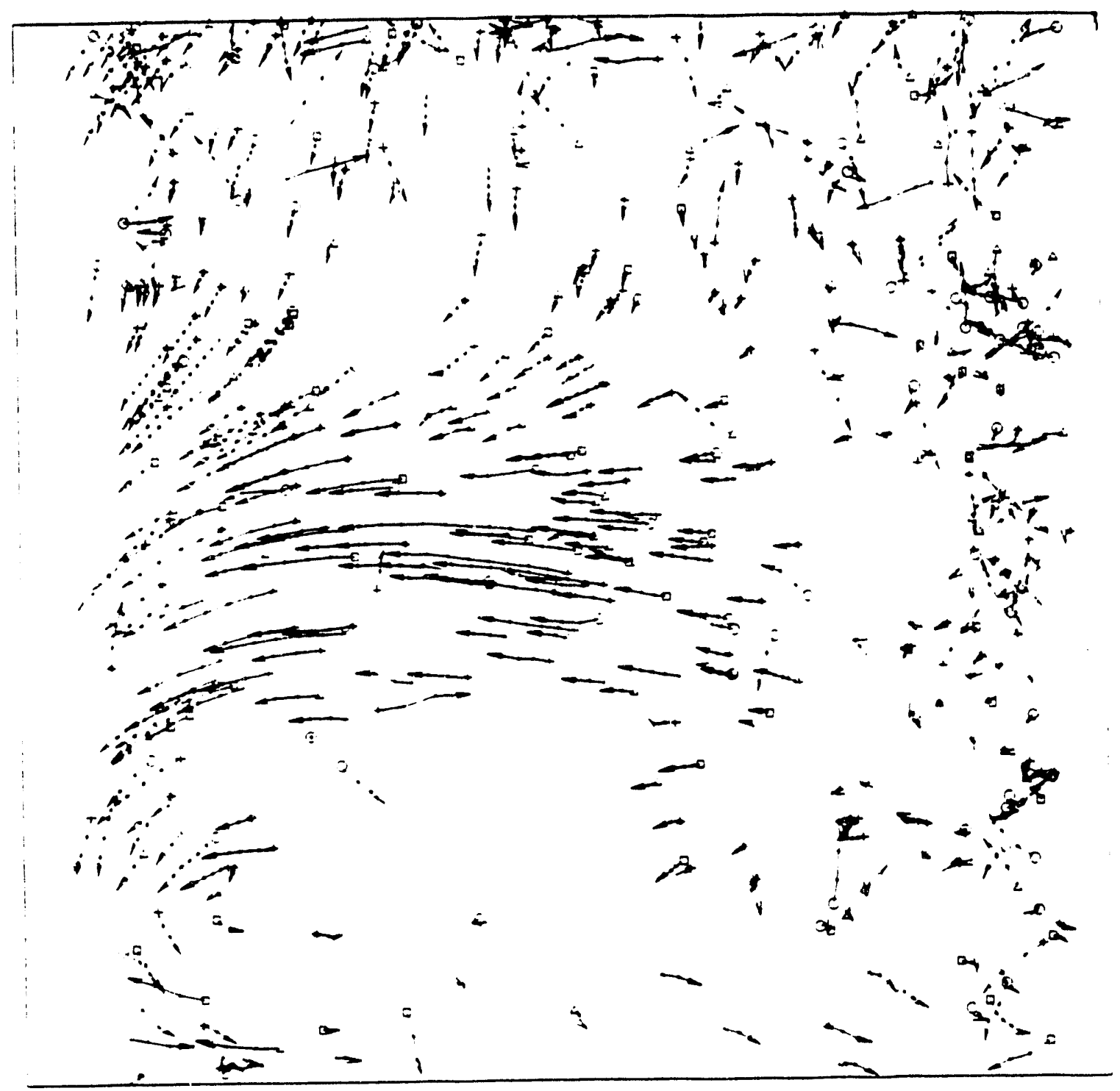

Camera view: $50 \times 50 \mathrm{~mm}$

Figure 14. MFT Method on Experimental Data. Frames 1.10 


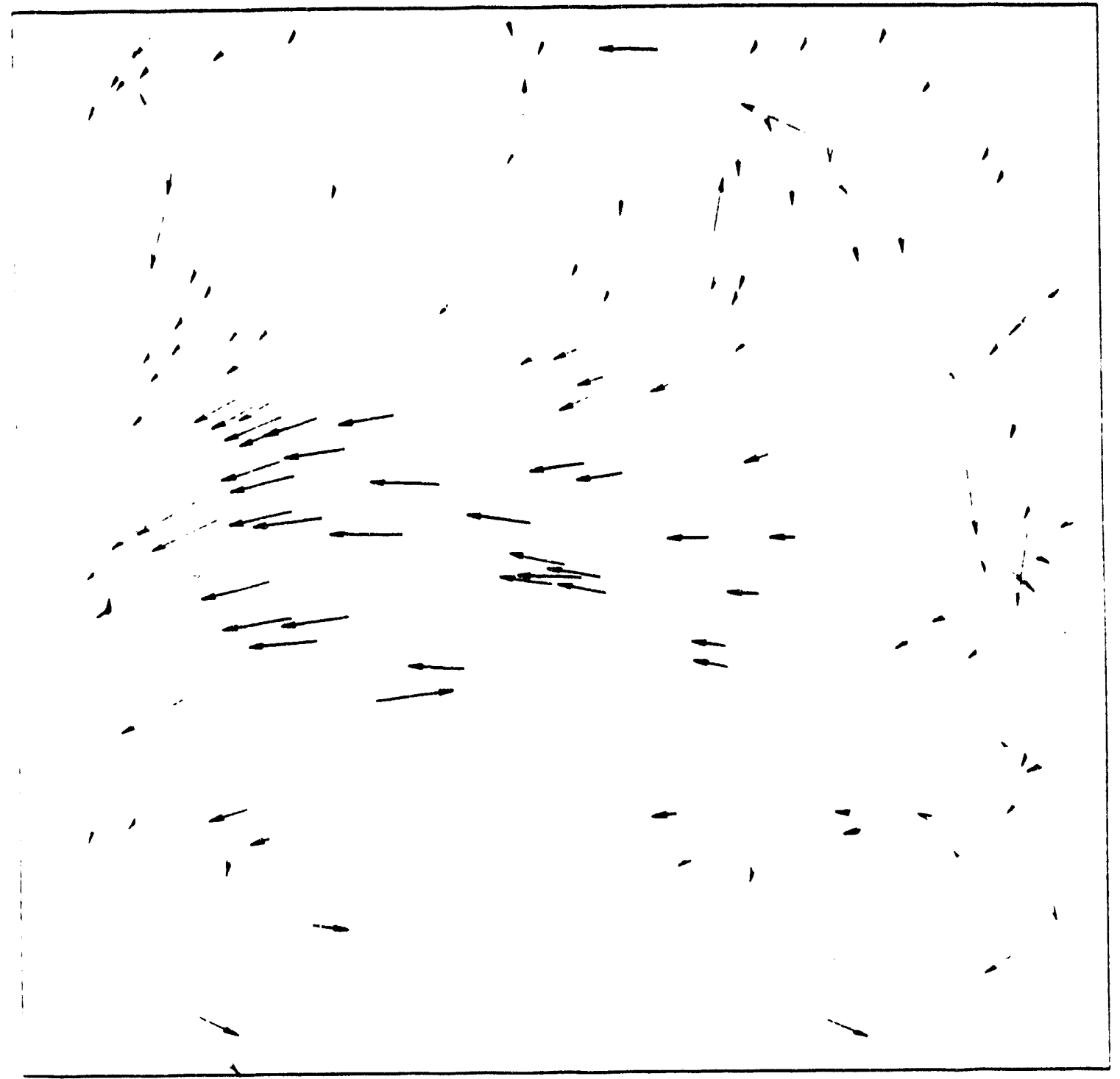

C'amera view: $50 \times 50 \mathrm{~mm}$

Velocity scale:

$10 \mathrm{~mm} / \mathrm{s}$

lector multiplier: 3

Figure 15. MFT Method on of Experimental Data. Frames 1-2 


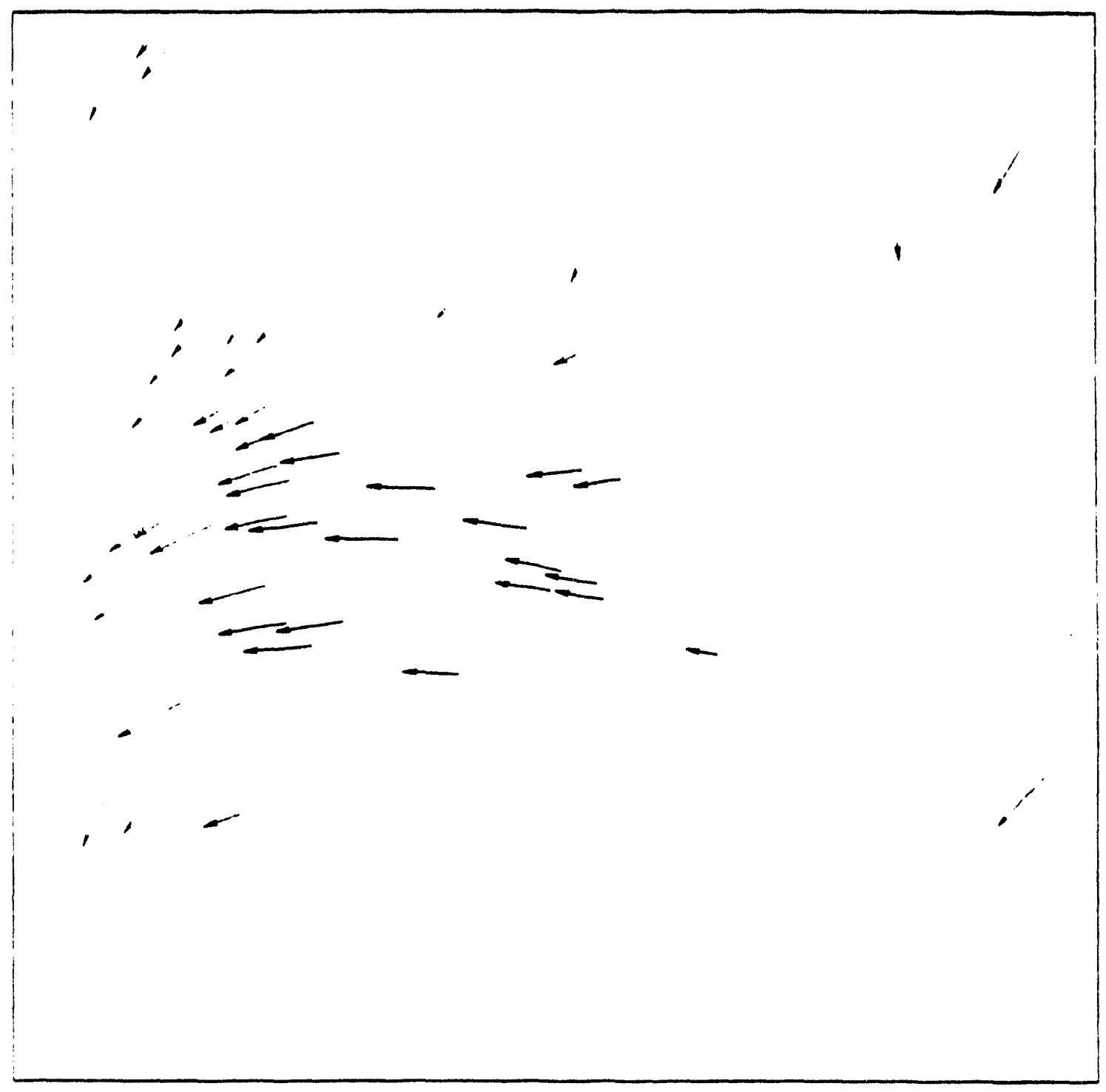

Camera view: $50 \times 50 \mathrm{~mm}$

Velocity scale: $\longrightarrow 10 \mathrm{~mm} / \mathrm{s}$

Vector multiplier: 3

Figure 16. MFT Method on Experimental Data. Frames 1-2 (with Cutoff) 


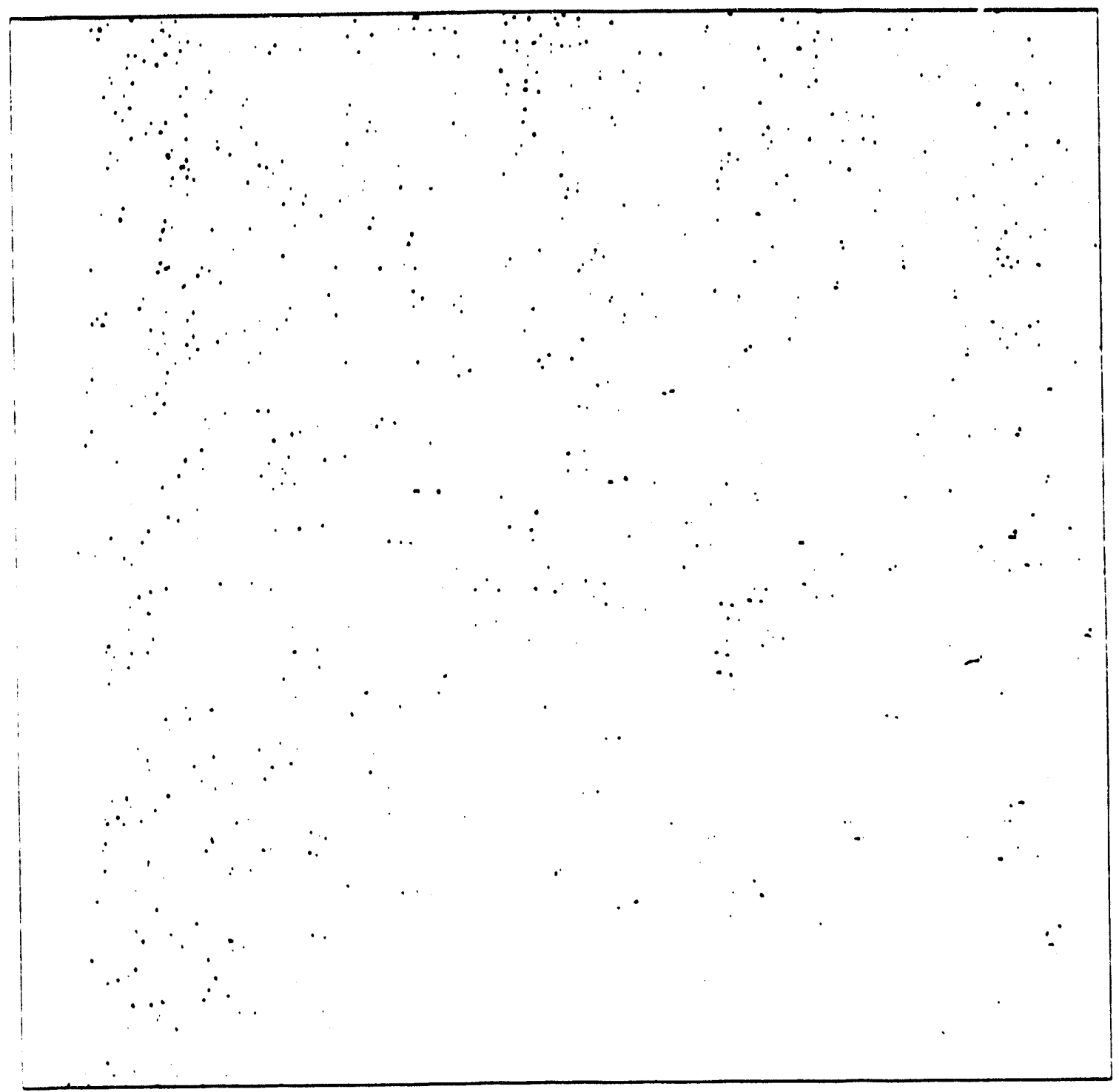

Camera view: $50 \times 50 \mathrm{~mm}$

Figure 17. Experimental Data Overlay, Frames 1.2 


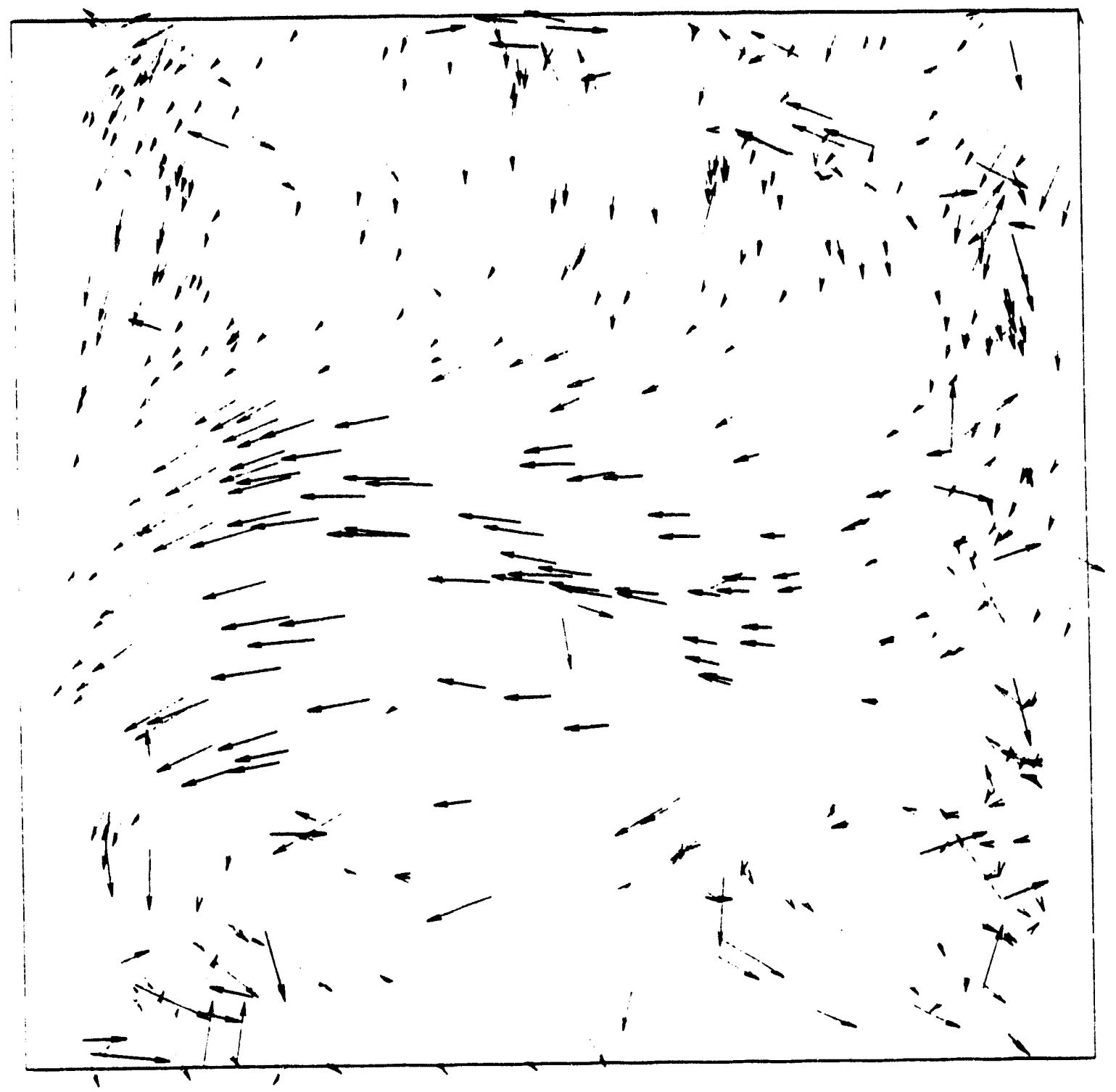

Camera view: $50 \times 50 \mathrm{~mm}$

Velocity scale: $\longrightarrow 10 \mathrm{~mm} / \mathrm{s}$

Vector multiplier: 3

Figure 18. C.C.T Method on Experimental Data. Frames 1-2 


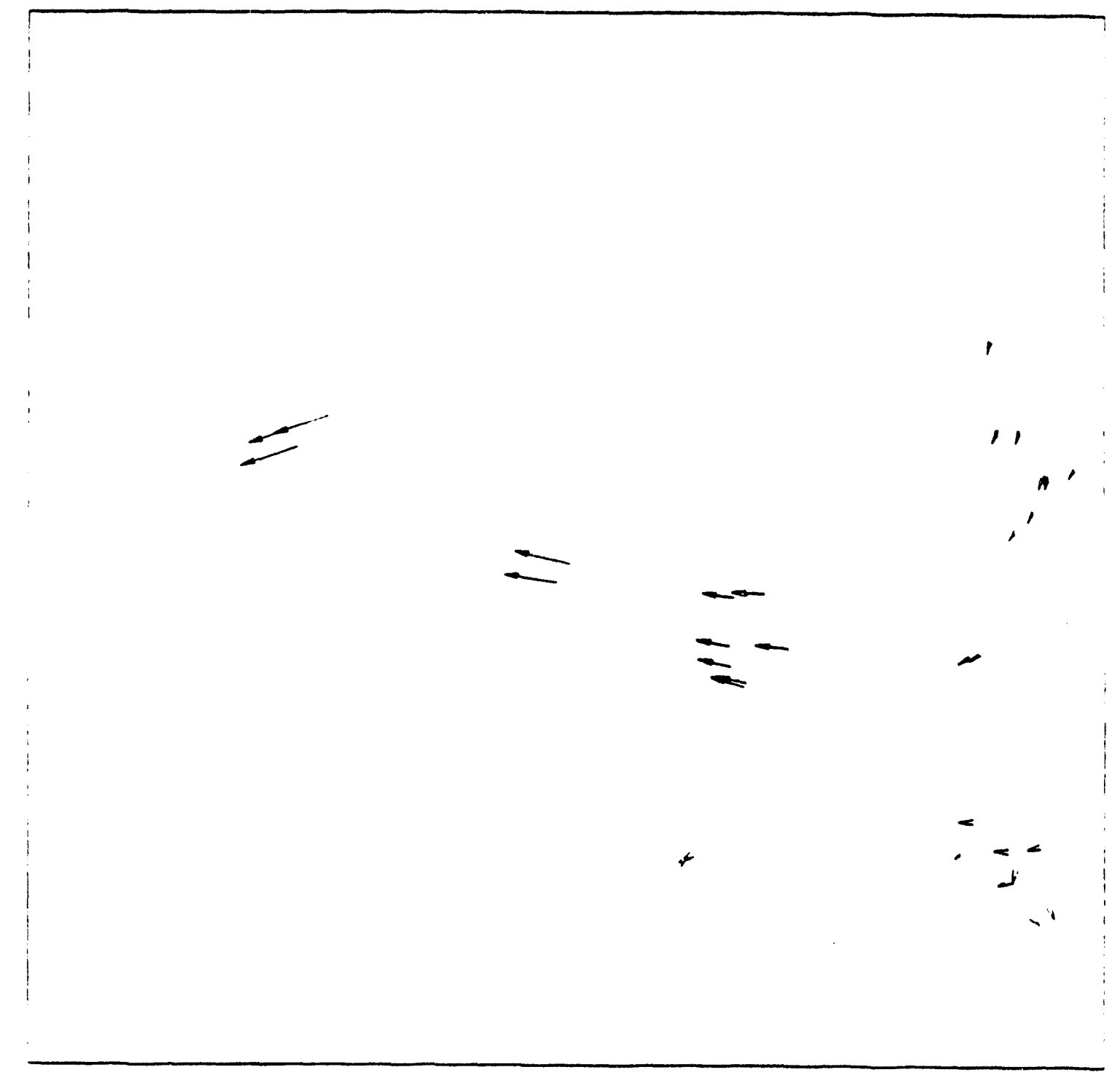

Camera view: $50 \times 50 \mathrm{~mm}$

Velocity scale: $-10 \mathrm{~mm}$ 's

Vector multiplier: 3

Figure 19. C.CT Method on Experimental Data Frames, 1-2 (with Cutoff) 
in the $x$ and $y$ directions were 0.0468 and 0.1400 . respectively: These results are very good and. suggest that the interpolation scheme is accurate.

The Hardy equations were then applied to the experimental data from the crosscorrelation tracking method using the initial cutoff value. Fig. 19. to produce the interpolated velociy field (multiplied by 3). shown in Fis. 20. Once the initial interplated flow field has been made. and the constants used with the Hardy equations stored. The cleanme process can be performed. This involves checking every vector from the initial anput of the tracking program against the interpolated vector field at that same poin: If the mignitude of the difference of these two vectors is within a few pixels. it is considered an accurnte vector. These vectors are then used to produce another. more refined. interpolated field. which is used to 'clean' the original picture. This iteration process is continued until no new vectors are added. Fig. 21 and Fig. 22 present the final cleaned instantaneous velocity plot and the refined interpolated plot (both plots multiplied by 3 ) of the experimental data by the cross-correlation method. A final number of 372 vectors was produced. A flow field streamline plot. Fig. 23. was produced using the refined interpolated plot. Note that there is no proof that these final flow fields are correct. and that only a qualitative evaluation with the general pattern of flow as presented by the experimental data frame overlays can be performed.

While performing this analysis. it was discovered that the cross-correlation method performed significantly better (i.e. had a higher yield. compare Fig. 15 and Fig. 18) than the mu!tiframe tracking technique on noisy images. This is due to the fact that 


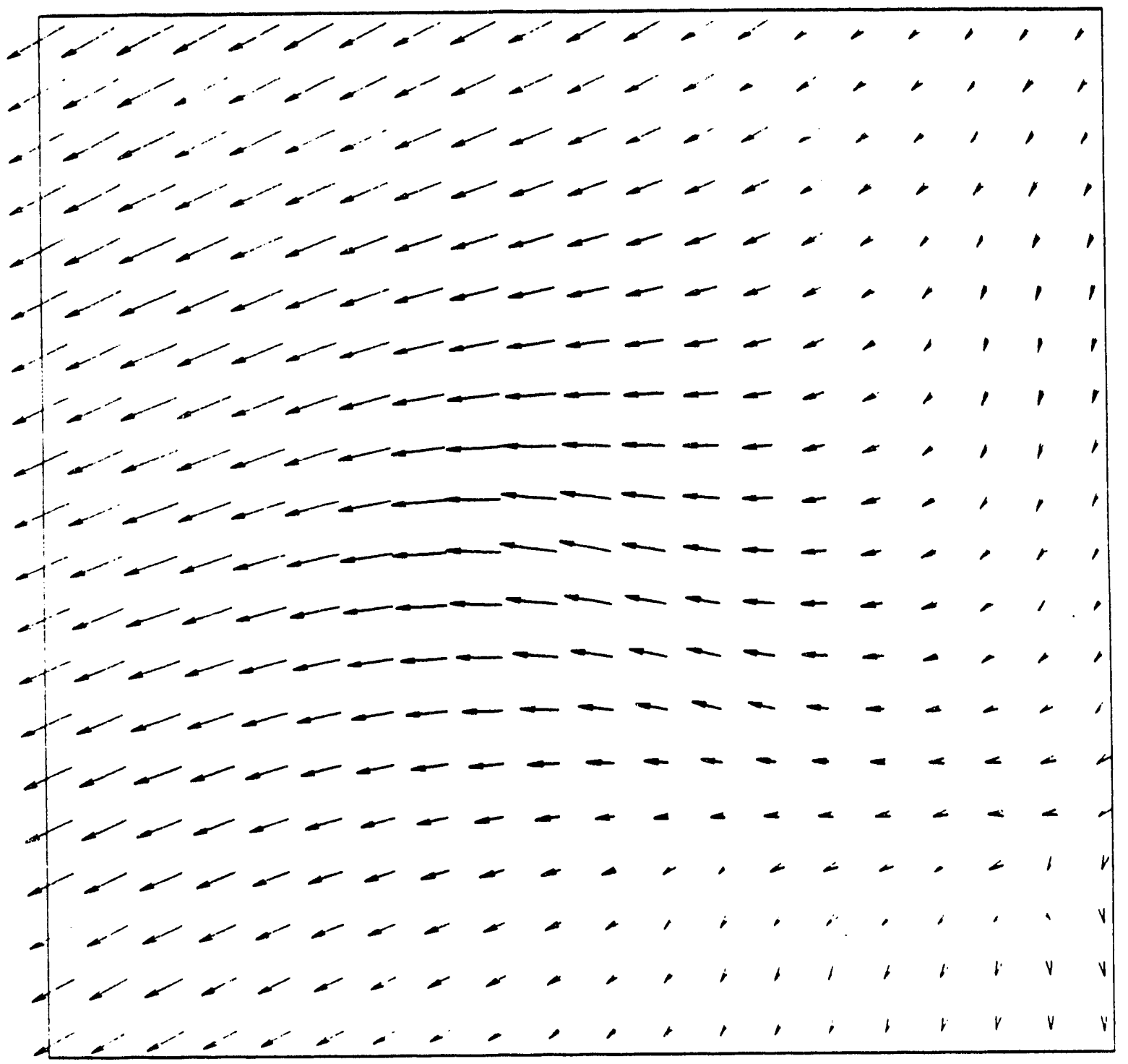

Camera view: $50 \times 50 \mathrm{~mm}$

Velocity scale: $-10 \mathrm{~mm}$ !s

Vector multiplier: 3

Figure 20. Initial Interpolated Vector Field of Experimental Data 


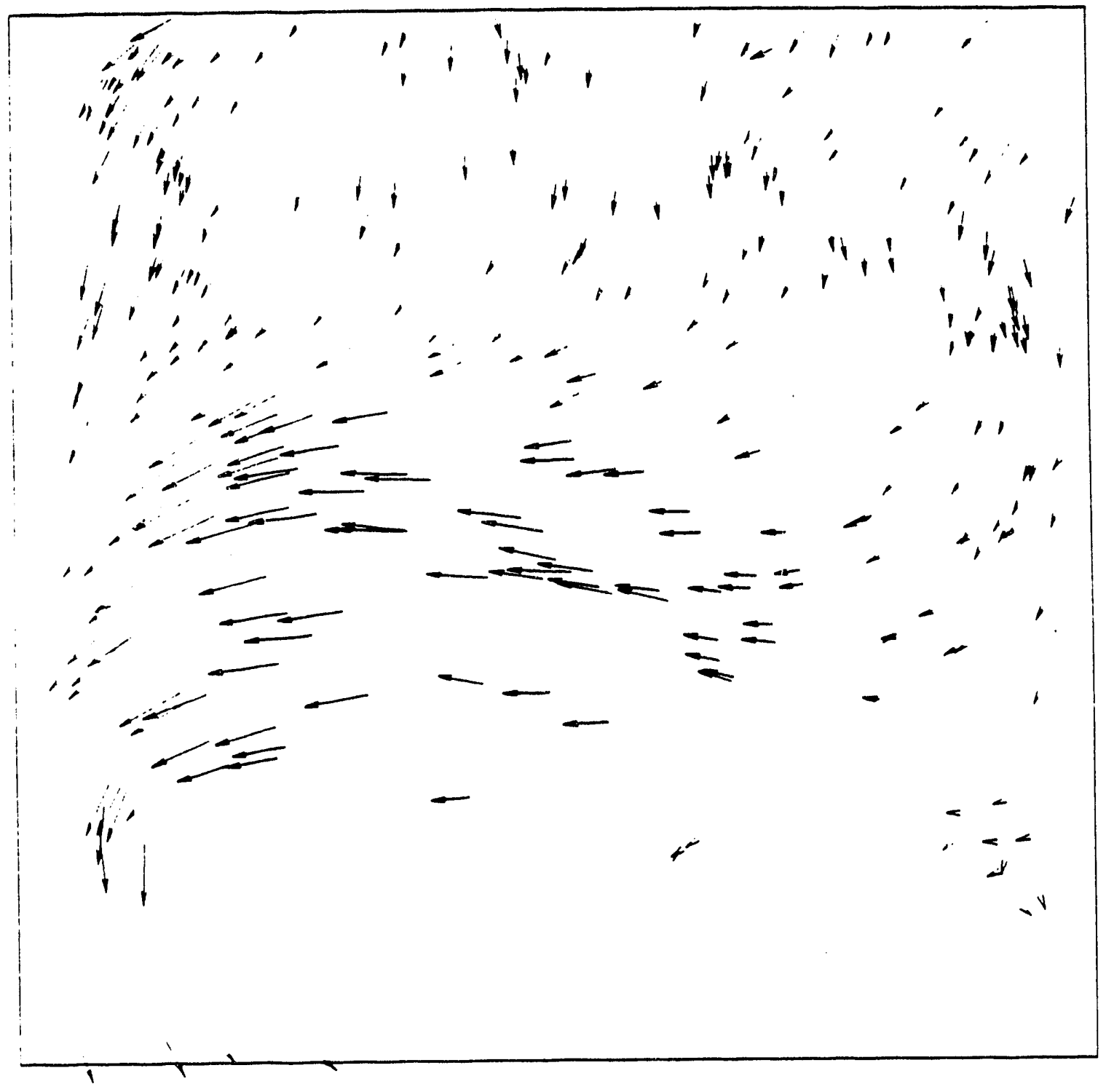

Camera view: $50 \times 50 \mathrm{~mm}$

Velocity scale: $-10 \mathrm{~mm} / \mathrm{s}$

Vector multiplier: 3

Figure 21. Final Instantaneous Vectors with Experimental Data 


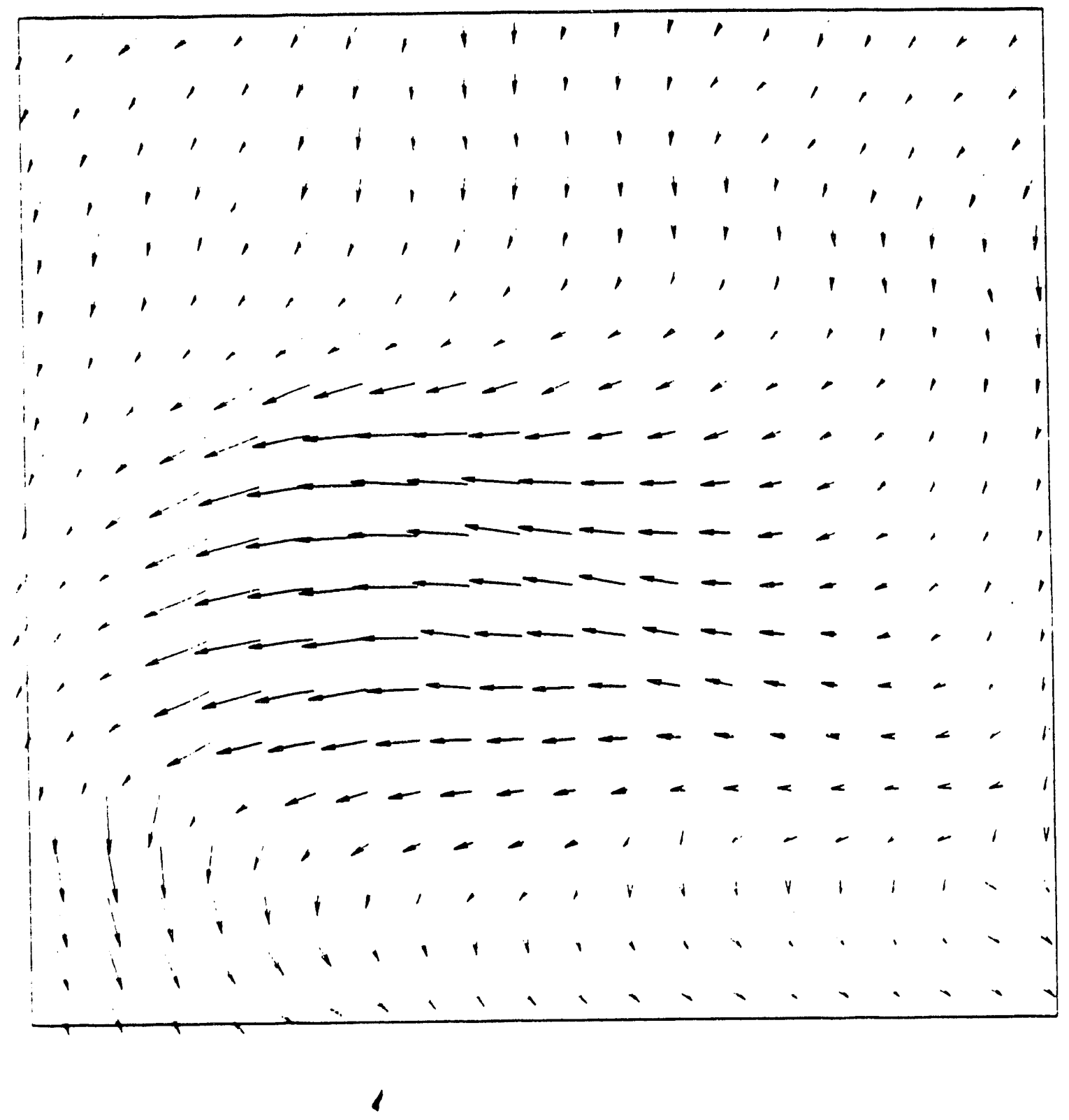

Camera view: $50 \times 50 \mathrm{~mm}$

Velocity scale: $\longrightarrow 10 \mathrm{~mm} / \mathrm{s}$

Vector multiplier: 3

Figure 22. Final Interpolated Vector Field with Experimental Data 


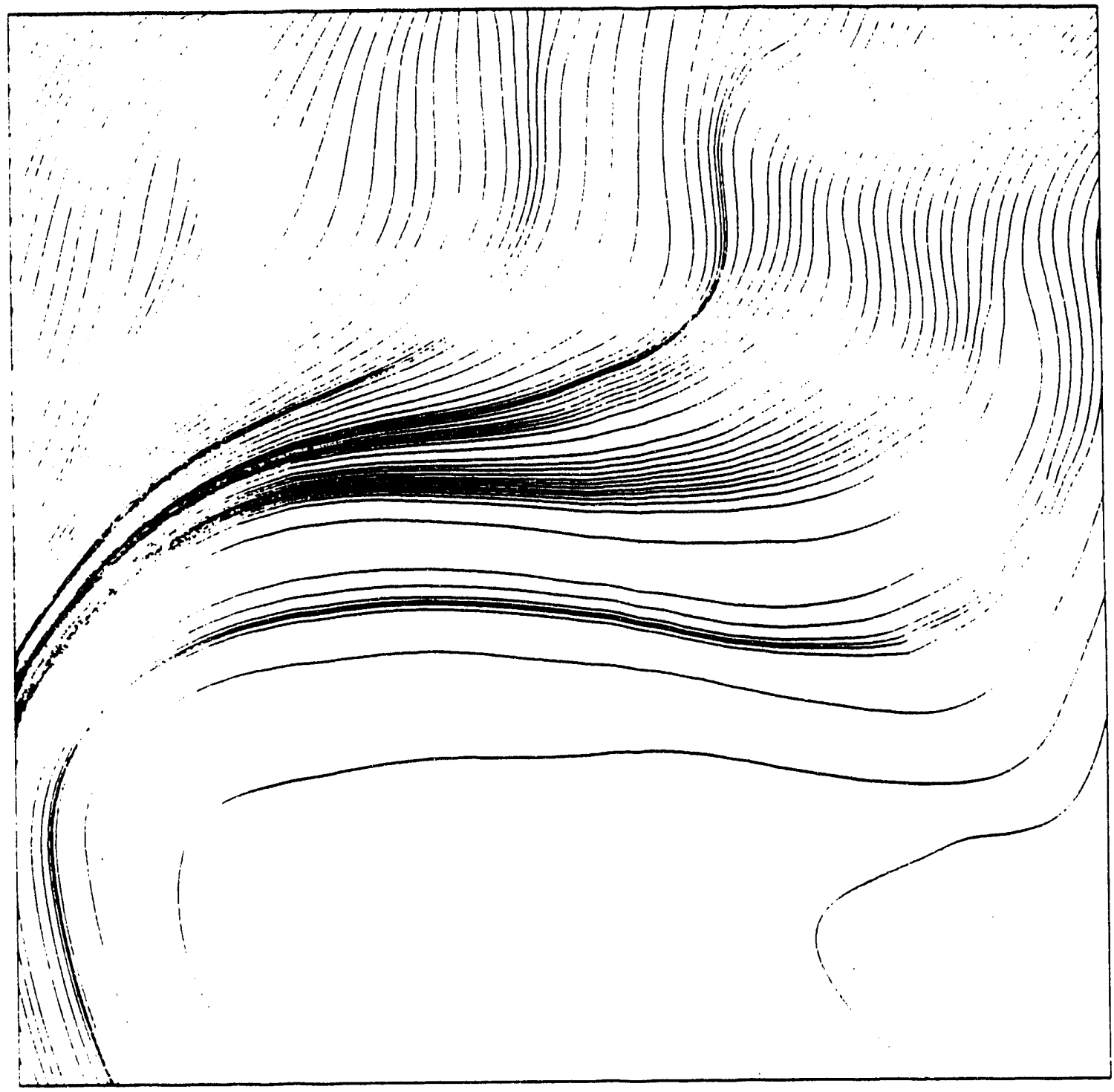

Camera view: $50 \times 50 \mathrm{~mm}$

Figure 23. Experimental Data Streamlines 
large amounts of noise will proride the multiframe tracking technique with many possible particle noices. Statistically this will increase the probability of producing an incorrect track by the multiframe tracking method. ('ross-correlation techniques inherently aroid this pitfall. due to the fact that it is statistically improbable to produce the same noise patterns hetween sequential frames. 


\section{C.HAPTER IV}

\section{STRATIFIED FLOW THEORY AND EXPERIMENT}

\section{II.1 Introduction}

Investigation of a two-phase. iorizontal. stratified. flow rewime is being performed to determine the interface drag force, and correspondingly. the dras coefficient. The drag force is due to the relature motion between the two fluids at the interface. This dran force cannot be solved with analytical methods. but can be experimentally determined.

Interphase drag plars an important role in two-phase fluid regimes. Study of twophase (and similarly two-component) flow regimes is necessary to properly understand and model complex fluid flows. Many computer codes which predict two-phase fluid How must determine interphase drag force. Typically a drag coefficient correlation is used which was empirically determined. One such code is RELAP.j MOD2 (Ransom et al.. 1985). This code is used extensively in the nuclear power industry to simulate a wide range of steady-state. transient. and accident conditions in pressurized water reactors. Some researchers have found that two-phase thermal-hydraulic codes do not model two-phase flow very well (Analytis et al., 1987: Hassan. 1987). Part of this deficiency has been attributed to an over-prediction of the drag force, which may be caused by an inappropriate drag coefficient (Putney, 1988). 
Two-phase stratified flow information was determined with the pulsed laser veIrometry (PLT' method. This tecimque is a full-field. two-dimensional. noninrasive How isualization technique. Many mrestigators have utilized this and similar imaging techniques to obtain full-field velocity measurements.

Direct digitization of the stratified flow images was accomplished with a highresclution imasing system $11024 x 1124$ pixels $x \&$ bit lidicon cameral. The data Was whalyzed with imaring system hardware and a series of new image processing and racking analysis software beinn developed for wor-phase How experiments. PIV "antures" particles in the flow ai me instant in time. Multiple images of the flow field were acquired by pulsing the laser and storing the digitized images. Analysis was performed later with the tracking software which was developed to match the particles from each of the consecutive image frames into tracks of the particles through time.

\section{IV: Interface Shear Stress Theory}

All gases and most simple fluds obey lewton's law of riscosury.

$$
\tau_{y x}=-\mu \frac{d \tau^{\circ}}{d y}
$$

This states that the shear force per unit area is proportional to the negative of the local velocity gradient. The shear stress (shown in Fig. 24) exerted in the $x$-direction on a fluid surface of constant $y$ by an adjacent fluid surface is denoted by $\tau_{x y}$, with $U$ denoting the $x$-component of the velocity vector. Shear stress may also be interpreted as the viscous flux of $x$-momentum in the $y$-direction. 

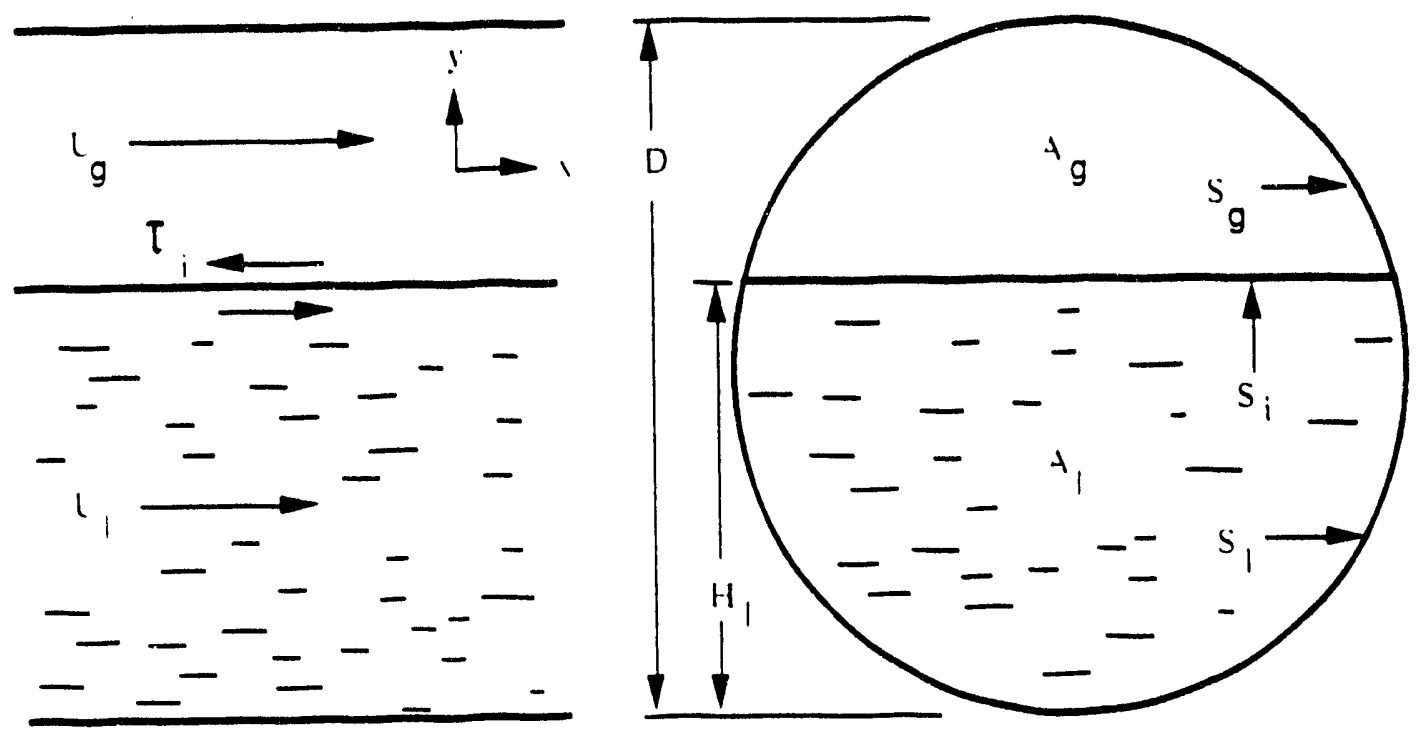

Ficure :4. Cocurrent Equilibrim Stratified Flow in a Pipe

Consider a cocurrent. equilibrium. stratified flow in a pipe as shown in Fig. 24.

Gas. liquid. and interface arerage velocities are denoted by $\dot{C}_{g}, \dot{C}_{1}$. and $\dot{\zeta}_{1}$. Gas and liquid flow areas normal to the flow direction are represented by $A_{0}$ and $A_{1}$. Gas. interface. and liquid surfaces are given by $S_{g} . S_{i}$. and $S_{1}$. The pipe diameter is $D$ and the liquid height is $H_{l}$. The interfacial shear stress can be evaluated in a conventional manner Taitel and Dukler. 1975). based on the Fanning friction factor

$$
\tau_{i}=f_{1} \frac{\rho_{g}\left(l_{g}-\left(\dot{C}_{i}\right)^{2}\right.}{2}
$$

with $\rho_{g}$ denoting gas density and $f_{i}$ denoting the interfacial friction factor. The gas friction factor $f_{g}$ is evaluated from the Blasius equation. and given in terms of the Reynolds number $R \epsilon$,

$$
f_{g}=C_{g}\left[\frac{\rho_{g} L_{g} D_{g}}{\mu_{g}}\right]^{-m}=C_{g}\left[R e_{g}\right]^{-m}
$$


with $D_{g}$ being the gas permeter and $\mu_{g}$ being the ras viscosity. The coefficients $C_{g}$ and $m$ are determued from theory or correlation. depending on whether the flow is lammar or turbulent.

It has been established ( Gazley. 1!40) (and conventionally used throughout the literature, that for smooth stratitied How. $f_{i}=f_{y}$. The sas hydraulic diameter is determined from

$$
D_{g}=\frac{t . t_{i}}{\left(S_{g}-s_{i}\right)}
$$

Thus. the gas is visualized as flowing in an closed duct. From laminar pupe flow theory. 11 will be shown tima approprate coefticients are $C_{G}^{\prime}=1 \%$. and $m=1$. In order $t 0$ compare expermemally determined values of shear stress with equation (20), it must be determined if these coefficients are appropriate for laminar channt flow.

Friction factor $f$ is typically defined by

$$
F_{k}=.4 \AA f
$$

where $F_{k}$, is the force exerted hy a fluid on a surface due to kinetic beharior. $K$ is the characteristic kineuc energy of the flud per unit volume. and $A$ is the characteristic area bounded by the wetted surface. For example, consider a gas-filled pipe of length $L$ and diameter $D$ (radius $R=2 D$ ). The aren is given by $A=2 \pi R L$. and the characteristic kinetic energy per unit volume is given by $\hbar=1 / 2 \rho{ }_{g}^{\circ}$. A momentum balance on the pipe gives a force caused by the pressure drop of $F_{k}=\pi R^{2}\left(P_{o}-P_{L}\right)$, where $P_{o}$ is the pipe entrance pressure and $P_{L}$ is the pipe exit pressure. Therefore. the pipe friction factor is given by

$$
f_{g}=\frac{D}{2}\left(\frac{P_{0}-P_{L}}{L}\right) \frac{1}{\rho T_{g}^{2}}
$$


An analytical solution to the pipe problem (Bird et al.. $19(6)$ ) for the average or bulk was relocity is guren by

$$
r_{\because}=-\frac{1}{4}\left(\frac{1}{\mu_{g}} \frac{\partial F}{\partial r}\right) R^{\prime}
$$

Substituting equation 125$)$ inte equation $(24)$ yields

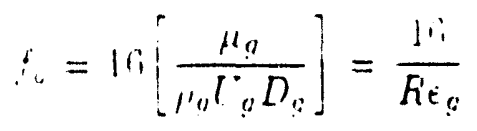

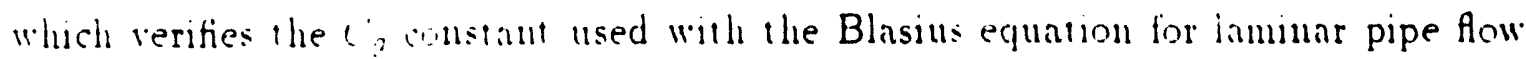
$w 1+h=1$.

Performung the same analysis for an enclosed duct or chamel filled with gas having dimensions: Height $H$. Widhh $H^{\circ}$. and length $L: A=2\left(H-\Pi^{*}\right) L . K=12 \rho L_{g}^{-2}$. and the momentum balance on the chamnel gives $F_{k}=H W\left(P_{0}-P_{L}\right.$. Therefor: the chamnel friction factor is given by

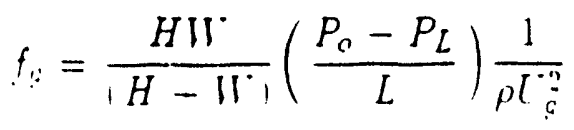

Average flow velocity for the channel can be found using the Narier-Stokes equations for continuity and $x$-momentum (rectangular geometry with $x, y$. and = vector components of velocity $\left.\mathrm{V}_{\mathbf{g}}\left(l_{g} \cdot \mathrm{l}_{g} \cdot I_{g}\right)\right)$. For constant density $\rho_{g}$, the continuity equation

$$
\frac{\partial \rho_{g}}{\partial t}=-\rho_{g}\left(\frac{\partial \tau_{g}}{\partial x}+\frac{\partial \tau_{g}}{\partial y}+\frac{\partial W_{g}}{\partial z}\right)
$$

will give (for steady-state conditions and $V_{g}=W_{g}=0$ )

$$
\frac{\partial U_{g}}{\partial x}=0
$$


Similarly: the $x$-moment um equation

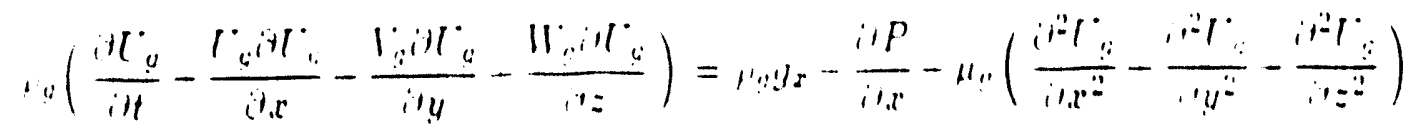

will yield Porsson s equation

$$
\Gamma \cdot v_{u}=\frac{1}{\mu_{!}} \cdot \frac{i F}{i r r}
$$

An analytical velocity solution on the rectangular pupe problem is not easily determuned since the equation of a rectanale does not have a constant Laplacian. However. birounh a coordinate transtormation and separation of variables. an analytical solnilon conslstun of a mitinte series involving hyperbolic sulle and cosine functions can be finund ( Lallaglois. 1!kit). This solution does not readily substitute intre equation (27). and it was decided to numerically solve Poisson's equation. First. it was necessary to define an expression for average velocity for the chamnel similar to equation (25).

$$
\dot{l}_{g}=-\frac{1}{C_{g}^{\prime}}\left(\frac{1}{\mu_{g}} \frac{d P}{d x}\right) R_{H}^{2}
$$

The iydraulic riddus $F_{H}$ is equn! to wice the hydraulic diameter. and using the standard definition that he hydranlic diameter is equal to four How areas over the wetted perimeter. yields $D_{H}=\frac{2 H \|}{H-11}$. Inserting these expressions into equation $(27)$ rields a equation similar to the Blasius equation for laminar pipe flow

$$
f_{g}=2 C_{g}^{\prime}\left[\frac{\mu_{g}}{\rho_{g} C_{g} D_{H}}\right]=\frac{2 C_{g}^{\prime}}{R \epsilon_{g}}
$$

Numerical analysis of Poisson's equation will give a gas velocity $l_{g}$ for an input forcing term $\left(\frac{1}{\mu_{g}} \frac{\partial P}{\partial x}\right)$, and the constant $C_{g}$ solved for from equation (32). Note that this "constant" is only applicable for the specified geometry. A program solving 
Poisson's velocity equation (Appendix $H$ ) was writtell. Average velocity and peak velocity were determined 10 he $11.32 .5 \mathrm{~m}$ s and $11.075 \mathrm{~m}$ s for a forcing term of -1000 . this yelds a value of 7.92 for the constant $C^{\prime}$ " usms the channel dimensions $(H=0.0762$ m. $\mathbb{H}^{*}=11.152 .4 \mathrm{~m}$.

The PLI test facility chammel relocity alution is araphically shown in Fig. 25.

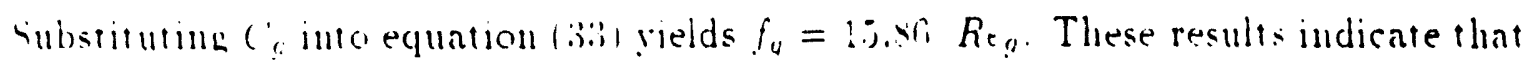
it trould he possible to compare expermmental shear stress dali obtimed from a test inamel havins the ahove dimensons th shear stress predicted from laminar pipe How ilieory

\section{II.3 Design of the PLI Stratified Flow Test Facility}

A flow test facility was constructed to allow full-field velocity measurements of a horizontal. two-phase. stratified flow with Pulsed Laser Velocimetry techniques. The channel flow test facility is illustrated in Fig. 20.

The enclosed transparent horizontal channel. constructed with 12.i mm thick Plex. ighs is $3.45 \mathrm{~m}$ long. $1.50 \mathrm{~mm}$ wide. and $80 \mathrm{~mm}$ tall. The channel lid is removable to allow for cleaning and the insertion of experiments. The lid has two 1 inch taps (only one shown) to allow attachment of a vent ralve and a $3-5$ p.s.i. relief valve. Nozzles. with plastic screens and flow straighteners (plastic straws), are placed at both ends to allow quick production of a two-dimensional flow. The nozzles convert the flow from the inlet tubing cylindrical geometry to the rectangular channel geometry quickly and smoothly. The nozzle design is illustrated in Fig. 27. 


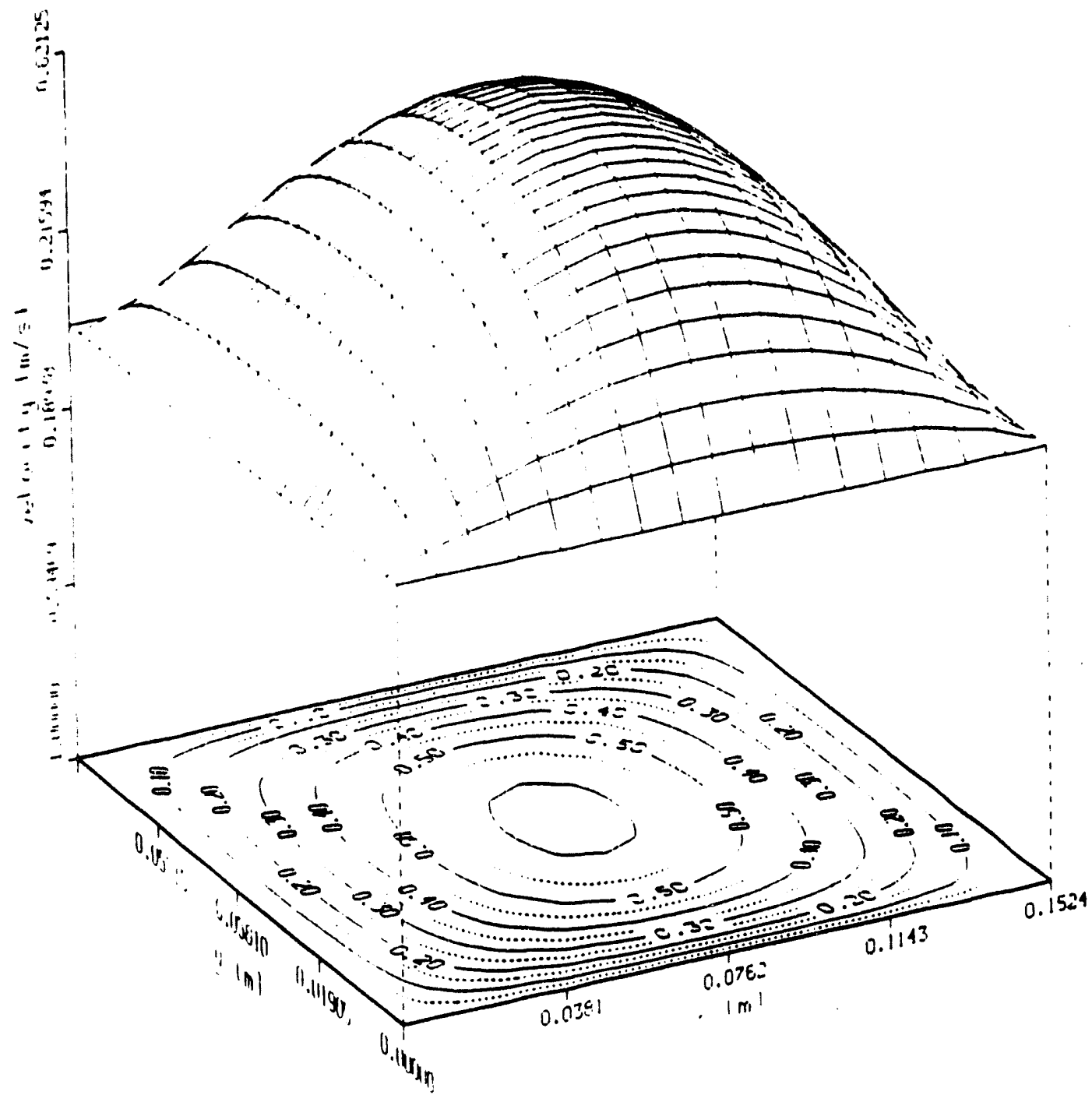

Figure 25. Numerical Velocity Solution for the Test Facility Channel 


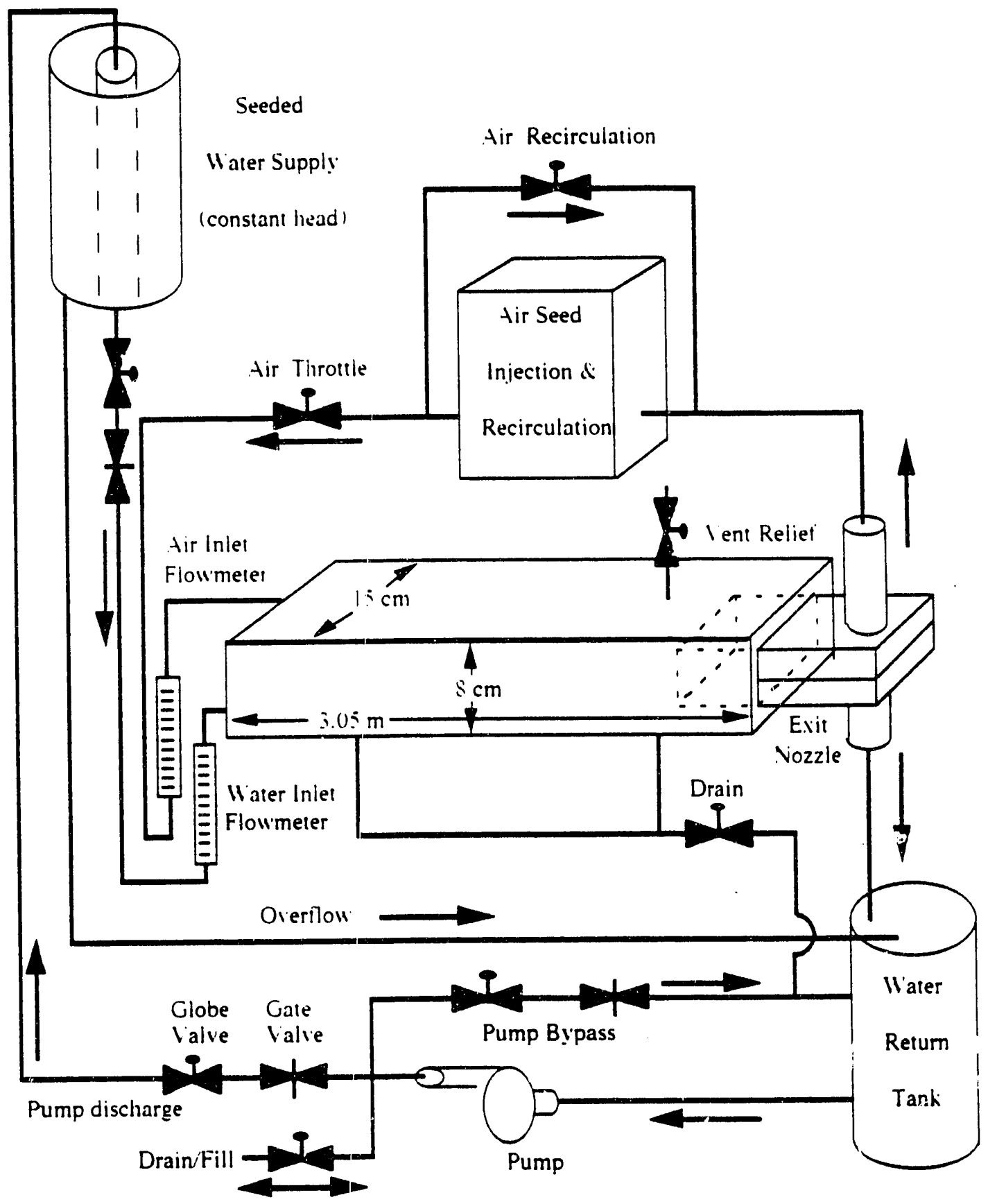

Figuie 20. PLV Stratified Flow Test Facility 


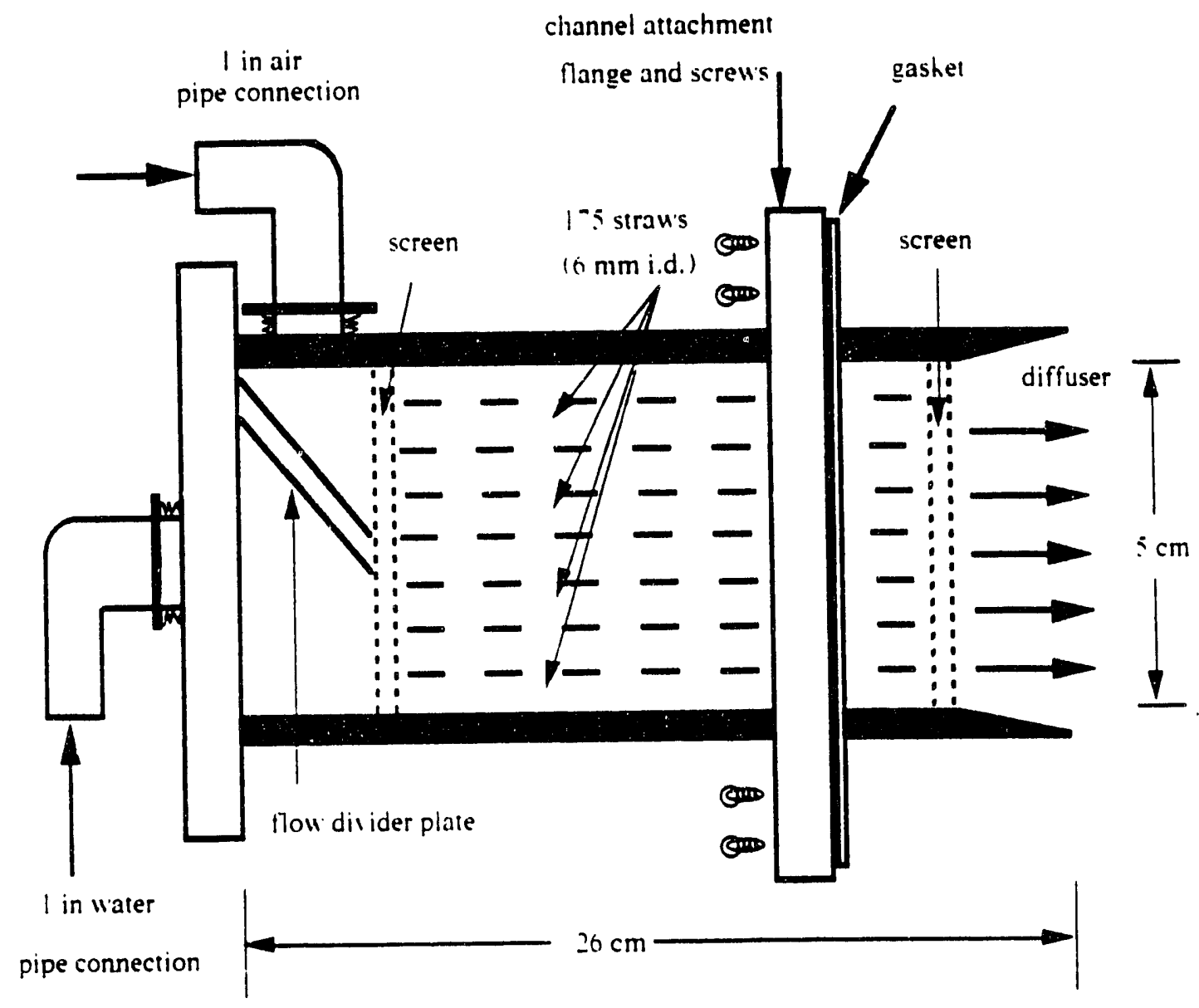

Figure 27. Nozzle Design for the PLV Stratified Flow Test Channel 
IVater. seeded with $6 \mu \mathrm{m}$ diameter. polystyrene, particle tracers (1.112 specific grarity. is metered to one end of the channel from a constant pressure source provided iy a constant head supply tank (5.j gal capacity) located 2.36 m above the channel. This provides a constant 2.5 p.s.i. water head to the channel inlet. The constant head supply tank consists of an inner pipe surrounded by an outer annulus. A $30 \mathrm{gpm}$ pump ensures that the inner pipe inside the supply tank remans full. maintaining the constant head. with the overflow int the outer annulus returning to the water return ank (n) çal capacity). The water pump also ensures a uniform seed distribution in the water by recirculation through the pump bypass. A garden hose with quick disconnect allows filling of the system from laboratory demineralized (D.I. water supply or system drainage (expedited by the $30 \mathrm{gpm}$ pump) through a valve connected to building drains. A flow control station. encompassing valves. pump controls. and air and water rotameters, was built. The gate and globe valves were used to shut off and throt tle the flow, respectively:

tir. seeded with air-filled particles or "microballoons". (vinylidene chloride. $30 \mu \mathrm{m}$ diameter. (0.036 g/ml density) can be metered to either end of the channel to allow cocurrent or counter-current flow experiments. The counter-current flow experiment is setup by reversing the air hoses at the channel inlet and outlet. A modified wet/dry shop vacuum cleaner (2 H.P., 10 gal capacity) was used to obtain both uniform seed distribution and provide the closed-loop air source. The modification consisted of attaching tees to suction and discharge ports of the vacuum cleaner to allow installation of a air bypass line. This produced a high internal recirculation which ensured seed mixing, and, at the same time, provided a low pressure bleed air flow to the channel. 
The vacum filter and the float ball and ball cage were remored. All water and air lines were constructed using $1 \mathrm{in}$ i.d. clear plastic "rgon tubing.

A typical experiment usually is set up by first checking that all valves are closed. and then filling the water return tank approximately three-fourths full from the D.I. water source through the drain ifll water valve. The water pump is started and the pump bypass opened to hegin recirculation. The pump discharge is opened to send water to the water suppiy tank. and the inner pipe is checked full by checking for flowing water in the crertow line. Mater flowrate to the channel is then controlled using the water rotameter and channel water inlet throttle valve. A water seed mixture is added through a nozzle connection after the water is flowing steadily through the channel. The seed is prepared br ultrasonic mixing of $1 \mathrm{gm}$ of seed with $500 \mathrm{ml}$ of D.I. water. Lisually: half to all of the mix is added. depending upon desired seed concentration. The air flow setup begins with 1.2 cups of dry seed placed inside the vacuum cleaner. The racum is started with the air throttle closed and the air recirculation valve fully open. Air flow to the channel begins by fully opening the air throttle for a minute or two. and then throtting to the desired flowrate.

The laser used is a Spectra-Physics DCR.3G Nd: IAG high energy, pulsed laser. It has been calibrated at a peak throughput energy of $1.0 \mathrm{~J} /$ pulse for its primary wavelength of $1064 \mathrm{~nm}$ (infrared). The pulse width is $8 \mathrm{~ns}$ with a variable pulse frequency of 1.24 pulses $/ \mathrm{sec}$. The laser can also operate in a "double-pulse" mode. splitting the energy of a single pulse into two pulses with a variable separation from 50 to 350 microseconds. Due to a large absorptivity of water for infrared light. a 
frequency doubling crystal is used to produce $53.2 \mathrm{~mm}$ light (green). reducing the maximum energ̣ 10 approximately $11.5 \mathrm{~J}$ pulse.

The lenses and mirror setup is illustrated in Fig. 22. The $7 \mathrm{~mm}$. circular. Gausian. distributed. light pulse is directed to the point of interest / center of the channel. y6 $\mathrm{cm}$ from water exit nozzlet hy a series of four mirrors. and shaped into a $1 \mathrm{~mm}$ thick. io mm wide. sheet of light with a series of three cylindrical lenses. All mirrors are icm in diameter. With high-energy contings. The first mirror in the beam path is a harmonic beam splitter gesigned to pass the infrared 10 a heam stop. and reflect the green light t. the lens setup. Lens dimensions are gives as length. width. and thickness: followed by a focal length $\mathrm{f}$. Lens $=1$ is $50.8 \times 511.8 \times(i .17 \mathrm{~mm}$. with $\mathrm{f}=$ $200 \mathrm{~mm}$. lens $=?$ is $10.0 \times 30.0 \times 8.89 \mathrm{~mm}$. with $\mathrm{f}=100 \mathrm{~mm}$. and lens ${ }^{\neq} 3$ is 50.8 $x 25.4 \times 12.79 \mathrm{~mm}$. with $f=25.4 \mathrm{~mm}$. The sheet is produced by first removing all lenses from the beam path. and centering the beam in all mirrors to the view point of interest. Mark this reference point on a sheet of paper. It is best to keep beam power low and to use black paper for the beam targe to reduce reflection. The first lens is inserted into the beam and centered: centering is insured when the distorted beam is returned to the reference point. Care must be taken to prevent damaging the optical components with the high energy laser pulse. This can be prevented by ensuring that the focal point of the first lens does not reside on the mirror, and all components are clean. This process is repeated with the second lens, and then the third lens. The final adjustment is made by fine-tuning the distance between lens \#2 and lens \# 3 , until the desired light sheet thickness is obtained. 


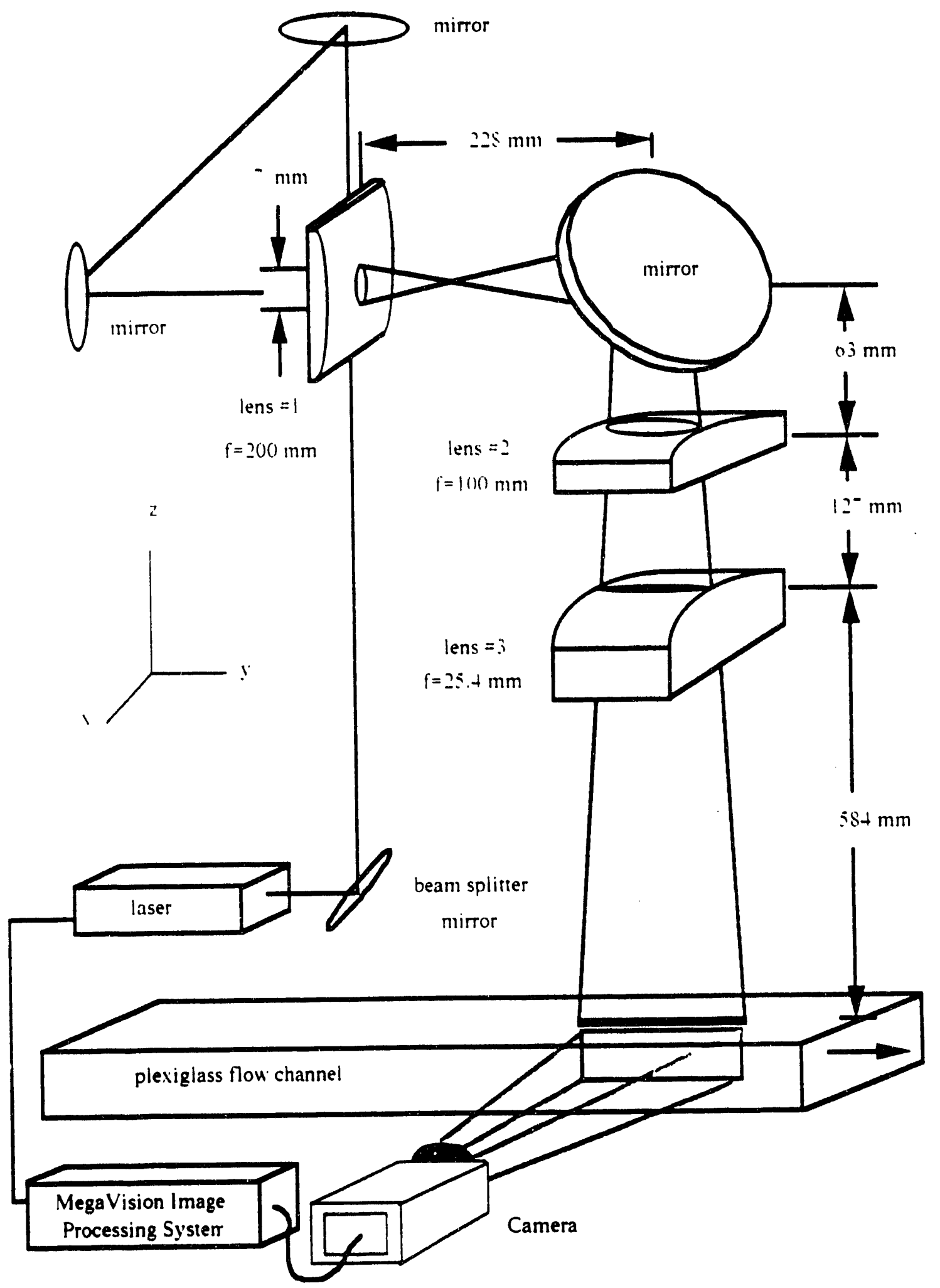

Figure 28. Lens Arrangement for Thin Sheet Production 
The sheet is passed through the channel lid (normal to it surface) into the moving fluid. coplanar to the flow pathlines. at the camera's focal plane which is imaging the flow through the side of the channel. It is best to apply a nonreflective coating to all surfaces inside the channel near the heam path to reduce light scattering from surfaces. Flat black electrical ane was applied to the inside bottom. inside top (with a slot removed to allow the beam into the channel). and inside back surface (opposite 16 the cameral of the channel. A slot was also remored at the taped chamnel bottom :urface. This was necessary hecause the energ̣ of the sheet was concentrated enough 16 "burn of" tape particles. Which the camera then imaged as seeds appearing to rise off the channel bottom due to the local heat production. This was a very interesting phenomena in which further study may be appropriate. Remoring the slot allowed the sheet to pass through the channel bottom. finally striking a flat black painted board. which supported the channel.

The pulsed laser light is scattered from the seed. and the camern directly digitizes images of the flow tracers. A short time later. a second laser pulse is introduced. and another flow image is required. Velocity calculations are then performed after determining particle positions. matching appropriate particles in the consecutive frames. and dividing by the time increment between recordings.

\section{IV.4 Light Scattering by Small Particles}

It is of interest to the PLV experimenter to know the scattering properties of various particles in relation to the particle image mode of PLV operations. The following theory and conclusions (Adrian and Yao, 1985) summarizes the scattering 
properties based on monodispersed particle populations and Mie's scattering theory for scattering from spherical particles.

The image plane intensity distribution can be determined by the following equations. The intensity of the light in the image plane $\mathrm{X}\left(\mathrm{X} . \mathrm{Y}^{\circ}\right)$ of the recording camera at time $t$ is $\mathcal{J}\left(x, t, \mathbb{H}^{\circ} m^{2 *}\right.$. and the exposure is given br:

$$
\varepsilon(\mathrm{X})=\int J(\mathrm{X} \cdot t) d t
$$

The mtensity of the image of the th particle. located at the point $x^{2}$ itt in the fluid. $15:$

$$
\left.J_{i}(t)=I_{\left(1, x_{1} t\right.} t\right) J_{n}\left(\mathrm{X}-. U_{n} x_{1}\right)
$$

with $I_{c}\left(x_{i}, t\right)=$ intensity of illumnating beam. and $\mathcal{J}_{c}\left(\mathbf{X}-. M x_{i}\right)=2$-D intensity distribution of the blurred particle image per unit illumination intensity. The function $\mathcal{J}_{0}$. also considered the transmissivity per unit incident intensity. normally has a maximum at the zero value of its argument. The expression for $\mathcal{J}_{0}$ states that a particle at $x_{i}$ is mapped into an image at $\mathrm{X}=-.14 x_{1}$. reflecting the image inversion produced by the lens of a camera having magnification.$M$.

$\mathcal{J}_{c}$ is given by the magnitude squared of the convolution of the point response function of the camera lens system and the geometric image of the particle. The details of these functions determine the precise shape and diameter of the blurred image. The diameter $\mathcal{J}_{o}$ can be estimated from the nominal image diameter, $d_{\epsilon}$ :

$$
\begin{aligned}
& d_{e}=\left(M^{2} d_{p}^{2}+d_{g}^{2}\right)^{1 / 2} \\
& d_{s}=2.44(M+1) f \# \lambda
\end{aligned}
$$


where $d_{s}$ is the diameter of the point response function of a diffraction-limited lens measured at the tirst dark ring of the Airy disk intensity distribution, $d_{6}$ is an ap. proximate quadrature representing the combined effects of mannification and image blurring in determinins the final diameter of the image. $d_{p}$ is the particle diameter. $f=$ is the focal length of the lens divided by the aperture diameter. and .1 is the light wavelenglh.

The mean intensty if the ith particle image avernged over an area of diameter $d_{1}$. is defined lo lie:

$$
\bar{T}:=\frac{t}{\pi d_{i}^{2}} \iint T_{1} d x, 11
$$

The integral of equation 1391 is the energy flux crossing the image plane. and must be equal to the energy. flux through the camera lens of the light scattered by the ith particle. given by:

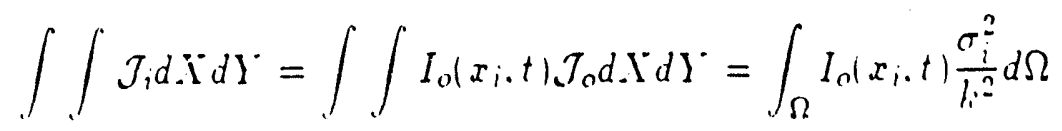

with $\sigma:=$. Mie scattering coefficient. $h=$ wave number $\left(=\frac{2 \pi}{T}\right)$ and $\Omega=$ solid angle subtended by camera lens. Thus:

$$
\overline{\mathcal{J}}_{i}(t)=\frac{4}{\pi k^{2} d_{e}^{2}} I_{o}\left(x_{i}, t\right) \int_{\Omega} \sigma_{i}^{2} d \Omega
$$

The image plane intensity distribution is found by integrating equation (40) over the image space.

Once the image plane intensity distribution is determined, the mean exposure of the imaging medium. the scattering power, and the particle requirements can be found. 
Assuming the illuminating intensity $I_{1}$ of a pulse with total energy It is uniform in rectangular dimensions of leng̣h $\lambda y$. thickness $\Delta z$. over a pulse duration it. then

$$
I_{11}=\frac{I^{\circ}}{\Delta y \Delta z i t}
$$

and

$$
11=\int \operatorname{In} d y d=d t
$$

Therefore. the equation for the mean exposure over the image plane is:

$$
\tau=\frac{t}{-i_{i}^{2} l_{i}^{2}} \frac{\|}{\Delta y \Delta z} \int_{\Omega} \sigma^{2} d \Omega
$$

Thus, the mean exposure of a sm:le particle image depends on three factors: illuminating intensity $\left(\frac{11}{\sqrt{y} J_{:}} \mid\right.$. scattering power $\left(\int \sigma^{2} d \Omega\right)$. and image energy concentration $\left(d_{t}^{-2}\right)$

Adrian and Yao (1985) investigated these parameters as applicable to particle image PLI: a summary of their findings follows. The largest effect on mean exposure is due 10. changes in diameter and refractive index of the scattering particle. and changes in the refractive index of the fluid. Scattering from particles in water is significantly weaker in water than from in air. In the Rayleigh scattering regime $1 d_{p} \quad \lambda$ ). scattering power is proportional to $d_{p}^{4}$. For $\left(d_{p}-\lambda\right)$. scattering power is proportional to $d_{p}^{2}$. and $d_{e}$ is proportional to $d_{p}$. There is an intermediate range between these limits (particles sizes from 1 to $10 \mu \mathrm{m}$ for typical PLV experiments) where $\dot{u}_{\varepsilon}$ is independent of $d_{p}$, the image diameter is dominated by diffraction from the photographic lens and controlled by the $f \#$ of the camera lens. The optimum particle size is a compromise between two opposing trends; the first being a large particle is desired because it is 
easily detected. and the second being a small particle is desired because the accuracy if velocity mensurements and the spatial resolution increases with decreasing particle 1ze. They suggest particle sizes in the $5-10 \mu \mathrm{m}$ range are appropriate for most particle imase PLI' experiments.

The particles used in the stratified flow PLI experiment were in the range $d_{p}>\lambda$. This means that the mean image intensity approaches a constant. independent of the partucle diameter. The air and water seed particles both showed image diameters "reater than particle diameters. The intensity of the images of the air particles were trealer than the water particles, due to the difference in refractive index of the two fludis. This suggests that a smaller diameter air seed can be used. However. for other reasons (arailability: seed injection method. and personnel safety). the $30 \mu \mathrm{m}$ diameter particle was used.

\section{IV.j Stratified Flow Data Acquisition}

Seeded water was introduced into one end of the channel at three flowrates: 1 (simulating a stagnant. half-filled open duct to the air flow). 1. and 2 gallons per minute (GPM). Cocurrent seeded air flow was also introduced at inree flowrates: 5 . 10. and 30 standard cubic feet per hour (SCFH).

Five problems were immediately evident. It became apparent that the exit nozzle screens and/or flow straighteners were preventing water flow at the air/water interface. This was probably due to surface tension. Water under the interface was moving as expected. To correct this, the exit flow nozzle was modified by removing the screens and straighteners, and inserting a dam. The dam (a strip of plastic half 
the hesght of a sireen) insured an approximately constant interface height ( 38 mm). reardless of the water flowrate. Prior ti dam placement. it was noted that interfice heght would increase with increasing water flowrate. After dam installation. wiater relocity profiles assumed the expected shape.

The second problem that occurred was that condensation wnuld appear on the inside channel wall in the air reglon whenever the water wa Howing. This reduced the laser liaht imensity entering the top of the channel. and also ubscured the camern rew of the atr th: The D.I. water is delivered warm to the hab. and the "fogging" was attributed to the difference between warm water and cool. air conditioned. Iaborntory. ain. It was beheved that letting the water set for a few days would allow temperature equalization. preventing the problem. However. condensation still occurred. A simple solution was 10 warm the channel in the area of interest prior 10 rumning the system. A few minutes with a incandescent lamp or a hair dryer prevented fogging for many hours.

The third and fourth problems. somewhat serendipitously had a common solution. The air seed concentration would quickly decrease. coating all inside surfaces. Besides the obvious problem of losing tracer material. it would also obscure the camera view after a few runs. It is believed that the air seed or the channel acquires a statuc charge while air is recirculating. The use of an acryclic cleaner, polish, and "static remover" on the inside surfaces of the channel and vacuum container limited the seed deposition.

The fourth problem was that a large meniscus at the air/water/plexiglass interface would form. climbing from the water surface up the channel wall, obscuring tale view 
of the air near the water surface. A small. inverted meniscus could be formed by iareful filling of the channel with water providing a clear view. However, the surface was unstable. and the meniscus would erentually "fall". especially if the system was humped or shocked. It was believed that some material could be applied to the plexishass surfice to change its surface tension. and it was it surprise to learn that the plexiglass cleaner was that material.

The last problem was that the aur recirculating inside the vacum cleaner would l.ecome rery warm after many hours of contmuous operation. especially at low air How bleeds. In fact it hecame so hot that it destroyed a vacum cleaner ia tigon lose collapsed. completely blocking recirculation. and the plastic bucket deformed and collapsed!). Thereafter. the racuum cleaner was shut off after data was collected.

Nine experiments were performed. for a total of of flow images. Seven sets of images (with 10 consecutive images per set) were captured with a 1024 by 1024 pixel. -bit. Yidicon digital camera in conjunction with the Megalision imaging system at a image rate of 0.00 frames per second $1150 \mathrm{~ms}$ between laser pulses 1 . These sets were llamed 0w.ja (0 GP.I water flow. 5 SCFH air flow), Owlla. 1w5a. I was (a second set with the same conditions), 1w10a. 2w5a, and 2 w10a. Two set of images (with 13 consecutive frames per set) were obtained with a 640 by 480 C.C.D Sony digital camera at an image rate of 18.94 frames per second (52.8 ms between laser pulses). The images were stored on a 4 MByte EPIX frame grabber board. These sets were labeled 2 w10am and 2 w30am. 
lolumetric water and air flowrate information were obtained from their respective rotameters during each expermment. along with channel water and an fow temperi. inre. Temperntures were recrided hy inserting wire thermocouples into the flow hy way of the upstream chamel vell valve iap.

IV di luale Anal! sis

The tracking process needs iracer mformation from the digital imases I tracer parti. cle centroid and areat falcuiate rector information. The Megalision hardware and

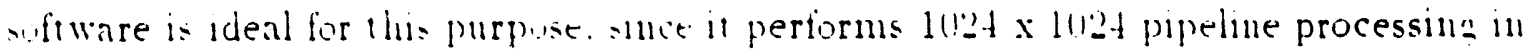
real thme. and allows interactre thresibld and filter functions.

The basic image analysis sequence is discussed below. See Appendix B for detailed processing values and programs. The first step to process images obtained with the Vidicon Megalision camera is to recall a stored (from PC hard drive or floppy disk) raw image into a memory board. A sharpen filter is applied to enhance the density gradient and clearly define the tracers trom the background. This filter sharpens a picture by subtracting an $: x$ pixel averaged filter from an accumulated picture. A negative or inverse of the image necessary for the following step I then obtained. Then. an interactive median filter is used to further define and separate the tracers from the background. meniscus. reflection from channel sides. etc. This filter uses a basic kernel and size (i.e. 17 pixel diameter circle), and then the basic kernel can be manipulated to obtain the desired results. An image is then obtained, with a 255 gray level (white) background and 0 gray level (black) particles. Again, an inverse is performed, to get a "cleaned" picture of white particles on a black background 
which is necessary for the final processing. This final processing provides the tracer information for the tracking programs. It uses the "cleaned" picture as a "mask" which is overlaid on the original picture. Any connected pixels in the original $x$. bit mage that appear under the mask are determined to be particles. and various parameters. such as $x$-centroid. y-centroid. area. average grạ level. shape function. etc.. can he calculated. The nutput data can be manipulated on the monitor for example. particles can be sesreanted hy size or aray levell or the output stored in a file.

The images obtained with the C'C'D camera and EPIX frame grabbers are analyzed smilarly, with one exception. They are loaded into a clean memory board in a certain position. flipped about the $x$ and $y$ axis. and then magnified by two. This is done to make them appear similar to the Megalision images. The reason is twofold. First. the tracking programs and final rector presentation plots are set up for 1024 by 10124 resolution images. Since the C'C'D camera has a 640 by 480 resolution, these programs would perform well. but the output would appear small. A simple modification 10 the programs could remedy this. The most important reason to magnify by two is that the interactive image threshold and filter operations are difficult to perform with the smaller images on the high resolution monitor, and it is crucial that this step is performed correctly. The twice magnified image now has a 1280 by 960 resolution. so that some of the $x$-dimension data is removed (approximately 128 of the original picture's pixels). For some images this may not be acceptable. however, for the channel pictures taken with the CC.D camera, little useful data was lost in the analysis. 
A overlay of the ten processed images (binary and inversed) for the channel experment 2w3lam is given in Fir. 2y. clearly showing the air seed at top. the interface. and seeded water flow at hottom.

The final processing of the image data occurs after the data files are transferred to the engineering mainframe computers (YAXs/. using the Ethernet line connection to the laboratory PC with FTP (File Transfer Protocol) software. A program (Appendix Bi takes the original data. splits it into separate air and water data files tio be discussed in a later section 1 .hecks for errors. and performs coordinate transforms. if desired. The Mesalision camera iakes data at a slight tilt. probably due tir a tube misalignment. and it is desired to rotate the data to the horizontal for esthetic reasons,

\section{II.T Vector Tracking}

It has become evident that some means to analyze images. process and track the sequential data. and produce visual and mumerical output. both quickly and automati. cally: must be derised. We can now take 26 images (EPIX) or 10 images (Megalision) within about $1 \mathrm{sec}$. The data quantity is enormous $(\approx 10 \mathrm{M}$ Byte $)$, and the process can be repeated in a few minutes. limited only by storage limits. The problem is that we can now take more data then we will ever have the time to manually analyze. The driving force behind this work has been to get a handle on that beast (information overload. which appears in most fields of study), and process the data automatically as a set of frames vs. individual frames, to make the problem more tangible. 


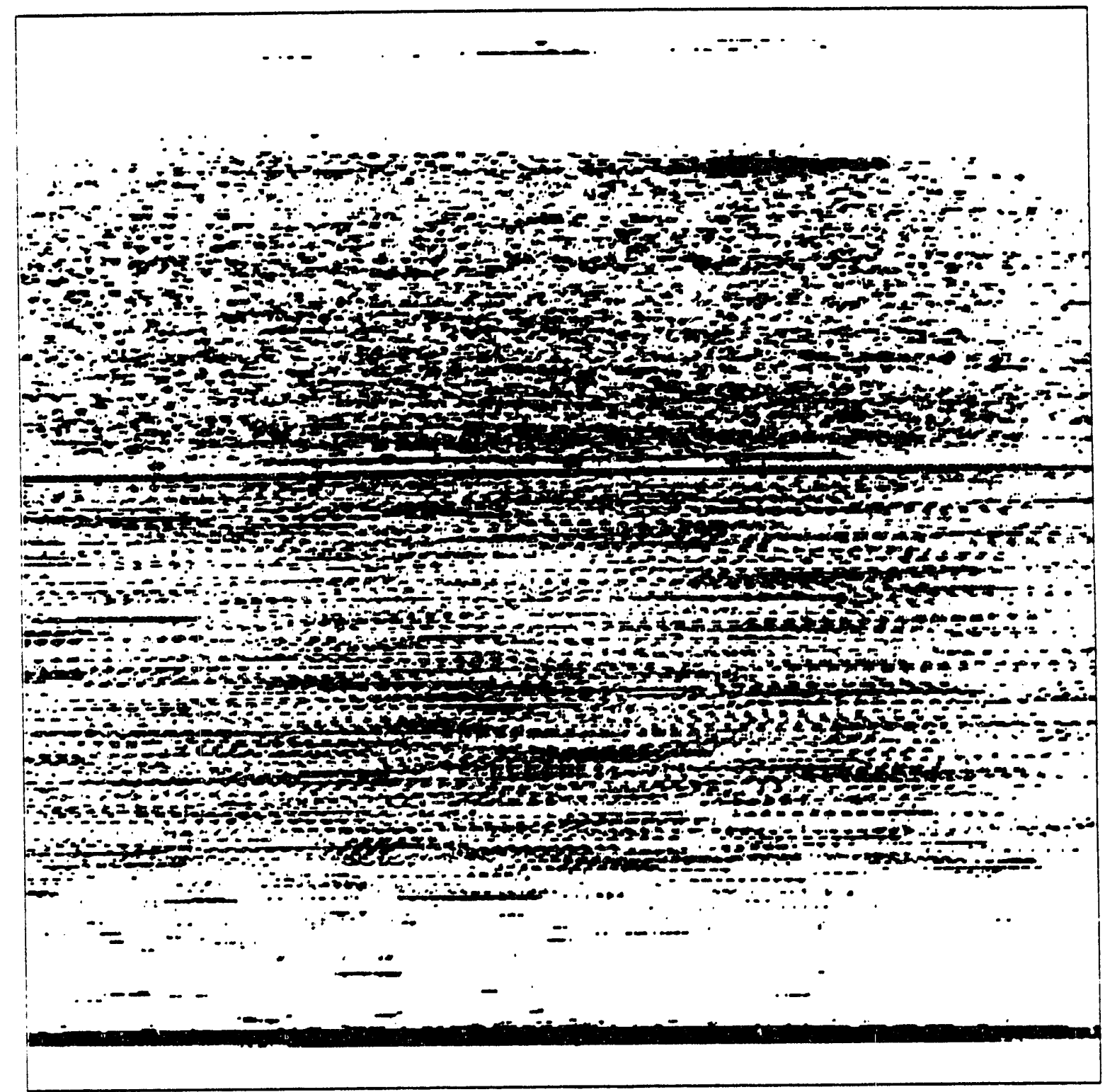

Flow direction:

Camera view: $94 \times 94 \mathrm{~mm}$

Figure 29. Binary Inverse Overlay, Set 2w30am 
The first step to process data as a set has already occurred. The program mentioned in the image andysis section has separated the air and water particles f based on relative position to the known interface coordinates). The input requirements were the set name. number of files in the set. coordinates of air. interface. Water. channel top or bottom. or coordinate transform. if relevint.

This data is tracked air and "ater separately/ by the cross-correlation tracking program (Appendix ("). Again. the major input is the set name. set type air or water). start and stop frames for partial trackingl. and the candidate and dynamic search region dimensions discussed in the tracking code chapter. The major output is a file With the best candidate recrors along with their respective correlation coefficients and pair confidence values. Each file 10 water and 10 air files for a set of 10 images $)$ will also have a set average and standard deviation cross-correlation coefficient and pair confidence value. The program was setup on the CRAY-IMP. with typical run times maring from a few hundred cpu seconds to as much as an hour. for those images with large seed concentrations. Appendix A includes a cross-correlation data sheet for each set.

A method. discussed in the code testing chapter. has been devised to auromatically "clean" vectors. This method has been further enhanced to clean a set of stratified flow vectors obtained with the tracking code. The program. AutoCleanSet (Appendix D), reads an input file with the name of the set. start and stop frames (for partial cleaning), air and water percent difference (PD) cleaning values, and boundary conditions $(B C)$ (location and number of points for top, interface, and channel bottom, if desired). 
The autocleaning is best described through example. Assume that the three BC locations have been identified. The complete uncleaned water vector file is input. The hest rectors are identified those with correlation coefficients greater than the frame average plus frame standard deviation and pair confidence values greater than frame standard deviationl. This usually is aboun 1012017 of the total. The chamnel bottom zero velocity or "nci-slip" $\mathrm{BC}$ is imposed with the addition of $3:$ high quality (perCert vector zerc velocity vectors at the hottom location. The Hardy-Multiquadratic aquations (equations (16-1S/) are used to make a full-field water flow equation. The -ruainal file is checied against the equation. Think of the PD value as a circle of some diameter centered at the arrowhend of a rector in the flow equation. For example. a $10^{(-}$, FD clean value would be a circle of 1 pixel radius centered at the tip of a 10 pixel long vector. If any vectors fall within the $P D$ value. they are added to the "cleaned" file. and the process reiterates until no new vectors (or some percentage. currently set $102(-1)$ is added. The water file is now cleaned. The water equation is extrapolated to the interface ( usually a few pixels above a water vector). and 128 interface velocity $B C$ rectors determined. It was determined the somewhat large number (128) was needed to smooth the air velocity gradient at the interface, giving more accurate shear stress results. The interface $B C$ vectors are added to the original air file, imposing the $B C$, that air and water velocities must be equal at the interface. The channel top "no slip" BC is added (32 vectors), and the air file cleaned. The output consisted of a separate. cleaned, air and water vector file and full-field flow equation for each frame pair (i.e. frame $1-2$. frame $2-3, \ldots$ ) of the set. 
A program was uritten to plot as a set the final results of the automatic cleamma process 1.Appendix (i). Figure 30 shows the cleaned air and water vectors from frame 12-13 of set 2w3ram. These pictures simulate a view from the $1024 \times 1024$ cameril. and the size of the riew frame is gren. Since the channel top and bottom were visible in the riew plane they are represented. along with a line depicting the interface. The recturs are shown without magnification, and a rector scale (used for both air air and Water vectors is provided. Velocity and shear profiles along the vertical y-axis ifrom data taken at camera centerline $x=i 12$ pixels are shown. The profiles are multiplied by a factor determined so that the maximum width of any profile in a set does hit exceed 200 pixels. These profiles are not draw io scale. The purpose of the profiles is to allow the experimenter to quickly perform a risual analysis of the data. Velocity. profiles are reviewed to check for steady-state. fully-developed flow. and to insure the boundary conditions used in the analysis were correctly applied. The shear profile is studied near the air water interface: for ideal flow conditions should set the boundary condition that the air shear will equal the water shear at the interface. The makinn of these profiles is discussed in the shear results section.

The necessity to separate air and water was determined by the $B C$ ( which was not imposed) that the air and water interfacial shear stress should be equal. Shear is equal to viscosity times velocity gradient. If viscosity is unequal at the interface (and. in this experiment, it is by two orders of magnitude due to the difference in fluid properties/. then, this implies that the velocity gradients of the air and the water at the interface be discontinuous. It was first attempted to process air and water files together. but. 


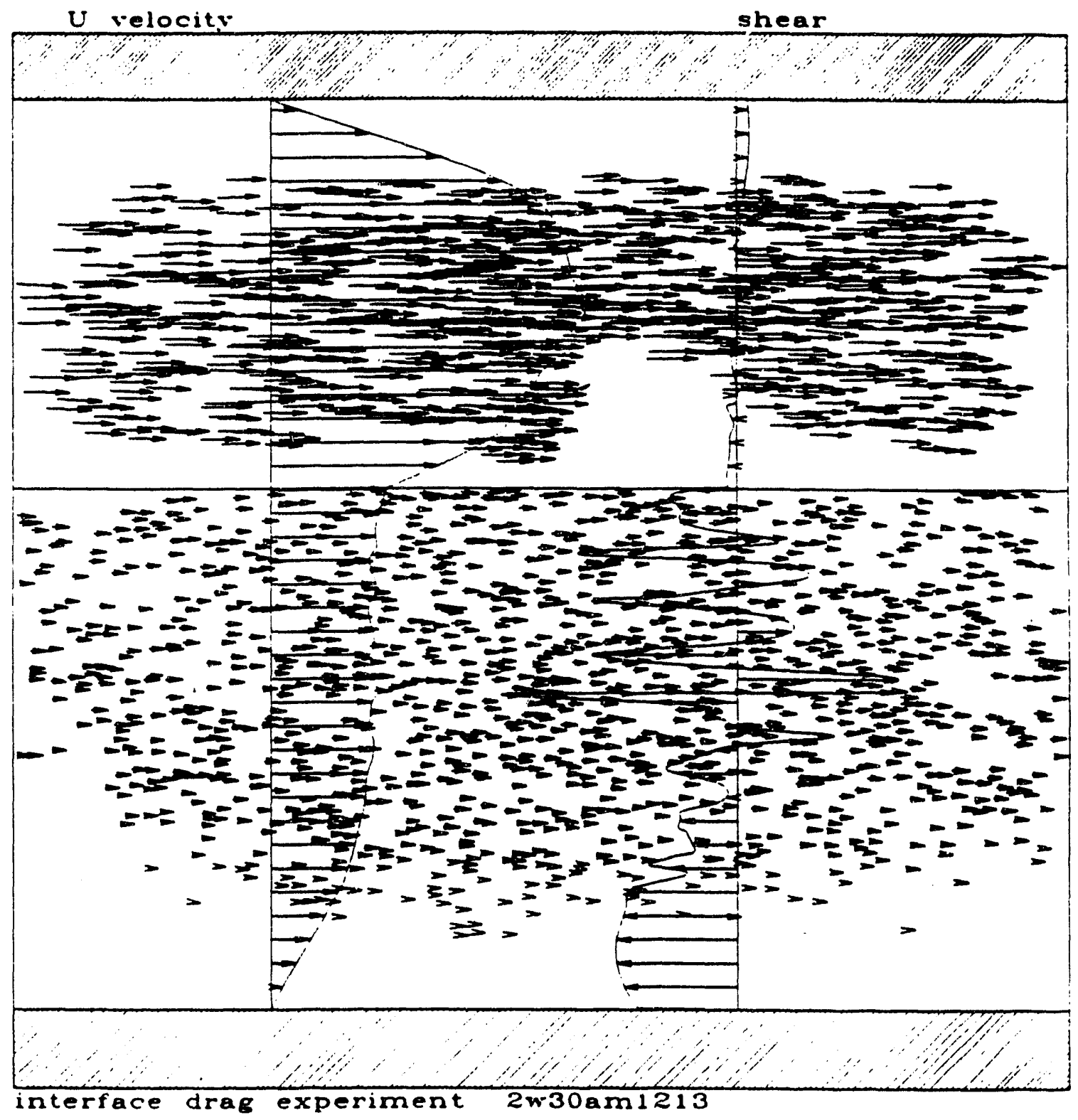

Camera view: $94 \times 94 \mathrm{~mm}$

Vector scale: $-50 \mathrm{~mm} / \mathrm{s}$

Velocity and shear profiles not to scale

Figure 30. Velocity and Shear, Set 2w30am. Frame 12-13 
the Hardy equation which resulted provided a smooth relocity interpolation at the interface. This mas because few air particles were imaged near the interface hence. few air vectors were determined hy the tracking program. The smooth interpolation was fine for the interface velocity $B C^{\prime}$. but completely unsatisfactory for the interfacial shear.

IV:S Interface Shear Calculations and Results

Flow parameters. such as veinity. vorticity and shear. can he calculated at any point in the flow field ance the final flow-field equation is known. The shear theory. equation (201) and equation 121 , is based on knowing arerage /bulk/ air velocity and interface velocity in the flow fieid.

A program was written (Appendix $E$ ) to take the final air and water flow-field velocity equations, differentiate them. and produce profile data files of velocity. vorticity. and shear. Shear stress is based on temperature dependent air and water viscosity. which needs to be determined. Temperature dependent riscosity (in poise) of air can be found using Sunderland's (Anderson. 14t4) correlation. Which is based on air riscosity at STP conditions $1 \mu_{1}=1.7894 \cdot 10^{-04}$ at $T_{n}=288.1\left(\mathrm{~K} \frac{\mathrm{G}}{\mathrm{cm} \sec }\right)$

$$
\mu=1.7894 \times 10^{-04}\left(\frac{T}{T_{0}}\right)^{1.5}\left(\frac{T_{0}-110}{T-110}\right) \frac{g}{\mathrm{cms \epsilon c}}
$$

Temperature dependent viscosity (in poise) of water from $\left(1-100 C^{\prime}\right.$ is found using CRC tables (note that $\mu_{20}=1.0019414 \times 10^{-02} \frac{g}{c m s e c}$ at $T=20 C^{\prime}$ ). For water temperature less than $20 C^{\prime}$.

$$
\mu=\frac{1301.0}{998.333+8.1855(T-20)+0.00585(T-20)^{2}}-3.30233 \frac{g}{\mathrm{~cm} \mathrm{sec}}
$$


For water temperature greater than $2\left(1 C^{\prime}\right.$.

$$
\mu=\mu_{20} \cdot 11 \frac{: 32-2 i 20\left(i-T i-0001053(T-20)^{2}\right.}{T-105.6^{2}} \frac{!}{c m s+c^{\circ}}
$$

The set profiling program uses a set name. start and stop frames. laser pulse separa110n time, a flag to determine the appropriate imaging system (Megalision or EPIX) . Wons with the image analys mannification factor. the camera view area. temperature of air and water flow, the $x$ position where the vertical profiles will he determined. and the channel hop. interface. and hottom locations. It will then determine relocity. velority gradient. vorticity. and shear at requested locations.

Test section average air velucity and interface velocity for frames 12 - 13 of set 2w.36 am are shown in Fig. 31 and Fig. 32. Since the data lespecially the air 1 does not encompass the entire camera view area. data is only used for profiling and calculational purposes in the region orer the average $x$ position plus or minus the standard deviation of all the cleaned air vectors. The channel average air velocity was determined by sampling every $25 t h$ p pixel position between the interface and the channel top. and every 25 th $x$ position (typically between the 200 to 800 pixel position). or approximately 500 points. Fiğure 31 presents data showing a small fluctuation in average velocity of the air over a small section of the channel. The average of the air velocity data (denoted by exp average) is the parameter $C_{g}$. used in equation (20). The large standard deviation from the average is due to the parabolic nature of the air flow field.

The experimental interface velocity and air shear were determined at every pixel along the interface, over the same width as the air velocity calculation. The average 


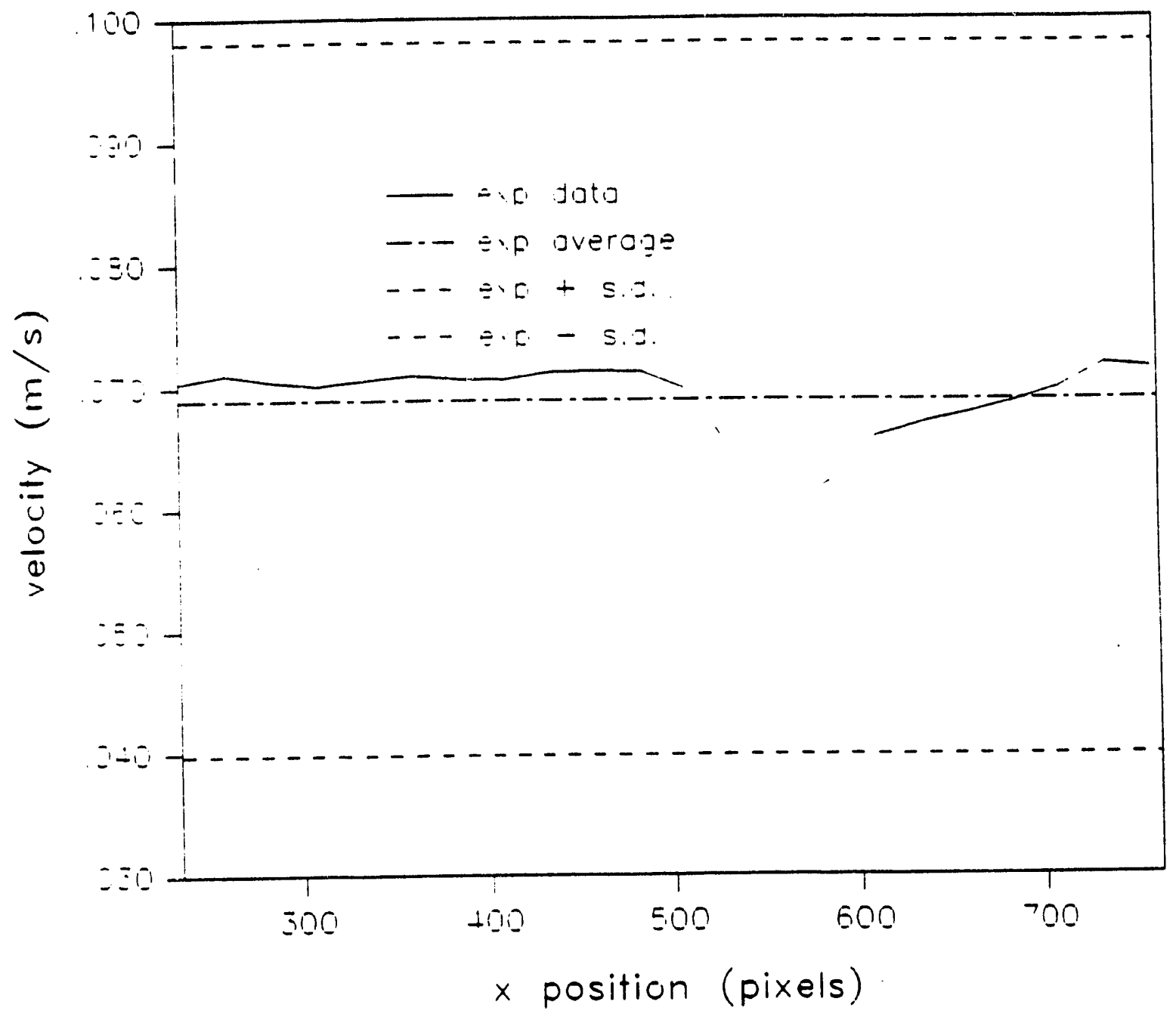

Figure 31. Average Air Velocity, Set 2w30am, Frame 12-13 


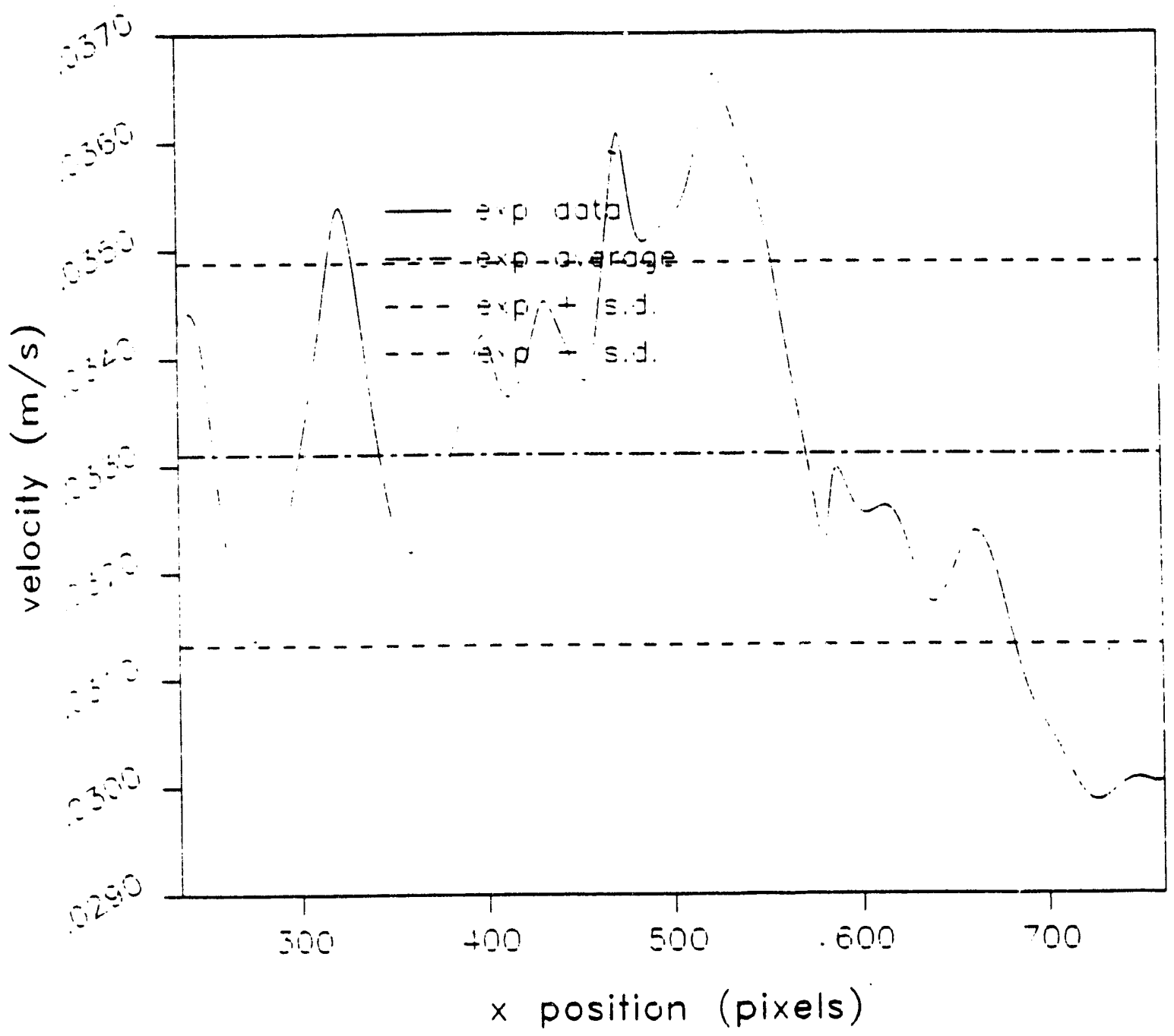

Figure 32. Interface Velocity. Set 2 w30am. Frame 12-13 
of the interface relocity data. shown in Fig. 32 (denoted by exp arerage), is the parameter $l^{*}$, used in equamon 120$)$. Air shear stress was determined using the differentiated Hardy relocity equation thetween the interface and one pixel above the interface to ietermine the velocity gradient). and the temperature corrected air riscosity value. The interface shear for frames $12-13$ of set 2 w.30am is shown in Fig. 33. Each figure also presents the arerage value. the average plus the standard deviation. and the arerage minus the standard deviation. In addition. Fin. $2 .:$ also presents the vatue of the therencal interacial shear stress hased on experimental conditions, as alculated using equanon i2!'!.

Ancher program i Appendix F/ was written to take the data trom the profiling program. and compute the theoretical shear. Air density. used in equation (20) and equation (21). was temperature corrected using the ideal gas law

$$
\rho_{g}=\rho_{0}\left(\frac{T_{0}}{T}\right)
$$

where $\mu_{0}=1.225 \mathrm{~kg} \mathrm{~m}^{3}$ at $28 \mathrm{~s} .16 \mathrm{~K}$. The output was a plot comparing the theory to the experimental data (with standard deviation). along with a linear least-square fit line through the theory points for the set. Figure 34 shows this plot with one datin point remored (from frame 5-6. where the profile showed the the air flowing backward. see complete data in Appendix A). A file containing experimental velocity and shear data for the air and water flow. and theoretical shear calculations for each frame in the set. is shown Fig. 35. Other pertinent information for the experiment. such as camera view area and magnification, fluid properties and dimensions, and gas Reynolds number and interface fraction factor, is also presented in Fig. 35. 


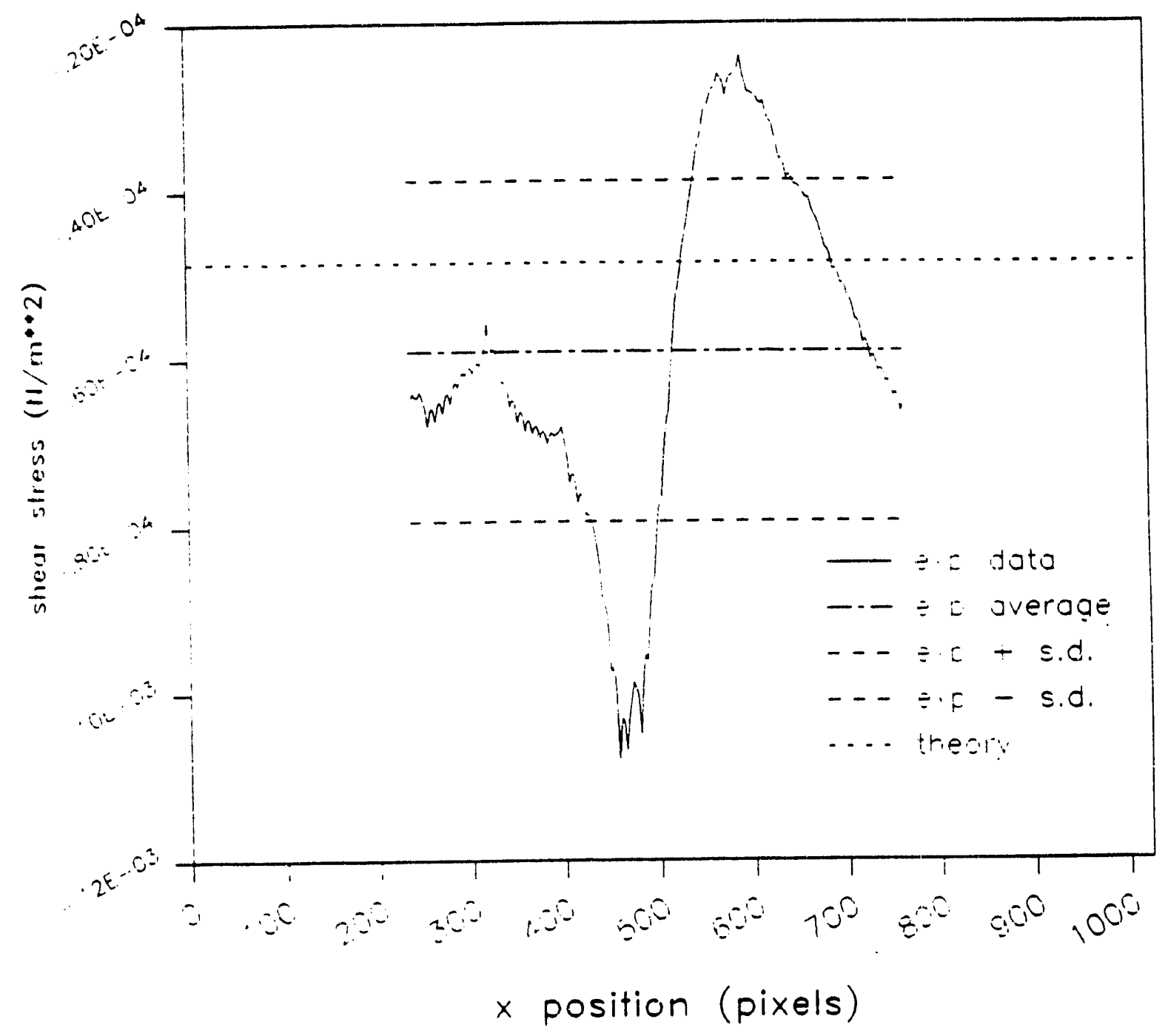

Figure 33. Interface Air Shear. Set 2w30am, Frame 12-13 


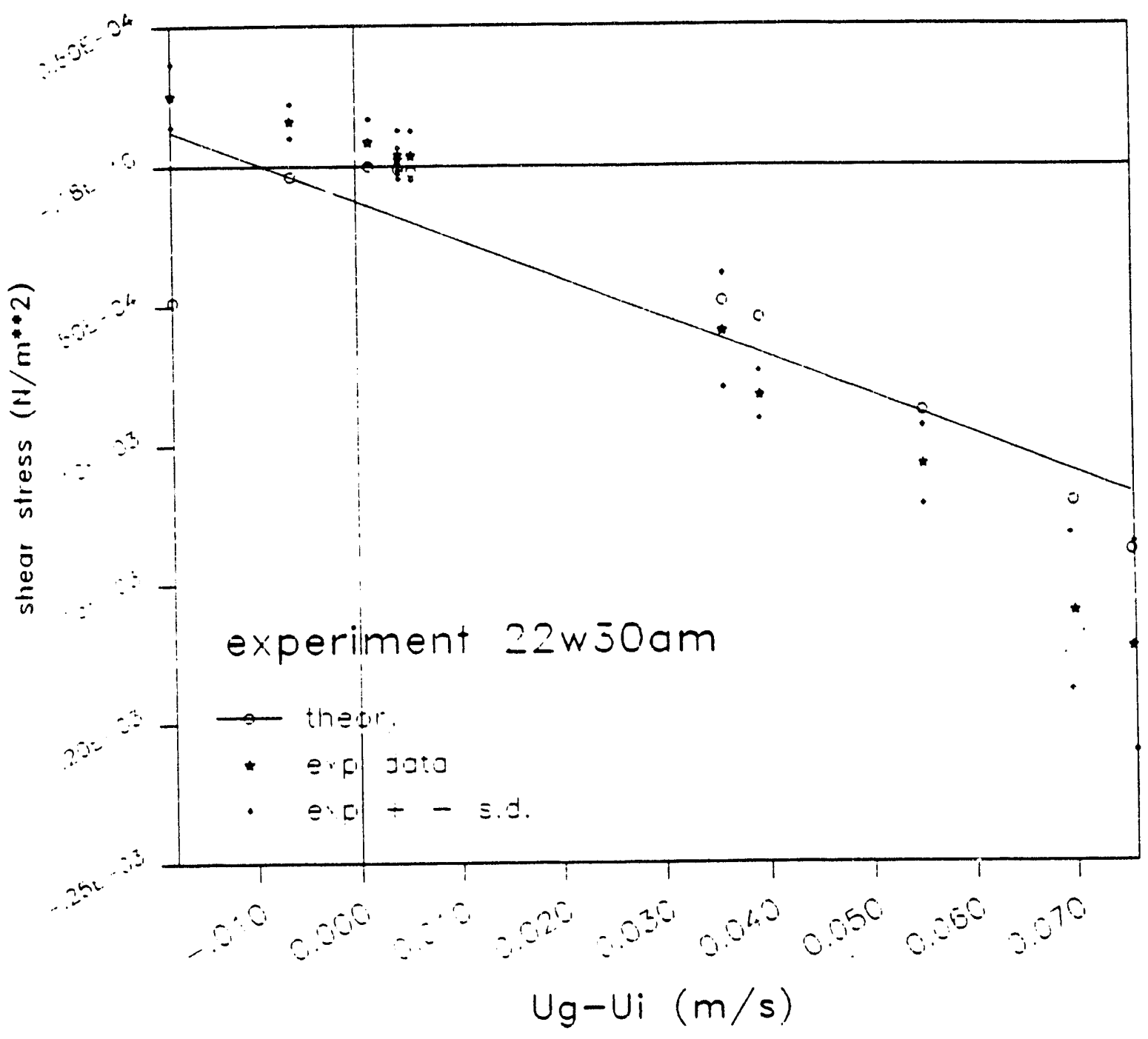

Figure 34. Shear Experiment vs. Theory Comparisons, Set 2w30am 


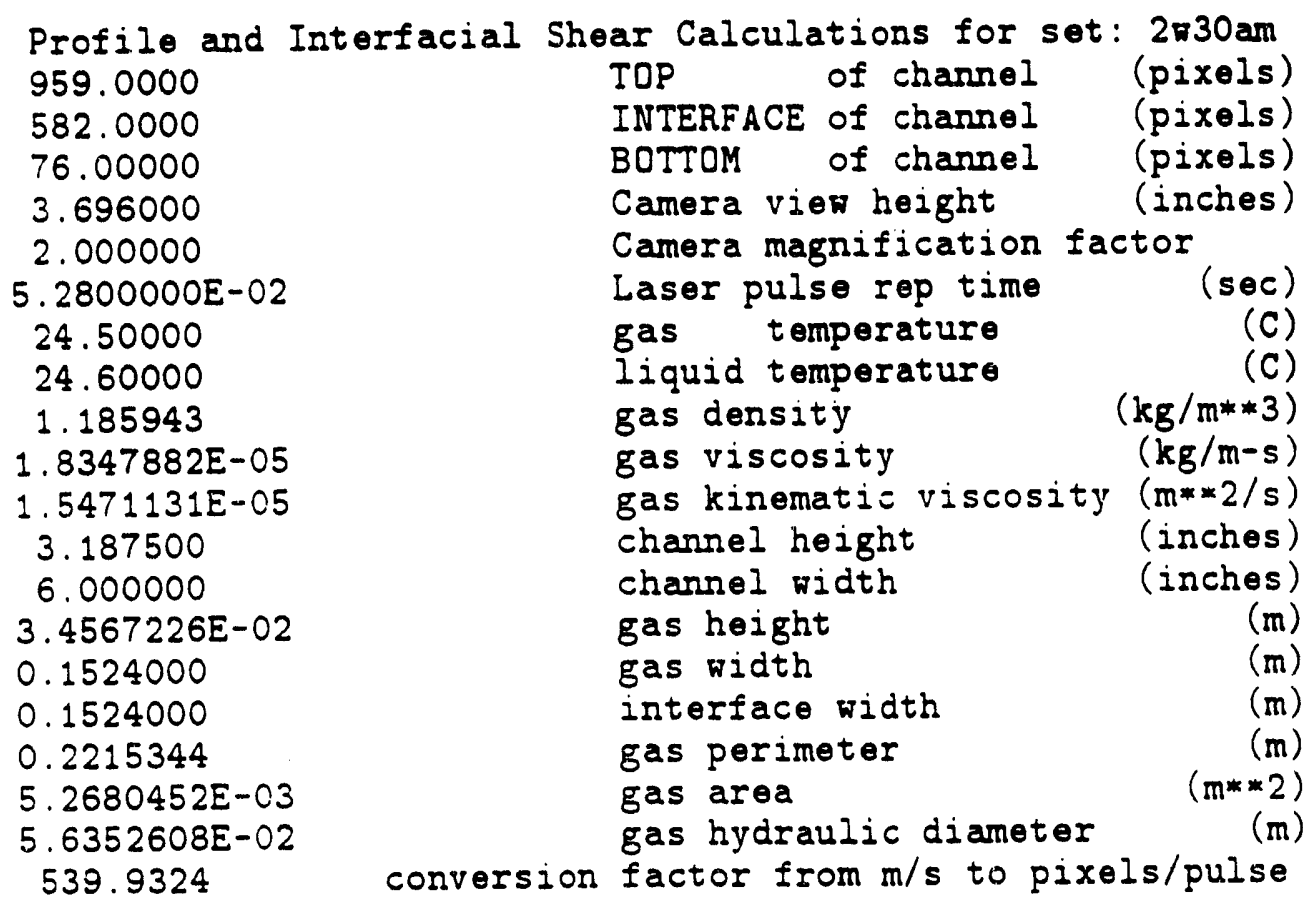

\begin{tabular}{|c|c|c|c|c|c|c|c|}
\hline \multicolumn{2}{|c|}{ frame } & $\begin{array}{l}\text { sater } \\
\mathrm{m} / \mathrm{s}\end{array}$ & $\begin{array}{c}\text { inter } \\
\mathrm{m} / \mathrm{s}\end{array}$ & $N / m^{2}=2$ & $\mathbb{N} / m * * 2$ & & $\mathrm{~m} /$ \\
\hline 1 & 2 & $0.258 E-01$ & $0.330 E-0$ & $.348 E-05$ & $860 E-05$ & $0.812 E-05$ & $0.343 E-01$ \\
\hline 2 & 3 & -01 & & & 4 & 63 & 01 \\
\hline 3 & 4 & & & & 14 & 0. & 18 \\
\hline 4 & 5 & & & & 3 & 0. & 100 \\
\hline 5 & 6 & & & -.7 & 0.7 & 0. & \\
\hline 6 & 7 & & & • & -.1 & 0. & \\
\hline 7 & 8 & & & .3 & 0.2 & & \\
\hline 8 & 9 & & & .9 & 0.3 & & \\
\hline 9 & 10 & & & .7 & 3 & & \\
\hline ( & 11 & & & -.1 & 0.2 & & \\
\hline 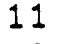 & 12 & & & 0.7 & & & \\
\hline & & & & $.1+\alpha$, & & $0.202 \pi$ & \\
\hline
\end{tabular}

velocity $(\mathrm{m} / \mathrm{s})$ and shear $(\mathrm{N} / \mathrm{m} * * 2)$ SET AVERAGES + $/$ - STANDARD DEVIATION $\begin{array}{ccc}\text { average values along interface from (min, max) } & (X=212 \\ 0.252 E-01+/-0.516 E-03 & U \text { rater } & \text { (bulk) } \\ 0.334 E-01+/-0.147 E-02 & U \text { interface } & \\ 0.525 E-01+/-0.361 E-01 & U \text { air } & \text { (bulk) } \\ -.637 E-04+/-0.666 E-04 & \text { shear rater (interface) } \\ -.372 E-04+/-0.783 E-04 & \text { shoar air (interface) }\end{array}$

$\begin{array}{cccccccc}\text { frame } & U_{g} & U_{i} & R e g & f i & \begin{array}{c}\text { shoar(thy) } \\ \mathrm{N} / \mathrm{m} * 2\end{array} & \begin{array}{c}\text { shear (exp) } \\ \mathrm{N} / \mathrm{m} * 2\end{array} \\ 1 & 2 & 0.343 \mathrm{~m}-01 & 0.330 \mathrm{~m}-01 & 125 & 0.128 & -.128 \mathrm{E}-06 & 0.860 \mathrm{E}-05 \\ 2 & 3 & 0.739 \mathrm{E}-01 & 0.346 \mathrm{E}-01 & 269 & 0.059 & -.544 \mathrm{E}-04 & -.822 \mathrm{E}-04\end{array}$

Figure 35. Profile and Interfacial Shear Calculations. Set $\cdot 2$ w30am 


\begin{tabular}{rrrlrrrr}
3 & 4 & $0.271 E-01$ & $0.334 \mathrm{E}-01$ & 99 & 0.162 & $-.381 \mathrm{E}-05$ & $0.161 \mathrm{E}-04$ \\
4 & 5 & $0.108 \mathrm{E}+00$ & $0.323 \mathrm{E}-01$ & 393 & 0.041 & $-.138 \mathrm{E}-03$ & $-.173 \mathrm{E}-03$ \\
5 & 6 & $-.484 \mathrm{E}-02$ & $0.325 \mathrm{E}-01$ & 18 & -0.908 & $0.750 \mathrm{E}-03$ & $0.749 \mathrm{E}-04$ \\
6 & 7 & $0.900 \mathrm{E}-01$ & $0.349 \mathrm{E}-01$ & 328 & 0.049 & $-.879 \mathrm{E}-04$ & $-.107 \mathrm{E}-03$ \\
7 & 8 & $0.359 \mathrm{E}-01$ & $0.317 \mathrm{E}-01$ & 131 & 0.122 & $-.128 \mathrm{E}-05$ & $0.244 \mathrm{E}-05$ \\
8 & 9 & $0.377 \mathrm{E}-01$ & $0.322 \mathrm{E}-01$ & 137 & 0.117 & $-.209 \mathrm{E}-05$ & $0.376 \mathrm{E}-05$ \\
9 & 10 & $0.106 \mathrm{E}+00$ & $0.360 \mathrm{E}-01$ & 386 & 0.041 & $-.120 \mathrm{E}-03$ & $-.160 \mathrm{E}-03$ \\
10 & 11 & $0.172 \mathrm{E}-01$ & $0.351 \mathrm{E}-01$ & 63 & 0.255 & $-.485 \mathrm{E}-04$ & $0.254 \mathrm{E}-04$ \\
11 & 12 & $0.358 \mathrm{E}-01$ & $0.316 \mathrm{E}-01$ & 130 & 0.123 & $-.128 \mathrm{E}-05$ & $0.406 \mathrm{E}-05$ \\
12 & 13 & $0.689 \mathrm{E}-01$ & $0.331 \mathrm{E}-01$ & 251 & 0.064 & $-.485 \mathrm{E}-04$ & $-.591 \mathrm{E}-04$ \\
\multicolumn{7}{l}{ Shear theory average $+/-$ standard deviation $0.203 \mathrm{E}-04$} & $+/-0.235 \mathrm{E}-03$
\end{tabular}

Figure 35. Continued 
This process was repeated for the nine experiments. All data was processed and presented in Appendix A. For the purpose of comparison of theoretical shear to experimental shear. three sets were remored from the final results plot. Two sets. 2w5a and 2w10a. were suspect since ther were obtained immediately prior to the discovery of the "melted" racuum cleaner. Another set. 2w10am. was very unstable (average air velociry reversing direction drastically hetween frames. Of the six sets used in the final comparison plot. one other point (frame $2-3$ of set 11 wa) was remored due

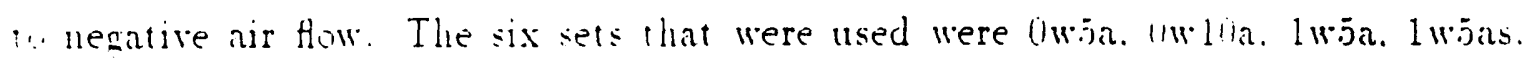
iwllia. and 2 witim. The complete comparison of theoretical with experimental shear stress results. using 51 mensurements. is presented in Fig. 36. This figure shows that theoretical and experiment ally obtained interface shear results compare favorably:

It has been determined that two conditions can exist where theory cannot predict

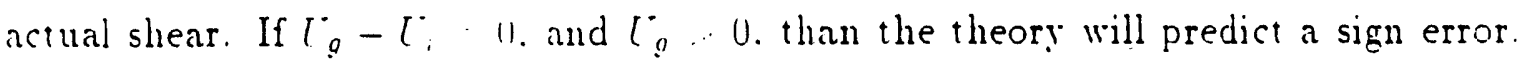
It must be admitted that this condition rarely exists in most flows. This is the cause of the large difference between theory and experiment highlighted by the furthermost left point on Fig. 36.

The other condition which can easily exist in unstable flows, such as that caused by a pipe break. and will certainly cause problems for 1- or 2-dimensional codes. is the condition that flow near the interface is transient. and dissimilar from bulk flow. This condition of interface flow reversal is seen in many of the images of set OW10A, an example is shown in Fig. 37. The experiment rightly determines a negative velocity gradient (implying positive shear) at the interface. However. since bulk air 


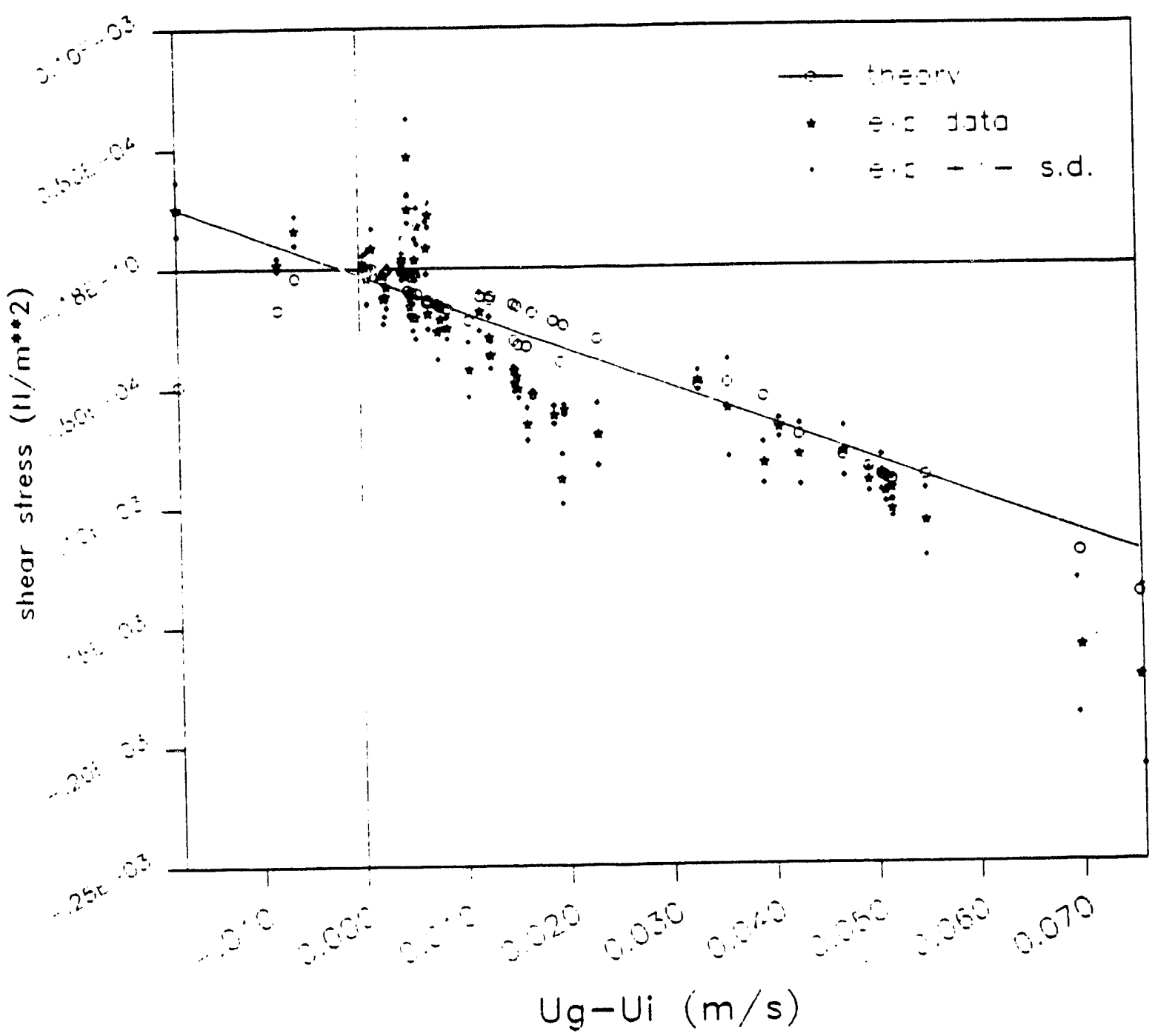

Figure 36. Shear Experiment vs. Theory Comparisons. All Sets 


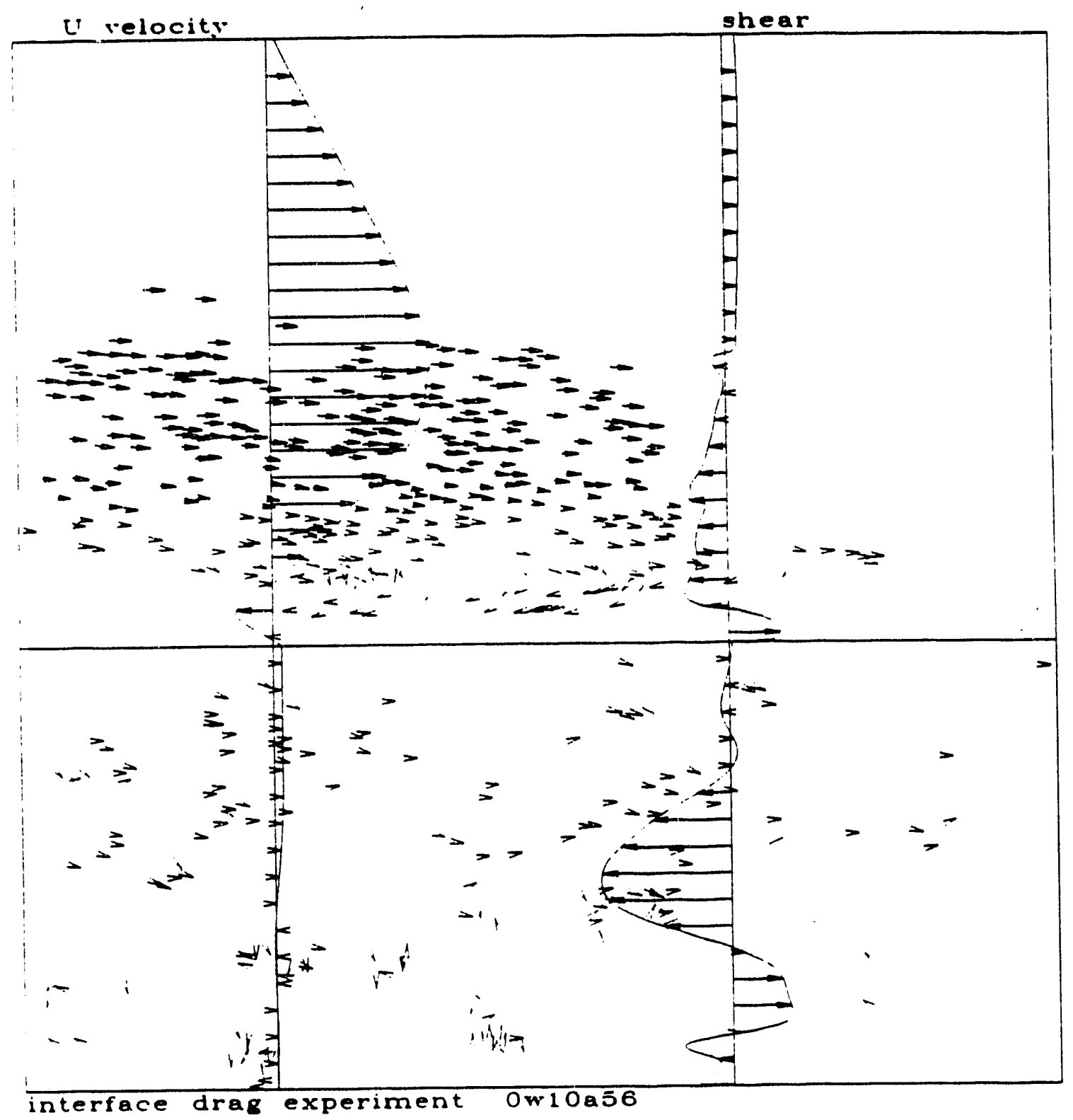

Canera view: $84 \times 84 \mathrm{~mm}$

Vector scale: $-20 \mathrm{~mm} / \mathrm{s}$

Velocity and shear profiles not to scale

Figure 3i. Velocity and Shear. Set 0w10a. Frame 5-6 
is positive. theory will predict negntive shear. This phenomena causes the cluster of positive experiment shear is. negative thenretical shear near $l_{y}-C_{i}^{*}=0$, shown on Fị.. Bì. 


\section{CHAPTER V}

\section{C.ONCLUSION}

Two methods have heen described which perform tracking of seed particles in a in a two-phase flow field. usms the Pulsed Laser Velocimetry method. One method tracks particles throngh four or more frames. The wher method involves correlating eroups of particles hetween wo sequential frames. These methods have heen proven to he fiss and reliable

A novel method has heen proposed which eliminates tedious. undesirable. manual operator assistance in remoring erroneous vectors. This method uses an iterative process involving an interpolated field produced from the most reliable vectors.

Since both of the trackins techniques presented in this paper can be performed quickly: it is recommended that experimental data he analyzed with both methods. if possible. This should be nerformed to verify the results.

It is felt that the largest contribution of this work has been the greatly reduced time it now takes to process mage data. not only individual frames. but also complete 1 sets of images. Ifuch of the work has been performed with this goal in mind.

A stratified channel flow facility was used to conduct two-phase interface studies. Flow visualization data was directly digitized with high resolution cameras using PLI techniques. and analyzed with new tracking software. Direct determination of interphase drag coefficients was performed. The interfacial drag experiment clearly shows that $\mathrm{PLV}^{\prime}$ can be an investigative flow visualization instrument. This was proven by the matching of interfacial drag theory to experimentally obtained drag 
results. In addition. in reference to this work. PLV has dramatically shown where and why with full-tield flow visualization), certain theory based on macroscopic. space. areraged behavior. is not applicable.

PLI has proven to be an accurate. full-field. noninvasive. quantitative velocity pro. filing techuque applicuble tu a wide range of flow patterns. The advent of increased speed and resolution of computer-based imaging systems has allowed the direct diginzation and analysis of particle mages. Though many improvements are possible in this field. the technigue = development at this tme may make it the preferable method for obtaming reiable velocity information about experimental. iransparent. How problems.

Recommendations for fut ure work continue to stress the need to analyze and present data quickly and accurately. Megalision software should be written to enable the user to enter the pertinent image analysis routines for a set of images. and walk away. Wuhout having to interactively enter each image manipulation for every image in a set.

Further. it is recommended that a "imaging" workstation he acquired. with the increased gains in interactive image manipulation and the zero cost (after overhead) of tracking and cleaning. more than offsetting the purchase cost. C'omputer time is money, and it took approximately 10-15 CRAY cpu hours to perform all the analysis prese nted here.

Speaking specifically on the PLV shear experiment, two facts are evident. Wide fluctuations are seen in air velocity, especially at very low flow. Therefore, the air side seed pump and recirculation system should be redesigned. possibly in the following 
manner. It is still believed that a closed loop is desired. Therefore. 10 achieve a doser representation to a constant pressure air supply. The tasks of pumping and recirculation should he separated. A possible suggestion would be a mixing box with an internal fan for recirculation purposes. and a separate blower for forcing the air seed mixture through the mixing box and channel.

hecondly: another means of "illuminatung" the flow field must be obtained. Due to laser limitations. we can only lake data in $5(1-310) \mu$ s and $511-150)$ ms time scales (or

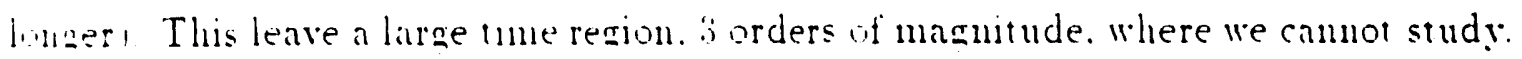
In ther words. we are forced to design an experiment to fit the equipment. This limution could he remedied with the purchase of another laser. or some other light source. possibly a high intensity "arc" strobe. This. by far. is the most important problem which must be solved. in order to adrance PLI studies at Texas AdN Linversity: 


\section{NOMENCLATURE}

$A=$ area. number of overlapped pixels

$B 1=$ number of 1 - valued pixels in correlation region in frame 1

$B 2=$ number of 1 - ralued pixels in correlation region in frame?

$B C^{\prime}=$ boundary condition

$C^{\prime}=$ correlation coefficient. Blasius friction factor constant

('C'T = cross-correlation trackins

D. $d=$ diameter

$f=$ friction factor. focal length

$f \equiv=f \cdot c a l$ length divided hy comera aperature

$F=$ force

$F 1=$ binary pixel value in image frame 1

$F 2=$ binary pixel value in image frame :-

$y_{x}=$ aravitational acceleratcin in $x$ cordinate direction

$H=$ height of region

$h=$ wave number

$K=$ inaracteristic kinetic energy per unit walume

$l=$ vector length

$L=$ length of region

$m$ = Blasius friction factor constant

$. M=$ camera magnification

MFT = multiframe trackin:

$x^{\circ}=$ number of vectors. number of orerlapped particles

$\mathrm{ISI}=$ number of spots /or particles/ per imase

$P=$ pressure

$\mathrm{PD}=$ percent difference $\mid$ cleaning parameter $\mid$

$R=$ radius. reliability index

$R \epsilon=$ Reynold's number

$S=$ surface. perimeter

$t=$ time

$T=$ temperature

$u=$ velocity

$"$ = velocity

ViT:I:IT' = vector velocity with $x, y . z$ components

$x \cdot y . z=$ rectangular spatial dimension components

$X(X, Y)=$ image plane rector coordinate position

Srmbols

$\delta=$ differential increment

$\Delta=$ increment

$\overrightarrow{\mathcal{E}}=$ exposure

$I=$ intensity of illuminating beam

$\mathcal{J}=$ intensity of particle image

$\lambda=$ wavelength

$\mu=$ viscosity

$\nu=$ kinematic viscosity

$\Omega=$ solid angle

$\partial=$ partial differential increment

$\pi=3.1418$

$\rho=$ density

$\sigma=$ multiframe tracking parameter, Mie scattering coefficient 


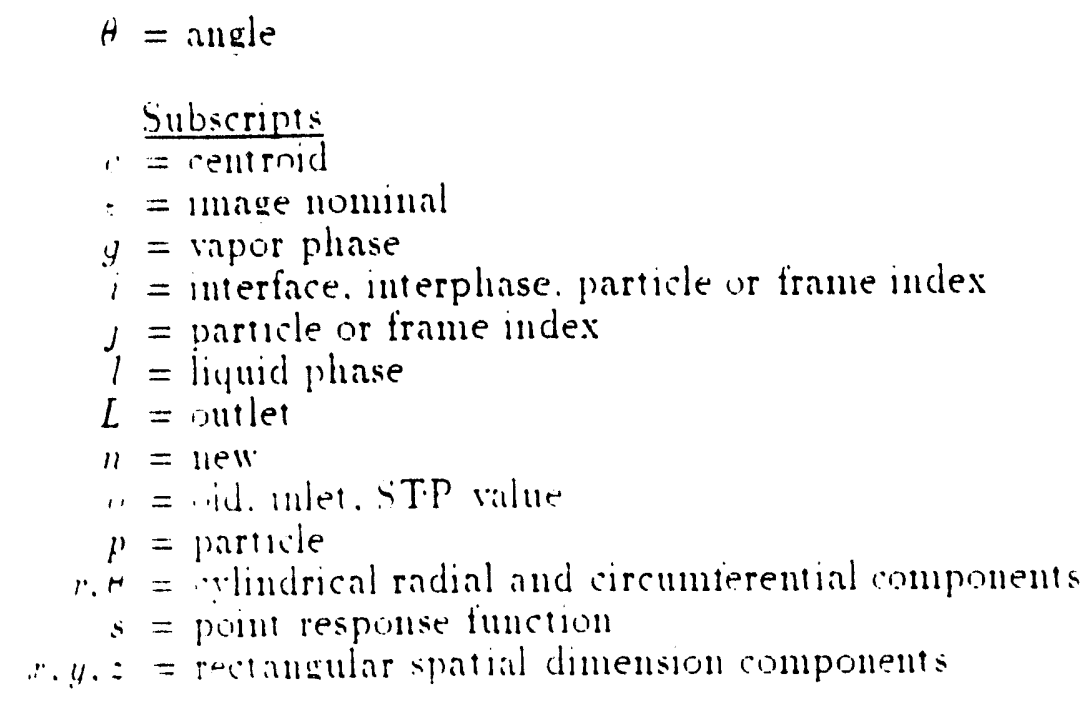




\section{REFERENCES}

Adrian. R.J. and Yao C.S., I!4.3. "Development of Pulsed Laser Velocimetry for Measurement of Fluid Flow." Eighth Symposum on Turbulence. Lniversity of Missouri-Rullit. pp. 17)1.186i.

Adrian. R.J. 1!184. "Scattering Particle C'haracteristics and Their Effect on Pulsed Laser . Measurements of Flund Flow: Speckle Velocimetry i.. Particle lmage

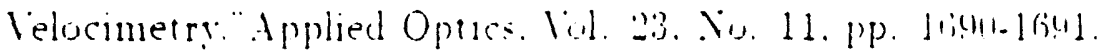

Adrian. R.J. and Vio. ('. LIM4. "Development of Pulsed Liser Velocimetry (PLI) for Measurement of Turbulent Flow. "Proceedings of the Srmposium on Turbulence. Rolla Lniversity. Missouri. pp. 171-1s6.

Adrian. R.J.. Yac. ('. 1:15.5. "Pulsed Laser Technique Application to Liquid and Ciasenus Flows and the Sontering Power of Seed Materials." Applied Optics. Vial. ㄴ. Ni. 1. pp. t1..;.

Adrian. R.J.. 198i, "Image Shifting Technique to Resolve Directional Ambiguity in Double-Pulsed Velocimetry:"Applied Optics. Vol. 25. No. 21. p. 385.5.

Adrian. R.J.. 198sa. "Statistical Properties of Particle Image Velocimetry Measurements in Turbulent Flow. "Laser Anemometry in Fluid Mechanics-Vol.III. Ladoan-Instituto Superior Tecnico. Lisbon. Portugal. pp. 115-124.

Adrian. R.J.. 1988b. "Double Exposure. Multiple-Field Particle Image Velocimetry for Turbulent Probability Density:" Optics and Lasers in Ençineering. Vol. 9. pp. $211 \cdot 228$

Adrian. R.J.. Offutt. P.IV.. Landreth. C'.C'.. Liu. Z.. and Hanratty. T.J., 1990. "Studies of Liquid Turbulence "sine Double-Puised Particle Correlation." Proceedings of the 5 th International Srmposium on Application of Laser Techniques to Fluid Mechanics. July 9-12. Lisbon. Portugal. p. 15.4.

Adrian. R.J.. 1991. "Particle-Imaging Techniques for Experimental Fluid Mechanics,"Annual Reviews in Fluid Mechanics, Vol. 23. Annual Reviews, Inc., Palo Alto. California.

Agarwal, J.K. and Johuson, E.M.. 1981, "Generating Aerosol for Laser Velocimeter Seeding,"TSI Quarterly, Vol. VII. No. 3. pp. 5-12.

Agui. J.C., and Jiménez, J., 1987. "On the Performance of Particle Tracking," Journal of Fluid Mechanics."Vol. 185, pp. 447-468. 
Analytis. G.. Richner. MI and Aksan. S.. 198T. "Qualification of Modifications of Interfacial Shear and Wall Heat Transfer of RELAP.5 MOD? 36.02 During Retiooding." American Nuclear Society. Winter Meetiag. Nov. 1:-1:\% Los . Angeles.

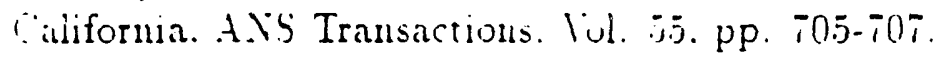

Anderson. J.D . Jr.. 1984. Fundamentale of Aerodynamics. McCiraw-Hill Book Company: Singapore.

trchbold. E.. and Ennos. A.E.. 1992. "Displacement Measurement from DoubleExpocure Later Photouraphs."Optica Acta. Vol. 19. No t. pp 2533.231.

Aruid. W. Hinsch. K.. and Platen. W.. 1986. Analysis of Non-Stationary Flows in. Evaluatme the Fringe Visibility in Speckle Velocimetry."Flow Iisualization II. Proceedings of the Fourth International Srmposium on Fiow Iisualization.

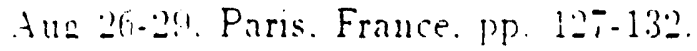

Biri. K.. Stewart. W. E., and Lishtfoot. E.X.. 14hGi. Transport Phenomena. John Wiley d. Sons. Inc.. Vew York.

Braun. M.J.. Canacci. V.A.. and Russell. L.A.. 1990. "Non-Intrusive Laser Based Computer Aided High Speed Flow Tisualization in an Air Tunnel." Proceedings of the 5th International Symposium on Application of Laser Techniques to Fluid Mechanics. July 9-12. Lisbon. Portugal. p.6.1.

Burch. J.M. and Tokarski. J.M.J.. 1958. "Production of Multiple Beam Fringes from Photographic Scatterers." Optica Acta. Vol. 15. No. 2. pp. 101-111.

Cman. R.E.. 1990. "Full-Field Velocity Measurements of Single and Two Phase Flows "sing Digital Image Pulsed Laser Velocimetry." Master Thesis. Texas At.II Cuiversity. College Station. Texas.

Chen. D.J. and Chiang.F.P. 1900. "Digital Processing of Young's Fringe in Speckle Photography." Optial Engineering. Vol. 29. No. 11. pp. 1413-1420.

Chu. C.. 1987. "A New Technique to Automatically Analyze Laser Digital Images for Two-Phase Pipeline Flow." Master Thesis, University of South Carolina, Columbia. South C'arolina.

Collicott. S.H. and Hesselink. L.. 1986. "Anamorphic Optical Processing of MultipleExposure Speckle Photographs." Optical Letters. Vol. 11. No. 7. pp. 410-412.

Coupland, J.M. and Pickering. C., 1988. "Particle Image Velocimetry, Estimation of Measurement Confidence at Low Seeding Densities,"Optics and Lasers in Engineering, Vol. 9. p. 201. 
Coupland. J.. Pickering. ('.. and Halliwell. X.. 1988. "Particle Image Velocinetry. The Ambiguity Problem." Optical Engineering. Vol. 2i. No. 3. p. 143.

Delahume. K. and Hassan. I.. 1(4) . "A Full-Field Droplet Velocity . Measurement of a Spray by Particle Imaging Displacement Interferometry." Proceedings, ASME llinter Annual Meeting. Session of Thermal Hydraulics of Adranced Vuclear Reactors. HTD-Vol. 150. Norember 25-30. Dallas. Texas. pp. 91-07.

Dudderar. T.D.. Meynart. R.. and Simpkins P.Ci.. 1988. "Full-Field Laser Metrology inr Fluid Velocity . Measurement." Optics and Lasers in Encmeering. Vol. @. pp.16i3-1!!!y.

Economitos. L.. 1988. "Image Processing and Analysis of Colored Particle Motions in Turbulent Flow." Ph.D. Thesis. Ohio State Cuiversity. Columbus. Ohio.

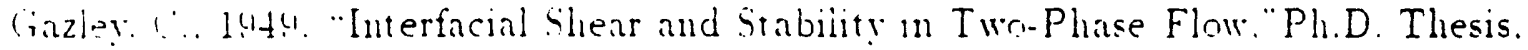
Imersity of Delaware. Cewark. Delaware.

(irant. 1. and Smith. Ci.H. Lust. “.Nodern Developments in Particle Image Velocimeiry." Optics and Lasers in Engineering. Vol. ". pp. 245-2(it.

Cirousson. R. and Mallick. S.. 197T. "Study of Flow Pattern in a Fluid by Scattered Laser Light." Applied Optics. Vol. 16. No. 9. pp. 2334.2336.

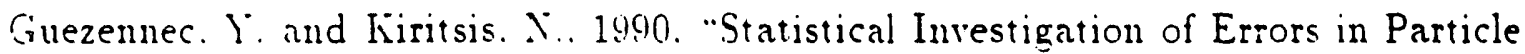
Image Velocimetry." Experiments in Fluids. Vol. 10. pp. 133i.14ti.

Hanzerack. E. and Ju. C. 1988. "Vew Technique to Automatically Analyze Laser Digital Images of Two-Plase Pipeline Flow." Optical Engineering. Vol. 27. No. T. July. p. 328 .

Haralick. R. 198(). "Edge and Region Analysis for Digital Image Data." (omputer Ciraphics and Image Processing. Vol. 12. p. 60.

Hardy. R.L.. 1971. "Multiquadric Equations of Topography and Other Irregular Surfaces."Journal of Geophysics Research, Vol. TG. p. 1905.

Hassan. Y., 1987. "Assessment of a Modified Interfacial Drag Correlation in TwoFluid Model Codes."American Nuclear Society Meeting. June i-11. Dallas, Texas. ANS Transactions. Vol. 54. pp. 211-212.

Hassan. Y'. Hild, R. and Blanchat, T., 1990, "Full-Field Velocity Imaging Technique using High-Energy Pulsed Laser Velocimetry," Proceedings SPIE/SPSE Symposium on Electronic Imaging Science and Technology, Santa Clara. CA, February 11-16, Vol. 1244, pp. 130-144. 
Hassan. Y. and Blanchat. T.. 1941. "Flow Velocity Measurements using Digital Image Pulsed Laser Velocimetry." Optical Engineering. Vol. 311. No. 3. pp. 1220121227.

Hassan. Y' and ('anaan. R.. 1!1!1. "Full-Field Bubbly. Flow lelocity Measurements Ising a Multiframe Particle Tracking Techuique." accepted for Experiments in Fluids.

Hild. R.D. lusc. . Single Phase Flow Visualization using Digital Pulsed Laser lelocimetry. "Master Thesis. Texas Ad.M liniersity. College Station. Texas.

Hueckel. M.H.. 1:71. "An Operator Which Lucites Edges in Digitized Pictures." Journal of the Association in Computing Machinery. Vol. 18. No. 1. p) $11.3-1.5$

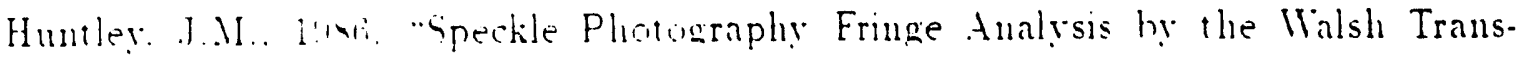

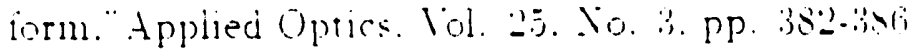

Huntley. J.A.. 1!su. "Speckle Photography Fringe Analysis: Assessment of Current Algorithms." Applied Optucs. Vol. 28. No. 2(1. pp. 4316i-4322.

Kowalski. J.E. 1G8i. "Wall and Interfacial Shear Stress in Stratified Flow in a Horizontal Pipe." AIChE Journal. Vol. 33. Io. 2. pp. 2it-2\$1.

Lakshmanan. K.. 19\$6. "Onantitative C'omputer Image Processing of C'olor Particle Markers in Flow Misualization."Ph.D. Thesis. Ohio btate Ciniversity. Columbus. Ohio.

Landreth. ' $C($ ' and Adrian. R.J.. ligkt. "Measurement and Refinement of Velocity Data Ising High Image Density Analysis in Particle Image Velocimetry." Applications of Laser Anemometry to Flud Mechanics. 4th Intermational Srmposium. Lisbon. Portugal. July 11-14. pp. 484-497.

Landreth. C'.'.. Adrian. R.J. and Yao. C'.S.. 1988. "Double Pulsed Particle Image Velocimetry with Directional Resolution for C'omplex Flows."Experiments in Fluids. Vol. 6. pp. 119-128.

Langlois. W.E. 1964. Slow Viscous Flow. The Macmillan Company, New York.

Lourenco. L.. 1986. "Theory and Applications of Particle Image Displacement Velocimetry."Flow Visualization and Digital Image Processing, June 9-13, von Karman Institute for Fluid Dynamics, Lecture Series 1986-09, Florida State University. Tallahassee, Florida. 
Lourenco. L. and Krothapalli. A.. 1988. "The Role of Pholographic Parameters in Laser Speckle or Particle Image Displacement Velocimetry: "Experiments in Flu-

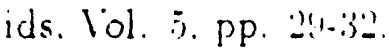

Lumrenco. L.MI and Krothapalli. A.. 1988. "Application of PIDV 1, the Study of the Temporal Evolution of the Flow Past a "ircular ('ylinder." Laser Anemometry in Fluid Mechancs-lol.IIl. Ladoan-Instituto Superior Tecnico. Lisbon. Portugal. pp. 161-1i8.

Mermart. R.. 1!18, "Eynal Velucity Fringes in a Rayleimh-Bernard Flow hy a Speckle Method."Apphed Opucs. Vul. 1!'. .0. 9. pp. 138.i-13sti.

Mernart. R.. 1:182. "Disital Image Processing for Speckle Fluw Velocimetry." Review of Scientific Lnstruments. Vul. in. ..o. 1. p. 110.

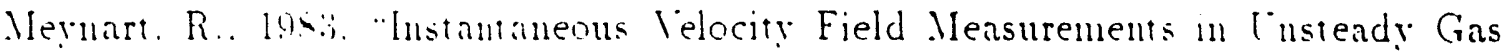
Flow by Speckle lelucmetry." Applied Optics. Vol. 2... No. 4. pp. 535-540.

Mernart. R.. 148j. "Von-Gaussian Statistics of Speckle Volse of Vuung's Fringes in speckle Velocmetry:" Applied Optics. Val. 24. No. 111. pp. 14tr-1453.

Carcowich. F.J. and Ward. J.D. 1990. ".Norms of Inverses and Condition Numbers for Matrices Associated with Scattered Data." Journal of Approximation Theory. Vol. 64. No. 1. pp. 194-44.

Oh. C.H. and Mahalingam. R.. 198i. "Interface Interaction in Twr.Phase Cas-Nonlewtonian Liquid Flow. "Industrial do Engineering C'hemistry Research. Vol. 26. pp. 2522.2528 .

Otsu. Y.. 1979. "A Threshold Selection Method from Ciray-Level Histograms."IEEE Transactions on Systems Man. and C'ybernetics. Vol. S.IC -4 . Vo. 1. pp. 62-66.

Putney. J.. 1988. "Proposals for Improring Interphase Drag Modeling for the Bubbly and Slug Regimes in REL.AP5."C'entral Electricity Generating Board. Research Report RD L 3306 R88. Surrey: L'nited Kingdom.

Ransom. V.. Wagner, R.. Trapp. J.. Feinauer, L.. Johnson. G.. Kiser. D. and Riemke. R.. 1985. "Code Structure. Systems Models, and Solution Methods."RELAP5/MOD2 Code Manual. Volume 1, Idaho Falls. Idaho.

Robinson. D.W., 1983. "Automatic Fringe Analysis with a C'omputer ImageProcessing System."Applied Optics, Vol. 22, No. 14. pp. 2169-2176.

Russ. K.M., 1988. "Particle Color Consideration in Flow System Inage Acquisition."Master Thesis. Ohio State University, Columbus, Ohio. 
Sheng. Z.. 1988. "Image Processing Technique for Determining the Velocity Field for a Fluid Flow." Master Thesı. Iniversity of Wyoming. Laramie. Wroming.

Ginha. S.K.. 19188. "Improving the Accuracy and Resolution of Particle Image or Laser Speckle Velocimetry." Experiments in Fluids. Vol. 6. pp. Bi-tis.

Taitel. I. and Dukler. A.E. 1975. "A Theoretical Approach to the LockhartMartinelli Cinrelation for Siratified Flow. "International Journal of .Multiphase Flow. Vol. 2. pp. jul-i)

limm. T. and leno. T. 1!si. .Expermental Sindy on the Coherent structure of Turbulent Open-C'hannel Flow using Visualization and Picture Processing." Journal of Flud Mechanics. Vol 17t. pp. 339-440.

Mans. H. and Kondo. S. Lu!n. "A Study on the Stratified Horizontal Counter-C'urrent Two-Phase Flow." Vuclear Enumeerme and Design. Vol. 121. p. ti..j.

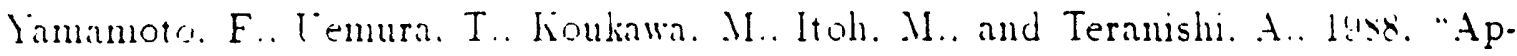
plication of Flow Visualization and Digital Image Processing Techniques to Insteady Viscous Diffusing Free Doublet Flow."Proceedings of the 2nd International Symposium on Fluid-Control. Measurement Mechanics. and Flow $\mathrm{Y} ;$ sualization. September :.9. Sheffield. C.K.. pp. 184-188.

Yano. M. and Cimeda. S.. 1986. "Lag Motion Between the Tracer Particles and the Fluid in Flow Visualization."Flow Visualization IV. Proceedings of the Fourth International Symposium on Flow Tisualization. Aug 26-29. Paris. France. p. 203

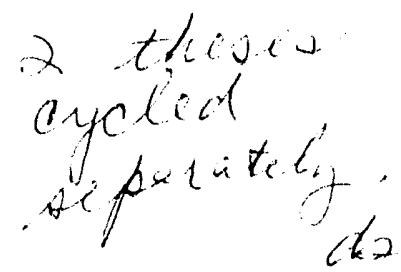



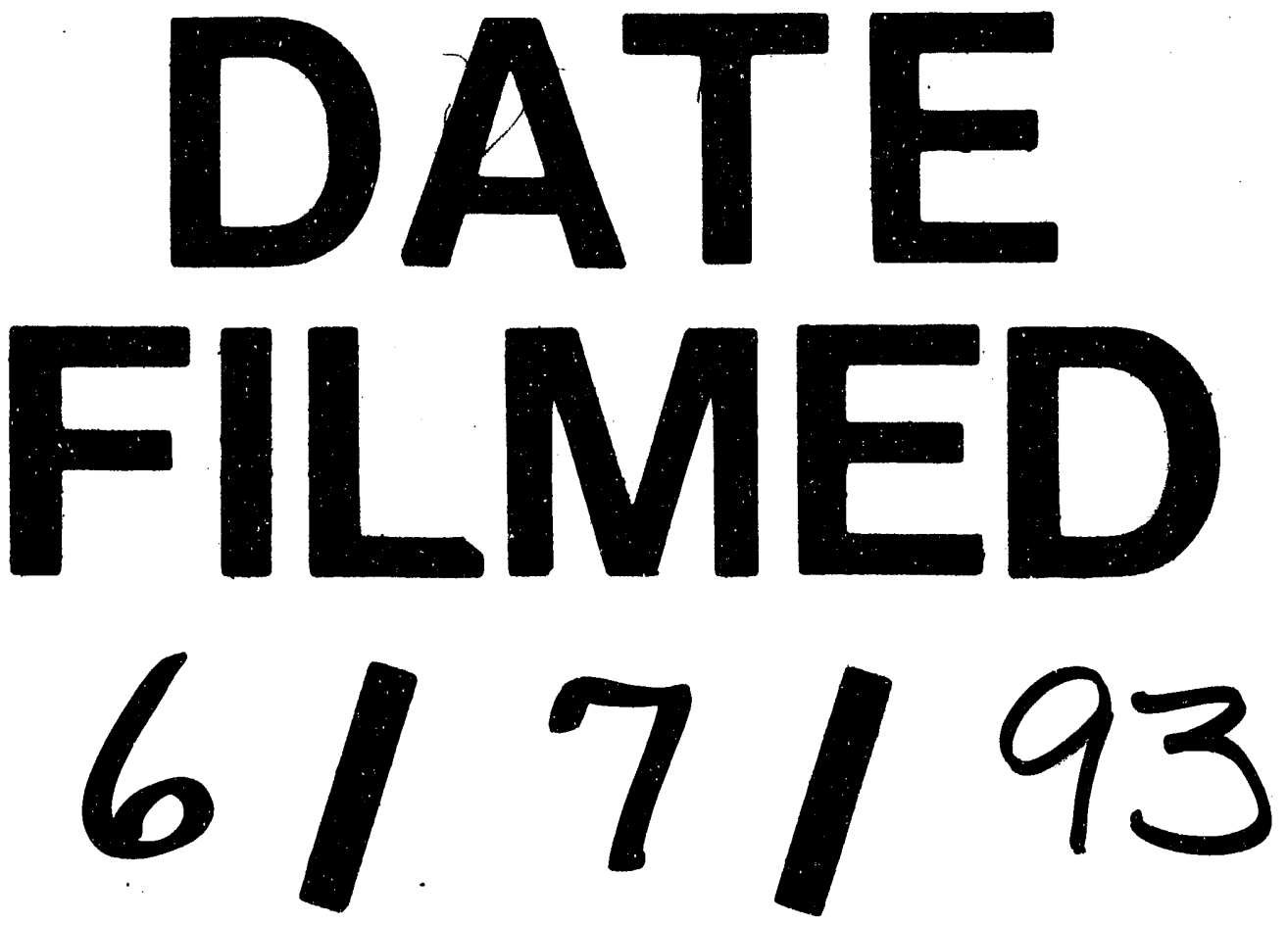
